Florida International University FIU Digital Commons

\title{
Calculations on the end-group conformational barrier in carotenoids and a study of the bioavailability of xanthophyll esters in humans
}

Francesca Alvarez-Calderon

Florida International University

DOI: $10.25148 /$ etd.FI14031610

Follow this and additional works at: https://digitalcommons.fiu.edu/etd

Part of the Chemistry Commons

\section{Recommended Citation}

Alvarez-Calderon, Francesca, "Calculations on the end-group conformational barrier in carotenoids and a study of the bioavailability of xanthophyll esters in humans" (2007). FIU Electronic Theses and Dissertations. 1272.

https://digitalcommons.fiu.edu/etd/1272 
FLORIDA INTERNATIONAL UNIVERSITY

Miami, Florida

CALCULATIONS ON THE END-GROUP CONFORMATIONAL BARRIER IN CAROTENOIDS AND A STUDY OF THE BIOAVAILABILITY OF XANTHOPHYLL ESTERS IN HUMANS

A thesis submitted in partial fulfillment of the requirements for the degree of MASTER OF SCIENCE in CHEMISTRY

by

Francesca Alvarez-Calderon 
To: Interim Dean Mark Szuchman

College of Arts and Sciences

This thesis, written by Francesca Alvarez-Calderon, and entitled Calculations on the Endgroup Conformational Barrier in Carotenoids and a Study of the Bioavailability of Xanthophyll Esters in Humans, having been approved in respect to style and intellectual content, is referred to you for judgment.

We have read this thesis and recommend that it be approved.
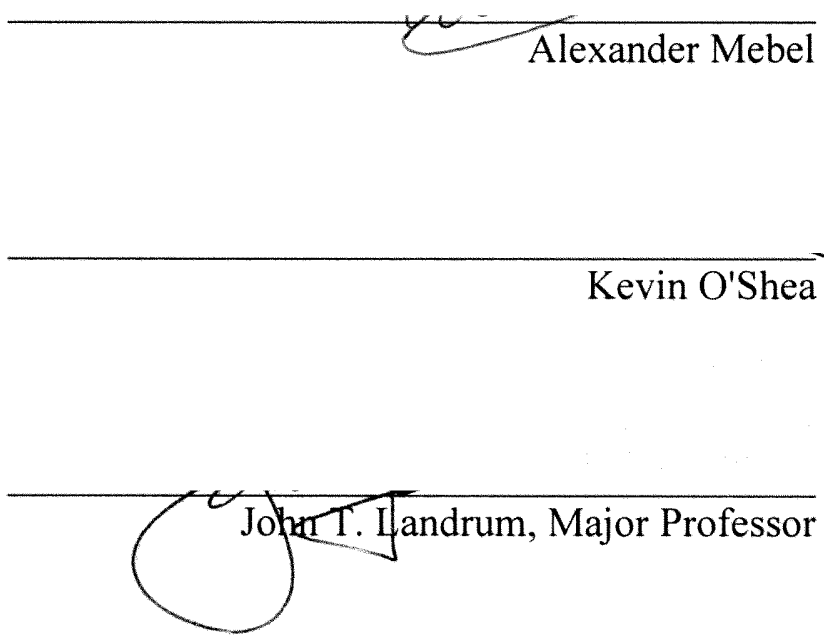

Date of Defense: June 28, 2007

The thesis of Francesca Alvarez-Calderon is approved.

Interim Dean Mark Szuchman

College of Arts and Sciences

ØDean George Walker University Graduate School

Florida International University, 2007 


\section{DEDICATION}

To my parents and sisters, your unconditional support and encouragement made all of this possible. To Daniel, your love makes me wake up everyday and pursuit my dreams. To Dr. Landrum, your passion for science has inspired me to succeed. 


\section{ACKNOWLEDGMENTS}

I would like to thank the members of my committee, Dr. Alexander Mebel and Dr. Kevin O'Shea for their support and understanding. Dr. Mebel was key in helping me understand computational programming. I would like to thank everyone in the lab, especially Yisi, Derick and Melissa for their unconditional help and friendship. I would like to thank Luz for being the best phlebotomist I have ever met and the volunteers who participated in the study for their patience and effort. Finally, I would like to thank my major professor and mentor Dr. John Landrum for his friendship through out my college career. I will not be here today if it wasn't for your help and encouragement. 
ABSTRACT OF THE THESIS

CALCULATIONS ON THE END-GROUP CONFORMATIONAL BARRIER IN

CAROTENOIDS AND A STUDY OF THE BIOAVAILABILITY OF

XANTHOPHYLL ESTERS IN HUMANS

by

Francesca Alvarez-Calderon

Florida International University, 2007

Miami, Florida

Professor John T. Landrum, Major Professor

The present study measures the increase in serum carotenoid concentration in 30 healthy individuals after supplementation with a low dose xanthophyll ester ( 3 and $6 \mathrm{mg}$ of lutein equivalent/per day) when compared to a placebo. Serum levels of carotenoids were measured using HPLC and showed an increase in the concentration of lutein, zeaxanthin and four lutein metabolites proportional to dose.

In order to further assess the importance of the end-group structure in carotenoids we have investigated the influence of the end-group type and functionality on the conformational energy barrier. We used the density functional method implemented on GAUSSIAN 98 to calculate the conformational energy curves for rotation of the $\beta$-ring or the $\varepsilon$-ring relative to short polyene chains around the $\mathrm{C} 6-\mathrm{C} 7$ single bond. A large barrier is observed for the interconversion of conformers in the $\varepsilon$-rings $(8 \mathrm{kcal} / \mathrm{mol})$ when compared to beta rings $(2.3-3 \mathrm{kcal} / \mathrm{mol})$. 


\section{TABLE OF CONTENTS}

I. INTRODUCTION

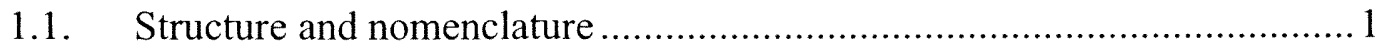

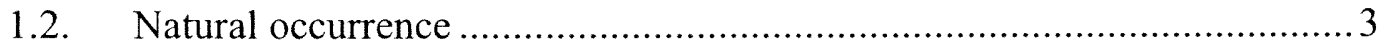

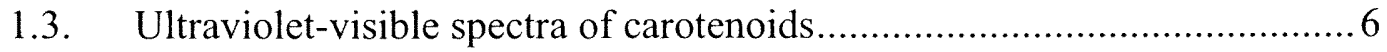

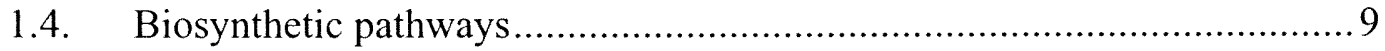

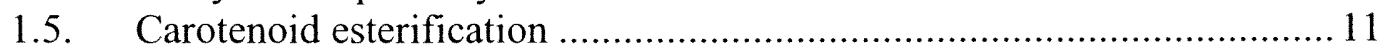

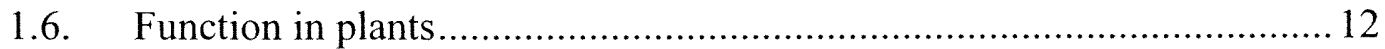

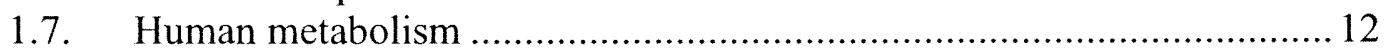

1.8. Carotenoids and human health........................................................ 13

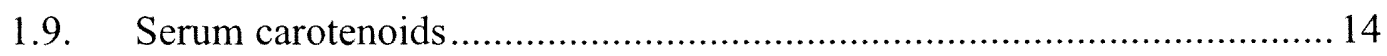

II. CALCULATIONS ON THE END-GROUP CONFORMATIONAL

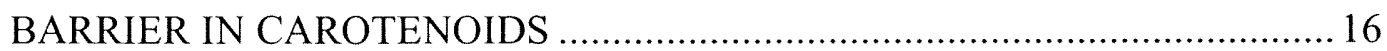

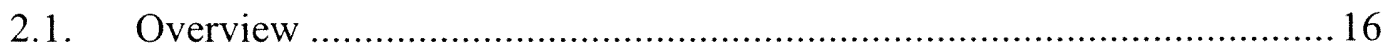

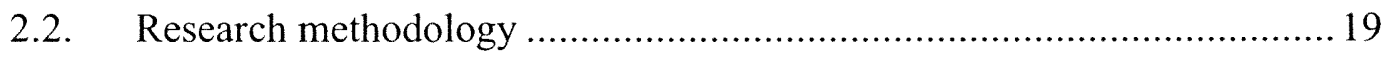

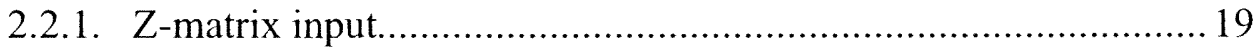

2.2.2. Computational methods ........................................................ 22

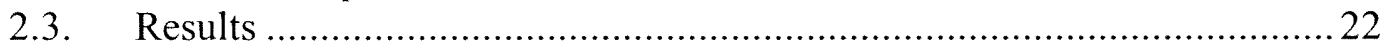

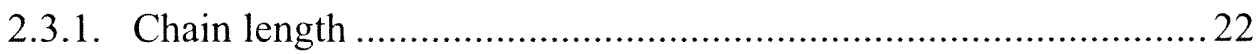

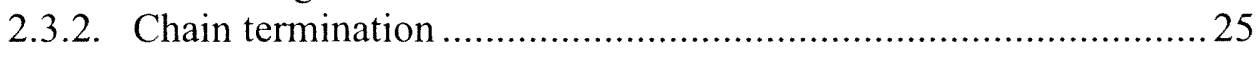

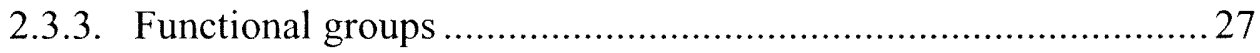

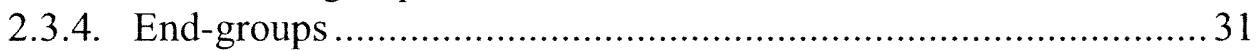

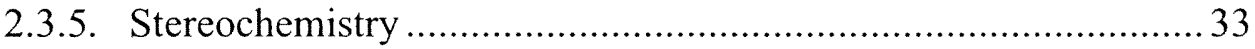

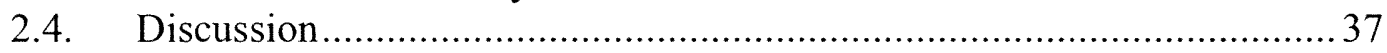

III. A STUDY OF THE BIOAVAILABILITY OF XANTHOPHYLL

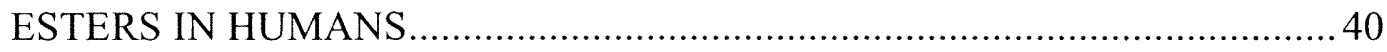

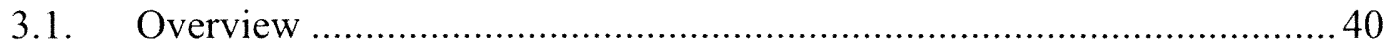

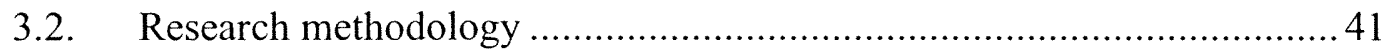

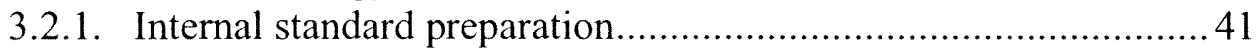

Synthesis of lutein ................................................................ 41

Column chromatography for the separation of lutein.................. 42

Monopentyl lutein ether standard preparation ............................ 43

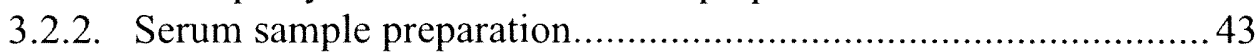

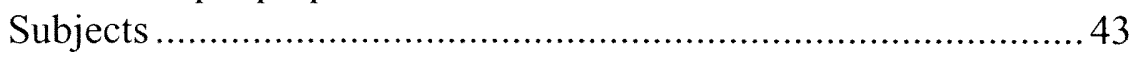

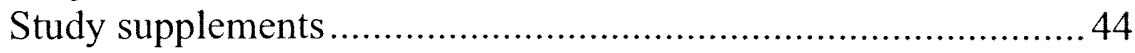

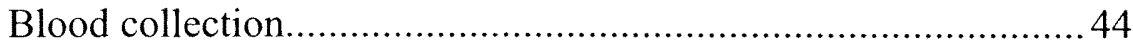

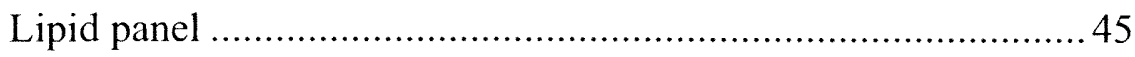

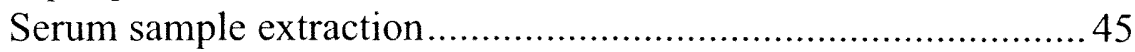

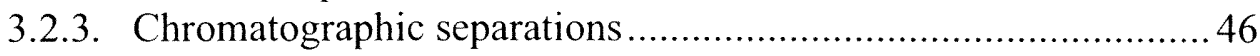

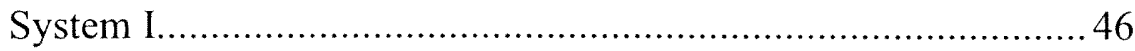




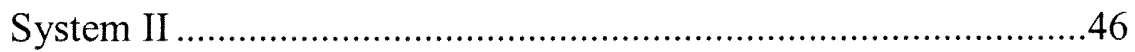

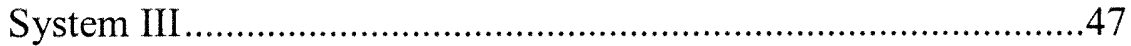

3.1.1. Ultraviolet-visible spectrophotometer …....................................47

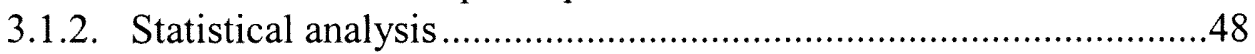

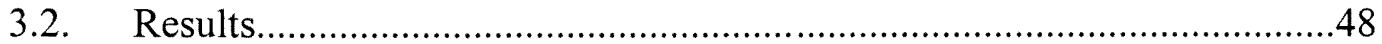

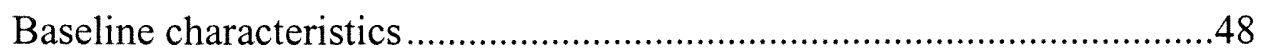

Analysis of xanthophyll esters supplement.............................................52

Spectroscopic characterization of serum components ..............................54

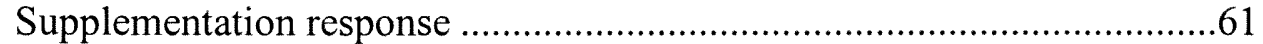

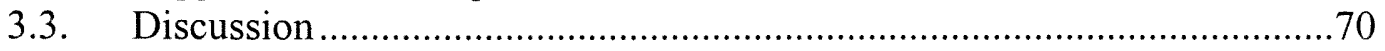

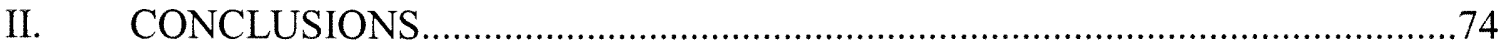

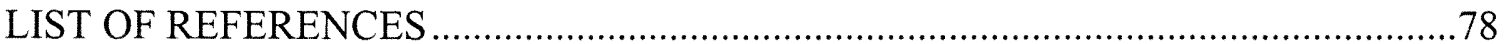

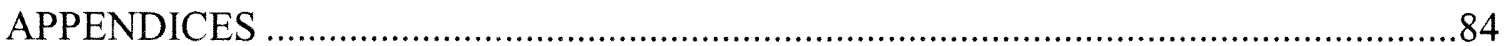




\section{LIST OF TABLES}

TABLE

PAGE

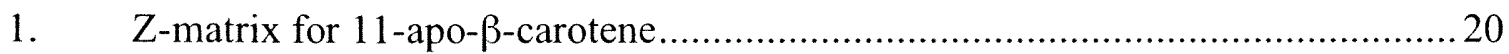

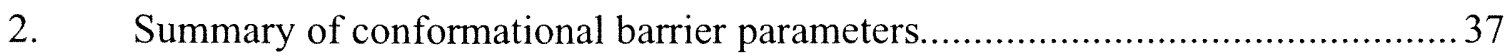

3. Baseline characteristics for supplemented subjects

(mean \pm standard deviation)

4. Retention time (Rt) and retention factor ( $\left.k^{\prime}\right)$ of carotenoids in human serum

5. Mean ( \pm SD) major serum carotenoids at baseline and postsupplementation for each group 70

6. Summary of selected conformational barrier parameters .75

7. Summary of serum carotenoids that experienced an increase in concentration with supplementation 


\section{LIST OF FIGURES}

FIGURE

PAGE

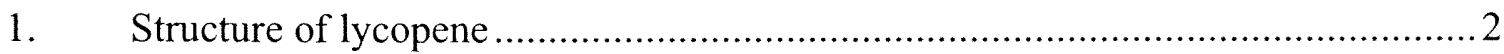

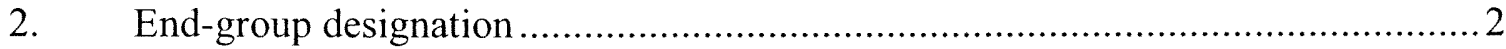

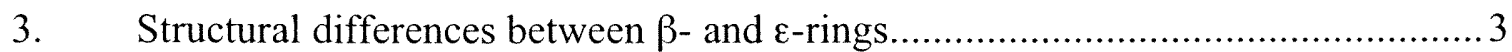

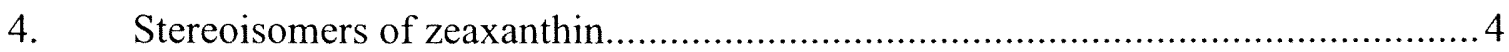

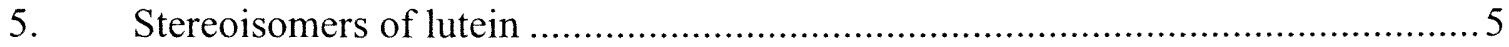

6. UV/Visible spectra of lutein showing band II and band III .......................... 7

7. Structure of lutein, zeaxanthin and lactucaxanthin...................................... 8

8. UV-Spectra of lutein, zeaxanthin and lactucaxanthin .................................. 9

9. General carotenoid biosynthetic pathway ......................................... 10

10. Structure of dipalmitoyl-lutein ........................................................ 11

11. Structure of major serum carotenoids ........................................... 14

12. 3D-Structure of 13-apo- $\beta$-carotene and 13-apo- $\varepsilon$-carotene ......................... 18

13. 3D-Structure of 11-apo- $\beta$-carotene showing selected bond lengths, bond angles and dihedral angles................................................... 19

14. Newman projection for $\mathrm{C} 1-\mathrm{C} 2-\mathrm{C} 3-\mathrm{C} 4$ indicating the sign

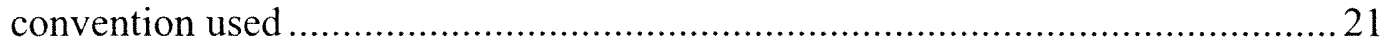

15. Structure of 11-apo- $\beta$-carotene $(O), 13$-apo- $\beta$-carotene $(\square)$ and 15-apo- $\beta$-carotene $(\triangle)$

16. Conformational barrier of 11 -apo- $\beta$-carotene $(\mathrm{O})$, 13-apo- $\beta$-carotene $(\square)$ and 15-apo- $\beta$-carotene $(\triangle)$.

17. Twist-chair conformations possible for $\beta$-ionone rings ............................25

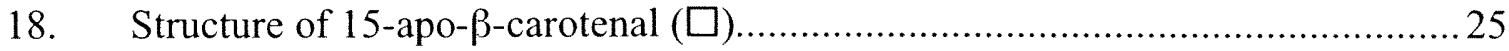

19. Conformational barrier of 15 -apo- $\beta$-carotene $(\triangle)$ and 15-apo- $\beta$-carotenal ( $\square)$. 
20. Structure of $\beta$-series: 15 -apo- $\beta$-carotenal $(O),(3 R)$-hydroxy-15apo- $\beta$-carotenal $(\square)$ and 3-oxo-15-apo- $\beta$-carotenal $(+)$; and $\varepsilon$-series: (6R)-13-apo- $\varepsilon$-carotene $(\diamond),(3 R, 6 R)$-3-hydroxy-15apo-e-carotenal $(\triangle)$ and $(6 R)$-3-oxo-15-apo- $\varepsilon$-carotenal $(\times)$

21. Conformational barrier of 15 -apo- $\beta$-carotenal $(O),(3 R)$-hydroxy-15apo- $\beta$-carotenal $(\square)$ and 3-oxo-15-apo- $\beta$-carotenal $(+)$....

22. Conformational barrier of (6R)-13-apo- $\varepsilon$-carotene $(\diamond),(3 R, 6 R)-3-$ hydroxy-15-apo- $\varepsilon$-carotenal $(\triangle)$ and $(6 \mathrm{R})$-3-oxo-15-apo- $\varepsilon$-carotenal $(\times)$.

23. Conformational barrier of 13 -apo- $\beta$-carotene $(O)$ and (6R)-13-apo- $\varepsilon$-carotene $(\diamond)$

24. Conformational barrier of (3R)-hydroxy-15-apo- $\beta$-carotenal ( $\square$ ) and (3R,6R)-3-hydroxy-15-apo- $\varepsilon$-carotenal $(\triangle)$

25. Conformational barrier of 3 -oxo- 15 -apo- $\beta$-carotenal $(+)$ and (6R)-3-oxo-15-apo- $\varepsilon$-carotenal $(\times)$.

26. Possible isomers of 3-hydroxy-15-apo- $\beta$-carotenal and 3-hydroxy-15-apo- $\varepsilon$-carotenal 34

27. Conformational barrier of (3R)-hydroxy-15-apo- $\beta$-carotenal $(\diamond)$ and (3S)-hydroxy-15-apo- $\beta$-carotenal $(+)$ 35

28. Conformational barrier of (3R,6R)-3-hydroxy-15-apo- $\varepsilon$-carotenal $(O)$, (3S,6R)-3-hydroxy-15-apo- $\varepsilon$-carotenal ( $\square$ ), (3S,6S)-3-hydroxy-15apo- $\varepsilon$-carotenal $(\triangle)$ and $(3 \mathrm{R}, 6 \mathrm{~S})$-3-hydroxy-15-apo- $\varepsilon$-carotenal $(\times)$ 35

29. HPLC gradient for the separation of carotenoid ester by System III (solvent A:81\% methanol, 4\% deionized water and $15 \%$ methyl tert-butyl ether, and solvent B: $6 \%$ methanol, $4 \%$ deionized water and $90 \%$ methyl-tert-butyl ether

30. Correlation between serum lutein concentration and cholesterol for females $\mathrm{r}=0.162(\mathrm{O})$, males $\mathrm{r}=0.875^{*}(\square)$ and combined $\mathrm{r}=0.15$. 50

31. Correlation between serum lutein concentration and HDL for females $\mathrm{r}=0.244(\mathrm{O})$, males $\mathrm{r}=0.748^{*}(\square)$ and combined $\mathrm{r}=0.117$

32. Correlation between serum lutein concentration and LDL for females $r=0.125(O)$, males $r=0.821^{*}(\square)$ and combined $r=0.188$

33. HPLC chromatogram of xanthophyll esters supplement 53 
34. HPLC chromatogram of a typical serum response at baseline (Subject 5, high dose group)

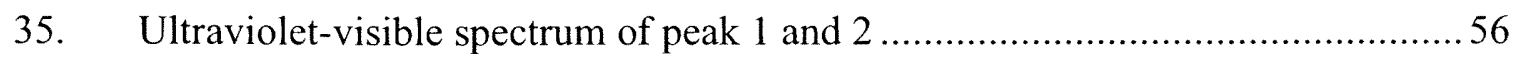

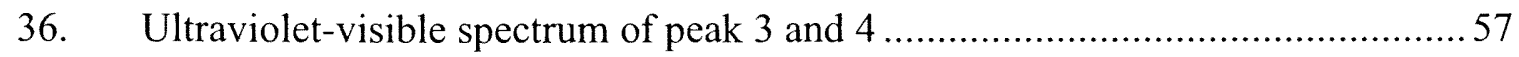

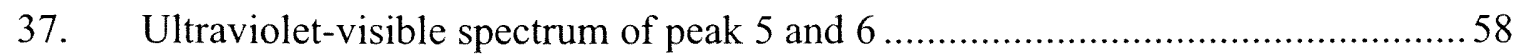

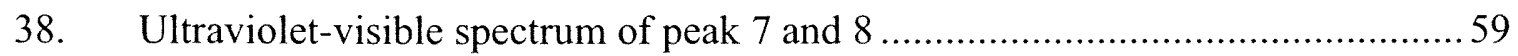

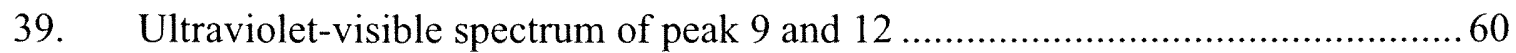

40. HPLC chromatogram of a typical serum response in the high dose group after supplementation (Subject 5).

41. Mean $( \pm \mathrm{SD})$ serum lutein concentration for each group: placebo in white, low dose in gray and high dose in black.

42. Increase in lutein serum concentration with dose.

43. Correlation between post-supplementation serum lutein concentration and baseline triglycerides concentration for females $r=0.106(O)$, males $\mathrm{r}=0.799^{*}(\square)$ and combined $\mathrm{r}=0.190$.

44. Correlation between post-supplementation serum lutein concentration and baseline HDL concentration for females $r=0.319(O)$, males $\mathrm{r}=0.838^{*}(\square)$ and combined $\mathrm{r}=0.029$.

45. Correlation between post-supplementation serum lutein concentration and baseline VLDL concentration for females $r=0.112(\mathrm{O})$, males $r=0.799^{*}(\square)$ and combined $r=0.196$. 65

46. Correlation between post-supplementation serum lutein concentration and baseline $\mathrm{C}$-reactive protein concentration for females $\mathrm{r}=0.221(\mathrm{O})$, males $\mathrm{r}=0.729 *(\square)$ and combined $\mathrm{r}=0.226$

47. Mean ( \pm SD) serum zeaxanthin concentration for each group: placebo in white, low dose in gray and high dose in black

48. Lutein metabolite 1 serum concentration: placebo in white, low dose in gray and high dose in black

49. Lutein metabolite 2 serum concentration: placebo in white, low dose in gray and high dose in black 
50. Lutein metabolite 3 serum concentration: placebo in white, low dose in gray and high dose in black..

51. Lutein metabolite 4 serum concentration: placebo in white, low dose in gray and high dose in black.. 


\section{CHAPTER I:}

\section{INTRODUCTION}

Carotenoids are naturally abundant pigments produced exclusively by plants, algae, bacteria and some species of fungi. [1] Animals cannot synthesize carotenoids and thus they rely on their diet for absorption. Carotenoids are found in significant quantities in the human body where their roles have been investigated. Several epidemiological studies have suggested a direct relation between carotenoids and improved health but the mechanism of action is yet to be proven. Only specific carotenoids are absorbed from the diet and they are selectively accumulated in certain tissues. Surprisingly, minor structural differences between carotenoids define their function and reactivity while not significantly affecting other physical properties such as solubility, polarity, oxidation potential, electronic states, etc. The importance of these structural differences between carotenoids and the mechanism by which carotenoids exert their effect on human health remains incompletely understood. In the present study, the effect of the structural differences in carotenoids were investigated by measuring the energy required for the rotation of the end-groups on carotenoids. Also, the present study monitored the bioavailability of carotenoids in subjects given low doses of a xanthophyll ester supplement.

\subsection{Structure and nomenclature}

Carotenoids, including the carotenes, and their oxygenated derivatives, xanthophylls, consisting of eight isoprenoid units joined in such a manner that the 
arrangement of isoprenoid units is reversed at the center of the molecule so that the two central methyl groups are in a 1,6-positional relationship and the remaining non-terminal methyl groups are in a 1,5-positional relationship. [2] All carotenoids may be formally derived from the acyclic $\mathrm{C}_{40} \mathrm{H}_{56}$ structure, figure 1, having a long central chain of conjugated double bonds. Due to the presence of the conjugated double bonds, carotenoids can undergo isomerization to cis carotenoids, commonly found in nature. [3]

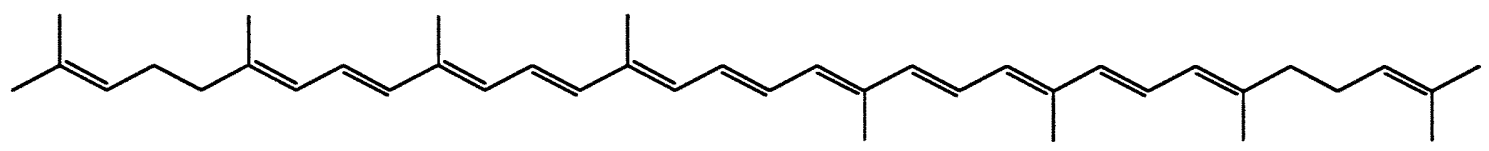

Figure 1. Structure of lycopene

The name of a specific carotenoid is constructed by adding two greek letters as prefixes to the stem name carotene, following the rules given by IUPAC. [4] The prefixes correspond to the end-group designation in carotenoids.

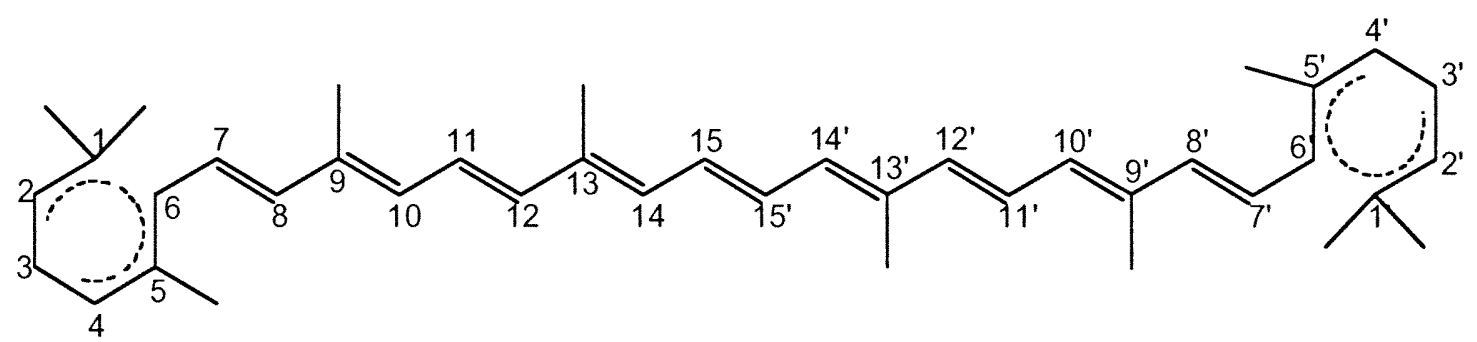

Figure 2. End-group designation

The difference in the position of a single double bond distinguishes between $\beta$ and $\varepsilon$-rings. In $\beta$-rings, the double bond occurs between $\mathrm{C} 5$-C6 extending the conjugation 
of the $\pi$ system into the ring, while in $\varepsilon$-rings, the double bond occurs between $\mathrm{C} 4-\mathrm{C} 5$, where it is isolated from the $\pi$-system of the polyene chain, figure 3 .
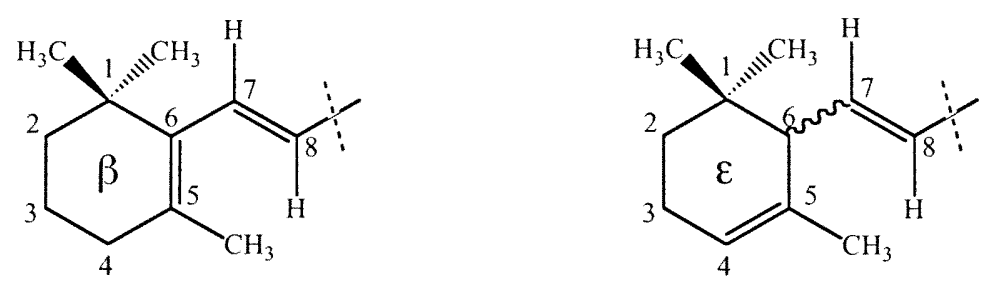

Figure 3. Structural differences between $\beta$ - and $\varepsilon$-rings

\subsection{Natural Occurrence}

Zeaxanthin has two $\beta$-ionone rings each bearing a hydroxyl group attached at carbon 3 or 3'. The most common form of zeaxanthin contains both hydroxyl groups in the R configuration, but zeaxanthin, with its two stereocenters, can exist as three naturally occurring stereoisomers, figure 4 . The principal stereoisomer of zeaxanthin is (3R, $\left.3^{\prime} R\right)$ $\beta, \beta$-caroten-3,3'-diol which is abundant in nature especially in egg yolk, orange, pepper, kiwi, grapes, spinach and various other fruits and vegetables. [5] Zeaxanthin also accumulates in human serum and tissues including the human macula. $[6,7] \quad(3 \mathrm{R}, 3$ 'S)$\beta, \beta$-caroten-3,3'-diol (meso-zeaxanthin) is also present in the human macula $[6,7]$, in shrimp (Paratya compressa compressa) and in several species of fish (Oncorhynchus keta, Seriola quinqueraduata, Micropterus salmoides, Tilapia nilotica [8], Salmo salar and Salmo gairdneri [9]). In addition, (3S,3'S)- $\beta, \beta$-caroten-3,3'-diol is found in the same species of fish as meso-zeaxanthin. $[8,9]$ 


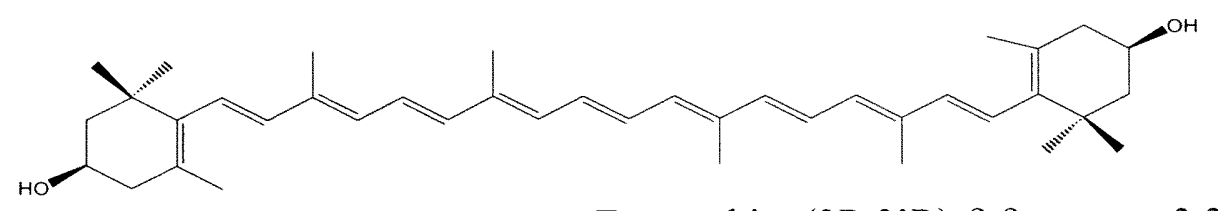

Zeaxanthin, (3R,3'R)- $\beta, \beta$-caroten-3,3'-diol

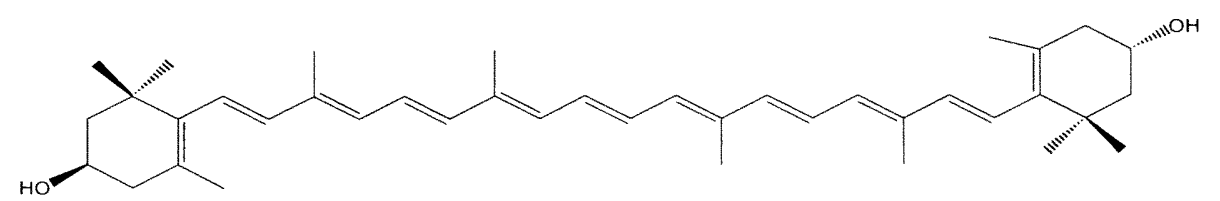

Meso-zeaxanthin, (3R,3'S)- $\beta, \beta$-caroten-3,3'-diol

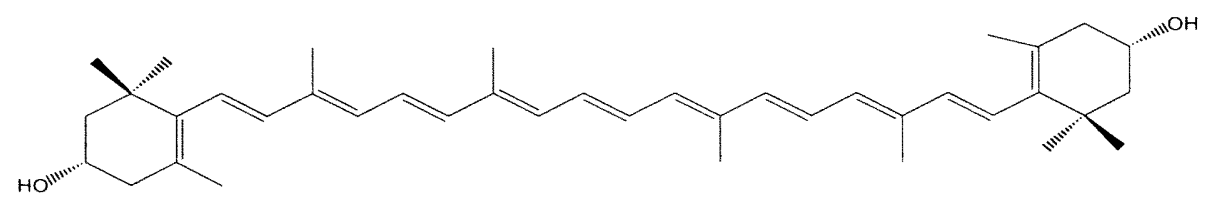

(3S, 3'S)- $\beta, \beta$-caroten-3,3'-diol

Figure 4. Stereoisomers of zeaxanthin

Lutein, a constitutional isomer of zeaxanthin in which one of the $\beta$-ionone ring is replaced by an $\varepsilon$-ionone ring, contains three stereocenters and can exists in eight stereomeric forms, figure 5. Of these, only five have been identified in nature (labeled with an asterisck in figure 5). The principal natural stereoisomer of lutein is (3R, 3'R, 6'R)- $\beta, \varepsilon$-carotene-3,3'-diol which is abundant in plants (maize, spinach, etc. [5]), egg yolk [10], in the plumage and beak of birds [11] and is accumulated in several animal tissues such as serum, macular region of the human eye [12], and adipose tissue [13]. 3'-epilutein or calthaxanthin [(3R,3'S,6'R)- $\beta, \varepsilon$-carotene-3,3'-diol] was identified in the petals of marsh marigold (Caltha palustris) [14, 15], the petals of Rosa gallica [16], the integuments of goldfish (Carassius auratus) $[17,18]$ and of several other fish species [19]. The term epilutein describes the relation between (3R,3'R,6'R)-lutein and the individual diastereomers of lutein. 


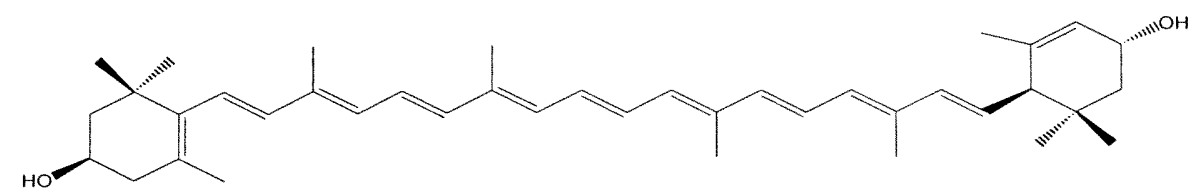

(3R,3'R,6'R)- $\beta, \varepsilon$-caroten-3,3'-diol*

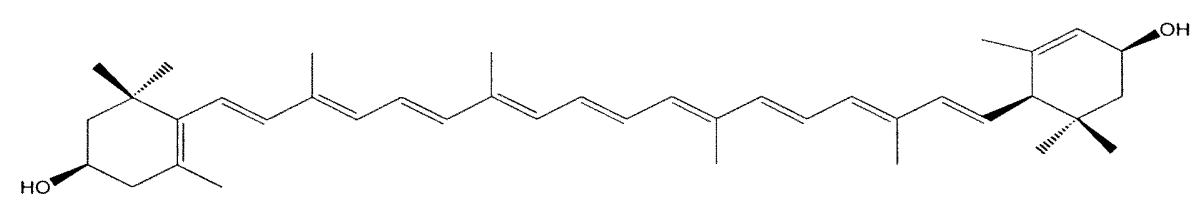

(3R,3'S,6'R)- $\beta, \varepsilon$-caroten-3,3'-diol*

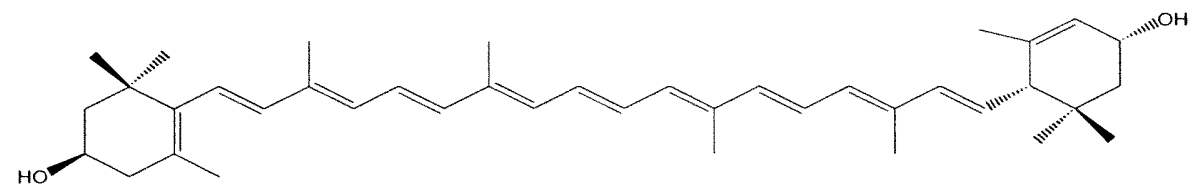

(3R,3'R,6'S)- $\beta, \varepsilon$-caroten-3,3'-diol*

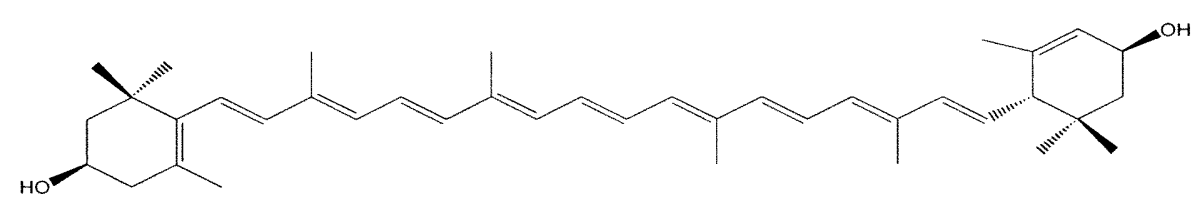

(3R, 3'S,6'S)- $\beta, \varepsilon$-caroten-3,3'-diol*

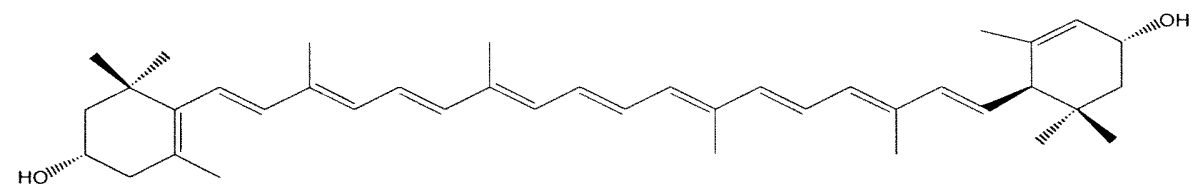

(3S, 3'R,6'R)- $\beta, \varepsilon$-caroten-3,3'-diol

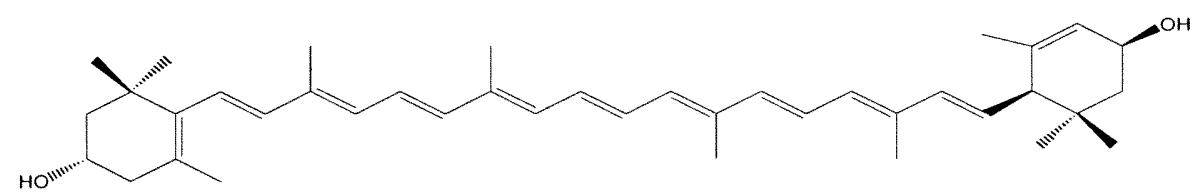

(3S, 3'R,6'S)- $\beta, \varepsilon$-caroten-3,3'-diol*

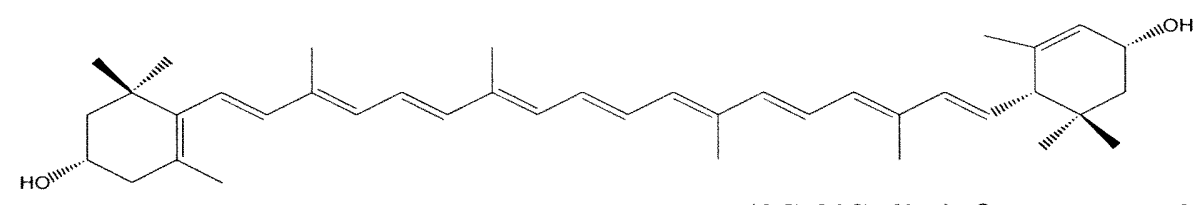

(3S, 3'S,6'R)- $\beta, \varepsilon$-caroten-3,3'-diol

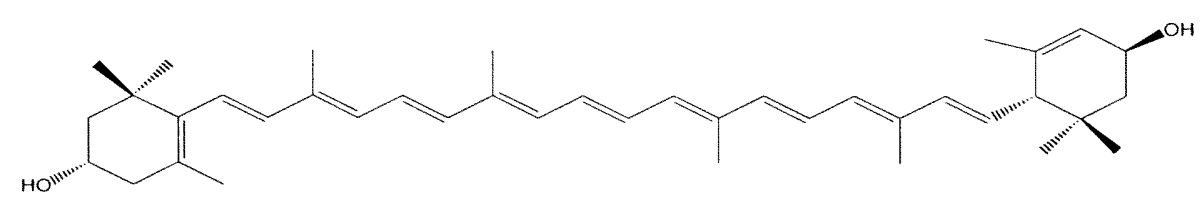

(3S, 3'S, 6'S)- $\beta, \varepsilon$-caroten-3,3'-diol

Figure 5. Stereoisomers of lutein 
6'-epilutein, (3R,3'R,6'S)- $\beta, \varepsilon$-carotene-3,3'-diol, and 3',6'-epilutein,

(3R,3'S,6'S)- $\beta, \varepsilon$-carotene-3,3'-diol, have been identified in the integuments of several fish species: Branchiostegus japonicus japonicus, Inimicus japoniicus, Platycephalus indicus and several others [20], and in eggs of dolphin-fish (Coryphaena hippurus) and flying fish (Prognichthys agoo) [21]. 3,6'-epilutein or (3S,3'R,6'S)- $\beta, \varepsilon$-carotene-3,3'diol have been identified in the integuments of Podothecus sachi and Epinephelus fario [20]. With the exception of 3,6'-epilutein, all naturally found lutein diastereomers have the stereocenter on carbon 3 in the $\mathrm{R}$ configuration.

\subsection{Ultraviolet-visible spectra of carotenoids}

Carotenoids absorb light strongly and exhibit intense absorption bands in the visible and ultraviolet region due to their extensive conjugated double bond system. Systems with multiple conjugated double bonds often show several peaks in their absorption spectra due to the electronic transitions between different vibrational energy levels. The UV-visible spectra of carotenoids provide valuable information for structural characterization and quantitative analysis. [1] The position of the wavelength of maximum absorbance $\left(\lambda_{\max }\right)$, the spectral shape and the intensity of absorption provides crucial information. The UV-spectra of carotenoids show three overlapping absorption bands, figure 6. The resolution of the peaks depends on the structure of the carotenoid. The fine structure can be described numerically by the ratio, \% III/II, where III is the intensity of the longest wavelength absorption band and II is the intensity of the middle band, measured from the minimum between the two peaks, figure 6 . Thus, the presence 
of $\beta$ - or $\varepsilon$-end group rings can usually be determined from the UV-spectra of the carotenoids.

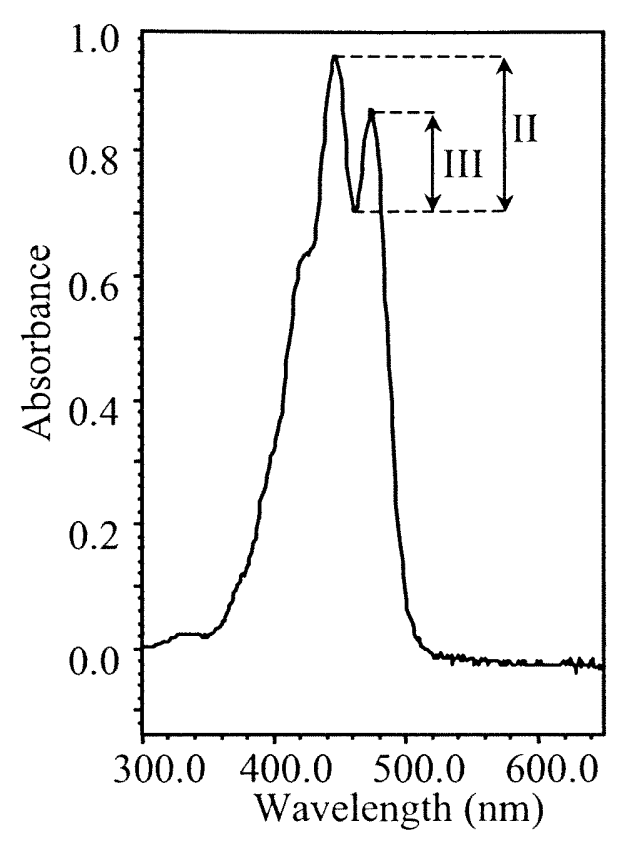

Figure 6. UV/Visible spectra of lutein showing band II and band III

The loss of the interaction between the double bond and the polyene $\pi$-system resulting from the interconversion between $\beta$ - and $\varepsilon$-rings results in a consistent $5 \mathrm{~nm}$ shift towards the blue region (hypsochromic shift) in the absorption spectra and causes an increase in the overlap of the absorption bands, especially between band II and III. The structure and UV-spectra of zeaxanthin $\left[\left(3 R, 3^{\prime} R\right)-\beta, \beta\right.$-carotene-3,3'-diol], lutein $\left[\left(3 R, 3^{\prime} R, 6^{\prime} R\right)-\beta, \varepsilon-\right.$ carotene- $3,3^{\prime}-$ diol $\left.^{\prime}\right]$ and lactucaxanthin $\left[\left(3 R, 6 R, 3^{\prime} R, 6^{\prime} R\right)-\varepsilon, \varepsilon\right.$-carotene3,3'-diol] demonstrate the effect the extent of conjugation have on the UV-spectra, figures 7 and 8 . 
In the xanthophyll series, zeaxanthin has the greatest conjugation with its two $\beta$ ionone rings, followed by lutein with a $\beta$-ionone ring and an $\varepsilon$-ionone ring and lactucaxanhin with two $\varepsilon$-ionone rings.
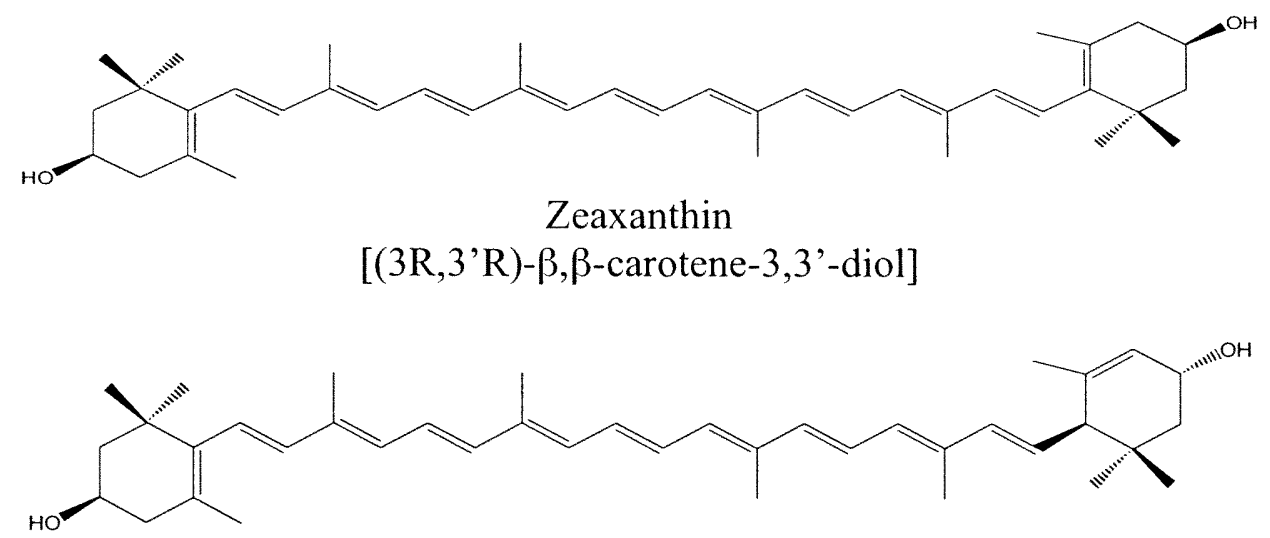

Lutein

[(3R,3'R,6'R)- $\beta, \varepsilon$-carotene-3,3'-diol $]$

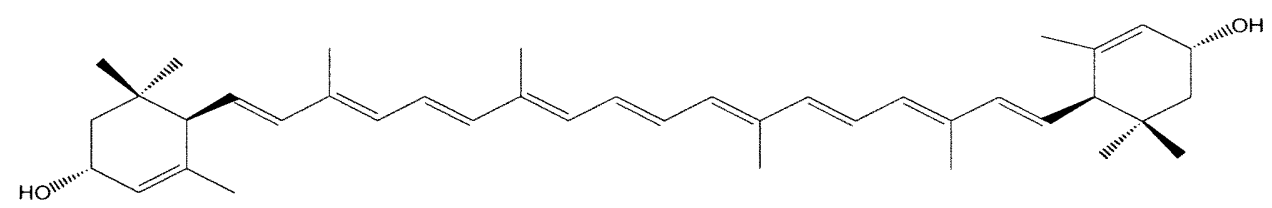

Lactucaxanthin

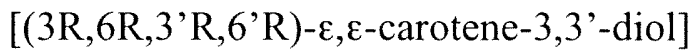

Figure 7. Structure of lutein, zeaxanthin and lactucaxanthin

The wavelength of maximum absorbance as measured in ethanol for this series is 450 [22], 445 and 439 [23] nm, respectively. A consistent $5 \mathrm{~nm}$ shift is observed with decrease conjugation. The increase in overlap between the absorption bands results in a $\% \mathrm{II} / \mathrm{III}$ of 25,60 and $95 \%$, respectively. A similar trend is observed for the carotene series which includes $\beta$-carotene $[\beta, \beta$-carotene $], \alpha$-carotene $\left[\left(6^{\prime} R\right)-\beta, \varepsilon-\right.$-carotene $]$ and $\varepsilon$ carotene [(6R,6'R)- $\varepsilon, \varepsilon$-carotene], for which $\lambda_{\max }$ is 450,445 and $441 \mathrm{~nm}$ and \% $\mathrm{II} / \mathrm{III}$ is 15-25 (depending on the solvent), 55 and $89 \%$, respectively. 


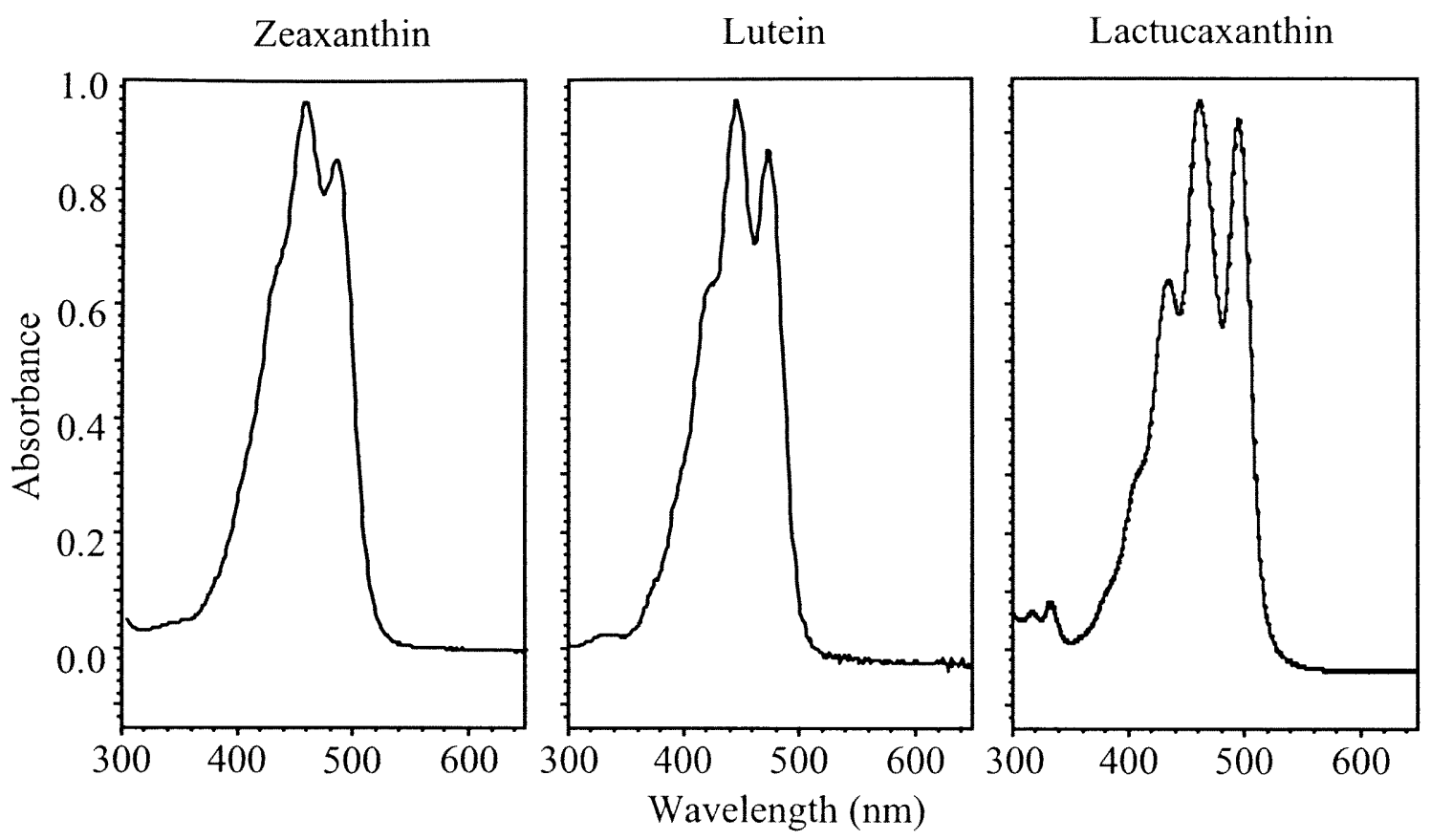

Figure 8. UV-Spectra of zeaxanthin, lutein and lactucaxanthin

\subsection{Biosynthetic Pathway}

$\mathrm{C}_{40}$ carotenoids are made in thousands of plant and microbial species, starting with the synthase-catalyzed condensation of two molecules of geranylgeranyl diphosphate $\left(\mathrm{C}_{20} \mathrm{PP}\right)$ to form phytoene, generally the all-trans isomer of phytoene. [24] Phytoene undergoes several levels and types of modification leading to the majority of the known carotenoids, figure 9 . The initial $\mathrm{C}_{40}$ condensation products are dehydrogenated in a stepwise manner by desaturase enzymes leading to the formation of lycopene. [25] In many organisms, desaturation is followed by cyclization, catalyzed by a $\beta$ - or $\varepsilon$-cyclase and leading to carotenoids with one or two cyclized ends. [26] A variety of further enzyme-catalyzed transformations that can include ketolation, hydroxylation, glycosylation and oxidative cleavage, act on substrates derived from the 
$\mathrm{C}_{30}$ or $\mathrm{C}_{40}$ backbones to produce the more than 700 known carotenoids. [27] Several of the xanthophylls bear hydroxyl groups on their end-rings which may be esterified with fatty acids in plant cells resulting in mono- and diacylated derivatives, further modifying the carotenoids. [28]

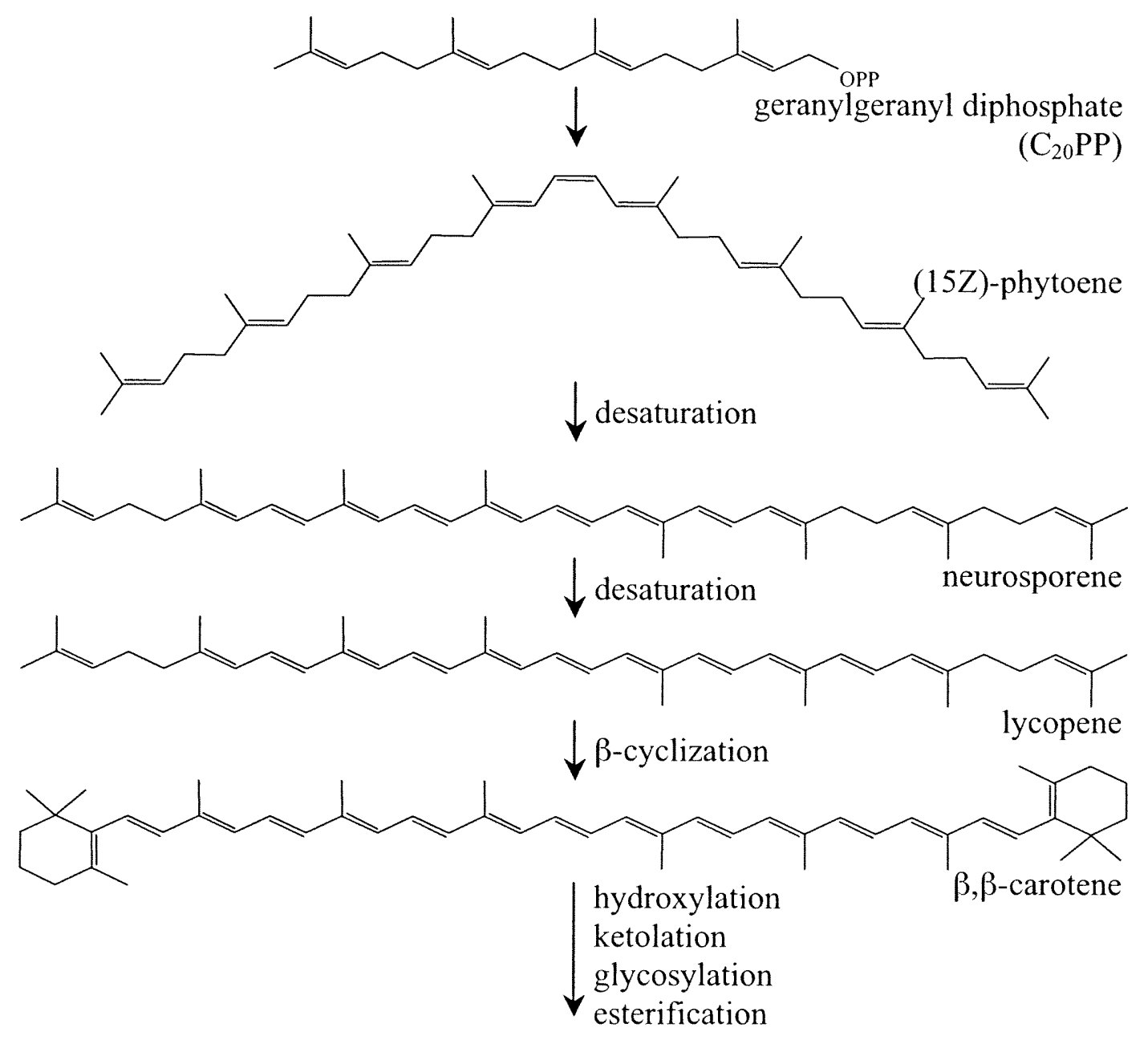

Figure 9. General carotenoid biosynthetic pathways 


\subsection{Carotenoid esterification}

Esterification occurs in most plant tissues, flower petals accumulate xanthophylls in their esterified form. Six different lutein diesters, specifically lauroylmyristoyl-lutein, dimyristoyl-lutein, myristoylpalmitoyl-lutein, dipalmitoyl-lutein, palmitoylstearoyl-lutein and distearoyl-lutein have been isolated from extracts of native marigold flowers. [28] The major lutein ester found in marigold flowers is dipalmtoyl-lutein, figure 10. Esterification allows the plant metabolic system to increase the liposolubility of xanthophylls, which is associated with plant senescence and fruit ripening. [29] Lutein diesters and other xanthophyll diesters occur in the carotenoid fractions of several fruits and vegetables including apple, apricot, avocado, chili, clementines, mango, orange, papaya, peach, yellow and red peppers, potatoes [29], kiwano, cape gooseberry and pumpkin in which the lutein diesters dimyristoyl-lutein, myristoylpalmitoyl-lutein and dipalmitoyl-lutein account for $2-5 \%$ of the total carotenoid content. [28]

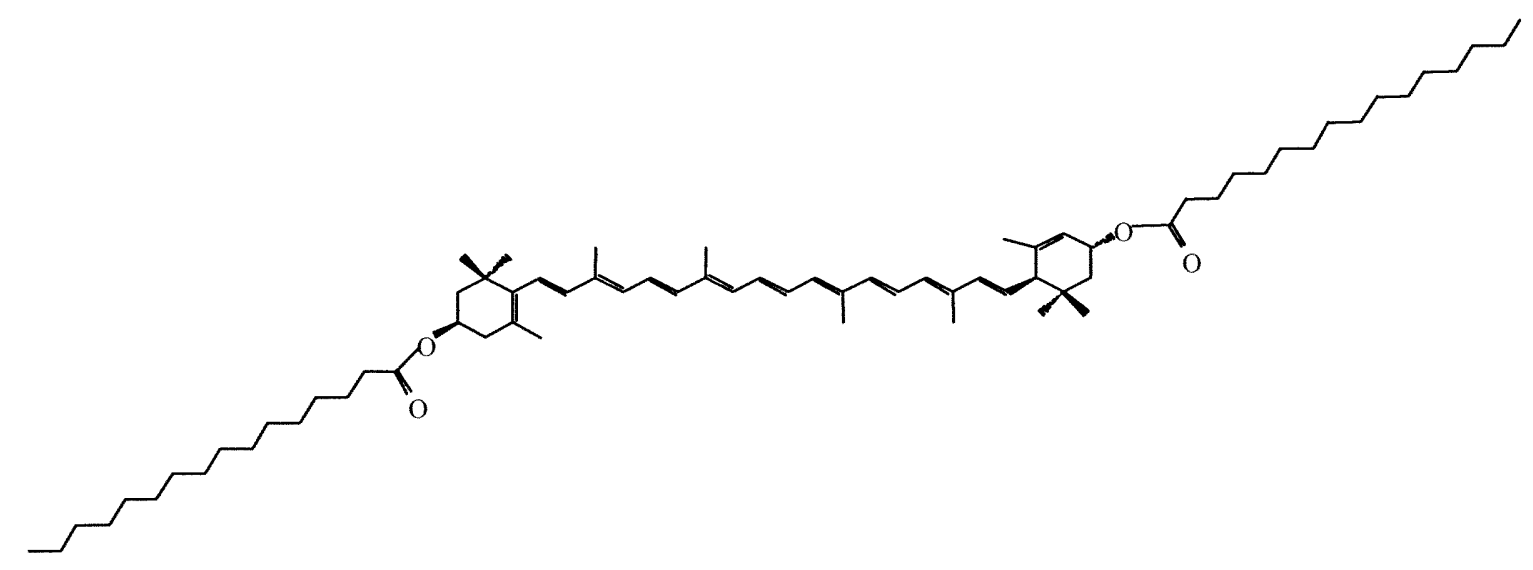

Figure 10. Structure of dipalmitoyl-lutein 
Esterification does not change the chromophore properties of the carotenoids but it does increase the liposolubility of xanthophylls. Their lipophilic nature helps to accumulate xanthophylls in lipid-rich plastoglobules, increasing colorant capacity and making fruits and flowers more attractive to animals that disseminate seeds and pollen. [30] When polyunsaturated fatty acids are esterified to xanthophylls, the antioxidant activity is diminished because the fatty acids are able to propagate the radical chain increasing the pro-oxidant reactions synergistically. [31]

\subsection{Function in plants}

Carotenoids are involved in photosynthesis as light-harvesting pigments and act to prevent the photochemical formation of singlet oxygen. [32] Carotenoids absorb light in the wavelength region where chlorophyll only absorbs weakly improving the efficiency of photosynthesis. Plants also contain several varieties of carotenoids that are involved in light energy dissipation, known as non-photochemical quenching, regulated by the xanthophyll cycle. [33] The xanthophyll cycle protects the thylakoid membranes against lipid peroxidation. [34] Within the thylakoid membranes, carotenoids are bound to specific carotenoid-binding complexes of the two photosystems, PSI is enriched in $\beta$ carotene while PSII is enriched in lutein. [35]

\subsection{Human metabolism}

Most fruits and vegetables contain both free carotenoids and their fatty acid derivatives. In the case of esterified carotenoids, these are hydrolyzed before being absorbed. The specific enzymes involved in the gastric hydrolyzation of ester 
carotenoids is unknown.[36] Esterified xanthophylls have been found in human serum and peripheral tissues in very low concentrations, less than $3 \%$ of the total serum lutein concentration, and only in individuals supplemented for an extended period of time with a high dosage xanthophyll ester supplement ( $15 \mathrm{mg} /$ day for 4 months).[37]

Carotenoids are lipid soluble, thus they follow the same absorption mechanism as most other fatty minor components. Dietary carotenoids are released from the food matrix and incorporated into mixed micelles composed of bile salts.[38] The lipophilic components from the diet are absorbed by the enterocytes, packed into chylomicrons in the intestines and transported to the liver where they are packed into other lipoproteins.[39]

\subsection{Carotenoids and human health}

Studies have shown that an increase in the consumption of carotenoids may be beneficial in preventing human diseases such as age-related macular degeneration (AMD) [40], cataracts [41], cardiovascular disease [42], cancer [43, 44] and other chronic disease [45]. Carotenoids, specifically $\alpha$-carotene, $\beta$-carotene and $\beta$-cryptoxanthin, are the major dietary source of vitamin A. [46] Carotenoids might help maintain cell-to-cell communication by reducing the damage caused by reactive oxygen species to cell membranes and their associated receptors and modulating immune cell function by influencing the activity of redox-sensitive transcription factors and the production of cytokines and prostaglandins.[47] Carotenoids may also act as photoprotectors against harmful UV radiation and to quench singlet oxygen. [48] 


\subsection{Serum Carotenoids}

The major serum carotenoids are shown in figure 11 .

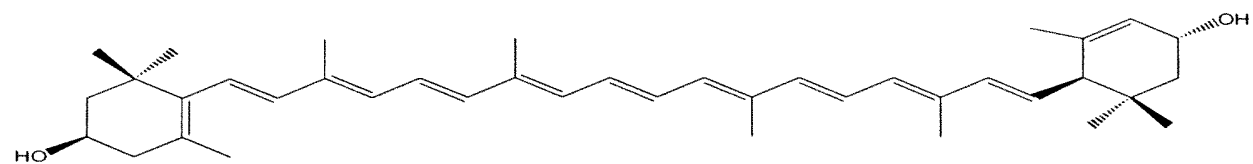

Lutein $\left[\left(3 R, 3^{\prime} R, 6^{\prime} R\right)-\beta, \varepsilon\right.$-carotene-3,3'-diol]

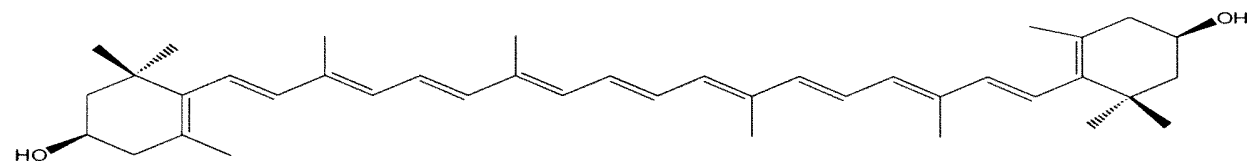

Zeaxanthin [(3R,3'R)- $\beta, \beta$-carotene-3,3'-diol]
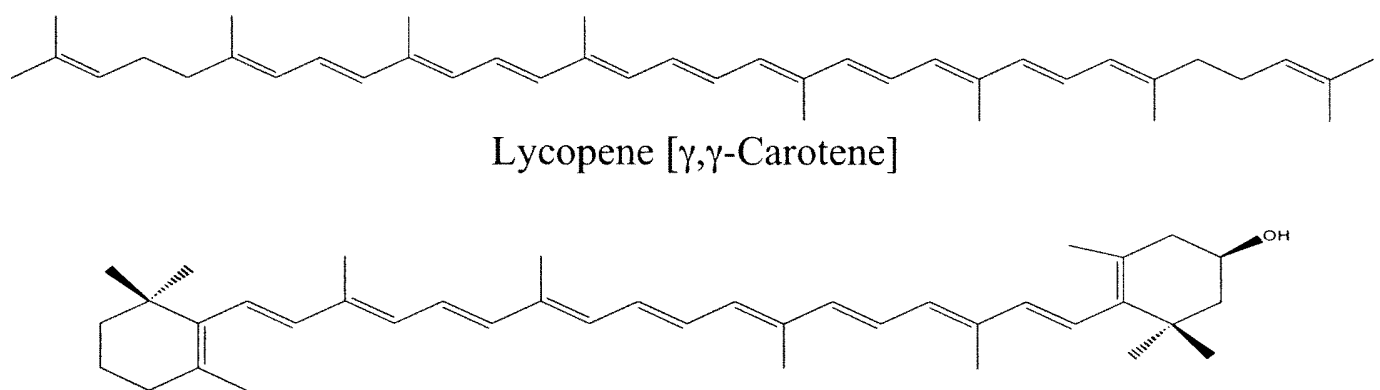

$\beta$-Cryptoxanthin [(3R)- $\beta, \beta$-carotene-3-ol]

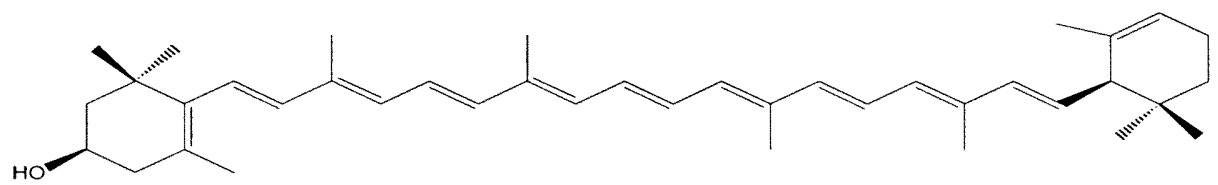

$\alpha$-Cryptoxanthin [(3R,6'R)- $\beta, \beta$-carotene-3-ol]
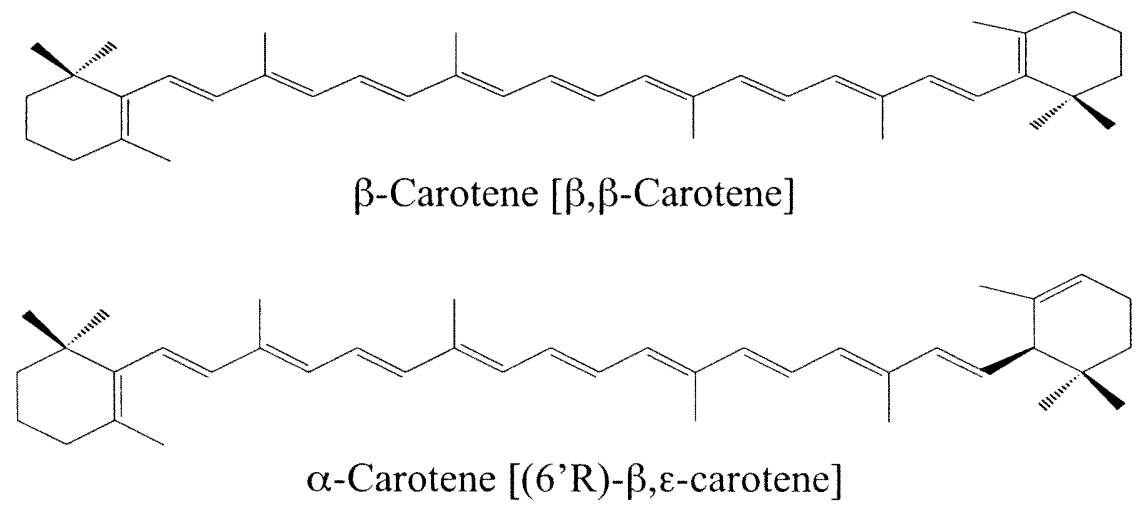

Figure 11. Structure of serum carotenoids 
The human diet comprises numerous carotenoids, but only 34 carotenoids, including 13 geometrical isomers and eight metabolites, have been identified in human serum and/or breast milk.[49] The major carotenoids present in serum include $\beta$ carotene, $\alpha$-carotene, $\alpha$-cryptoxanthin, $\beta$-cryptoxanthin, lycopene, lutein and zeaxanthin, figure 11, but the specific profile is dependant on the individual diet. These carotenoids account for $90 \%$ of the plasma carotenoid pool in serum. [50] Other tissues, specifically the liver, adipose tissue, colon, pancreas, prostate, macula and skin, accumulate significant amounts of these carotenoids. [51, 52] 


\section{CHAPTER II:}

\section{CALCULATIONS ON THE END-GROUP CONFORMATIONAL BARRIER IN CAROTENOIDS}

\subsection{Overview}

Extensive research has been performed on the significance, structure and metabolism of biologically important carotenoids both in vivo and in vitro. But little research have been devoted to address the importance that conformation may have on these carotenoids within membranes, or their structure within protein binding pockets of proteins which are specific carotenoid binders. [53-55]

The correlation between dietary carotenoids and the carotenoids routinely found in extracts from human serum/plasma reveals that only selected carotenoids make their way into the human bloodstream, and there is further selectivity in the uptake of carotenoids into a number of human tissues, notably the retina. The presence of these carotenoids in human tissues requires that they be effectively absorbed from the diet and selectively transported. This is now recognized to involve a variety of carotenoid binding proteins. Carotenoids are lipophyllic and are soluble and accumulate in cellular membranes. The behavior of carotenoids in biological membranes is related to their structure, in particular to their orientation within the membrane. The xanthophylls, with their polar end-groups, may span the membranes and anchor with the polar heads of phospholipids while carotenes may be embedded within the membranes. Polar carotenoids are present in thylakoid membranes where they regulate membrane fluidity. Also, certain carotenoids disrupt the geometry of the binding pockets in proteins. 
$\beta$-carotene is bound and cleaved in vivo by $\beta$-carotene $15,15^{\prime}$-monooxygenase, whereas the xanthophylls and other oxygenated derivatives are not. The xanthophylls, zeaxanthin and lutein, support the light harvesting complex assembly while lactucaxanthin does not which suggests that the three dimensional geometry of the endgroups in these carotenoids is a key to their incorporation in the protein assembly.[56] Differences in the behavior of xanthophylls in both membranes and proteins can be seen and can be attributed to difference in their end group structures. The presence of a $\beta$-end group or an $\varepsilon$-end groups in carotenoids would appear to favor the ability of the carotenoid to adopt specific orientations in membranes. The conformational barriers between the possible geometric conformations will dictate the energy required for the carotenoid to adopt one specific orientation as opposed to another.

$\beta$-ionone rings, as those found in zeaxanthin and $\beta$-carotene, exhibit near or quasi co-planarity between the polyene chain and the plane of the ring. It is widely accepted that the $\beta$-ionone rings prefer a conformation in which the double bond in the cyclohexene ring is in a quasi-S-cis geometry relative to the polyene chain. In $\varepsilon$-rings, due to the presence of a stereocenter at C6', this co-planarity is disrupted. The change in hybridization at $\mathrm{C} 6$ from $\mathrm{sp}^{2}$ to $\mathrm{sp}^{3}$ causes a considerable increase in the crowding between the methyl groups on $\mathrm{C} 1$ and $\mathrm{C} 5$ and the vinylic hydrogens, $\mathrm{H} 7$ and $\mathrm{H} 8$. The bent $\varepsilon$-ionone ring in lutein is visible in the $3 \mathrm{D}$-structure of the shortened apocarotenes, 13-apo- $\beta$-carotene and 13-apo- $\varepsilon$-carotene, figure 12. 


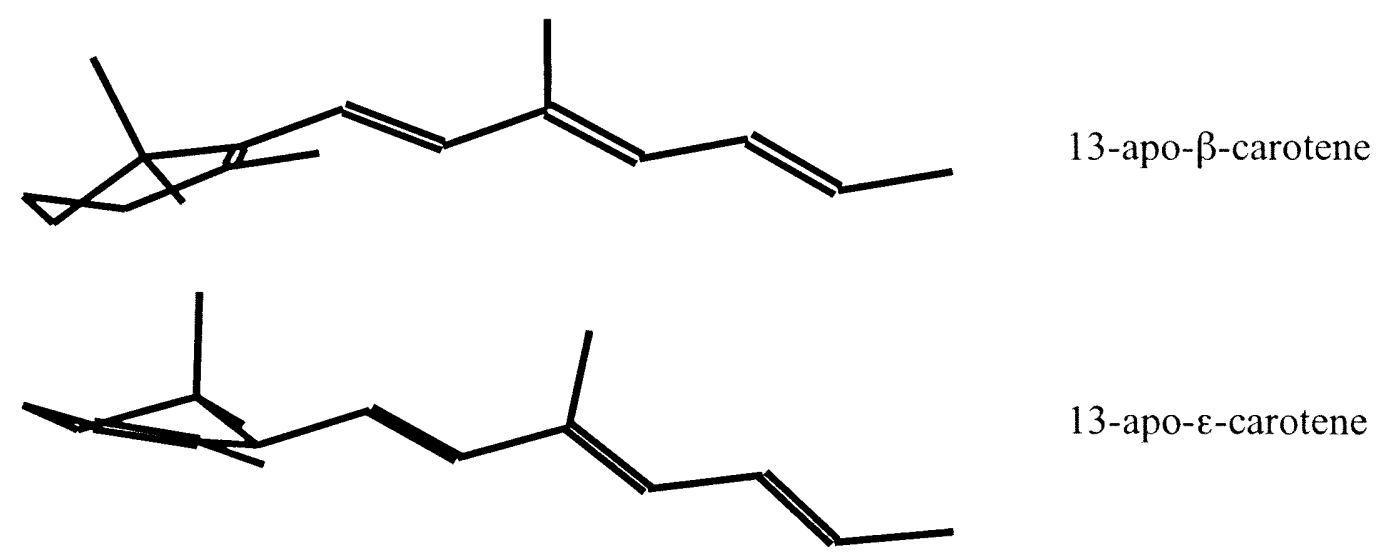

Figure 12. 3D-Structure of 13-apo- $\beta$-carotene and 13-apo- $\varepsilon$-carotene

The principal aim of this study is to model several biologically important carotenoids specifically $\beta$-carotene $[\beta, \beta$-carotene $]$, lutein $\left[\left(3 R, 3^{\prime} R, 6^{\prime} R\right)-\beta, \varepsilon\right.$-caroten-3,3'diol], zeaxanthin [(3R,3'R)- $\beta, \beta$-caroten-3,3'-diol], oxo-lutein [(3R,6'R)-3-hydroxy- $\beta, \varepsilon$ caroten-3'-one $]$ and oxo-zeaxanthin $[\beta, \beta$-caroten-3,3'-dione $]$ to discover their preferred orientation end-group ring in space relative to the polyene chain. The carotenoids investigated are symmetrical with respect to the $\mathrm{C} 15-\mathrm{C} 15$ ' single bond, thus a shortened model composed of apocarotenals was used to increase the efficiency of the computations. Secondly, determination of the effect that chain length in the shortened model has on the $\mathrm{C} 6-\mathrm{C} 7$ rotational barrier of carotenoids by varying the chain length of several structures. Thirdly, determine the effect of chain termination on the C6-C7 rotational barrier, specifically the presence of an aldehyde functional group at C15. Finally, determine the effects of substituents present in the cyclohexene ring on the C6C7 rotational barrier and the presence of different stereoisomers of those carotenoids. 


\subsection{Research methodology}

\subsubsection{Z-matrix input [57]}

In this study, a z-matrix was constructed starting from an arbitrarily selected atom, labeled 1 in figure 13. The z-matrix specifies the locations of and bonds between atoms using bond lengths (angstroms), bond angles and dihedral (torsion) angles (degrees).
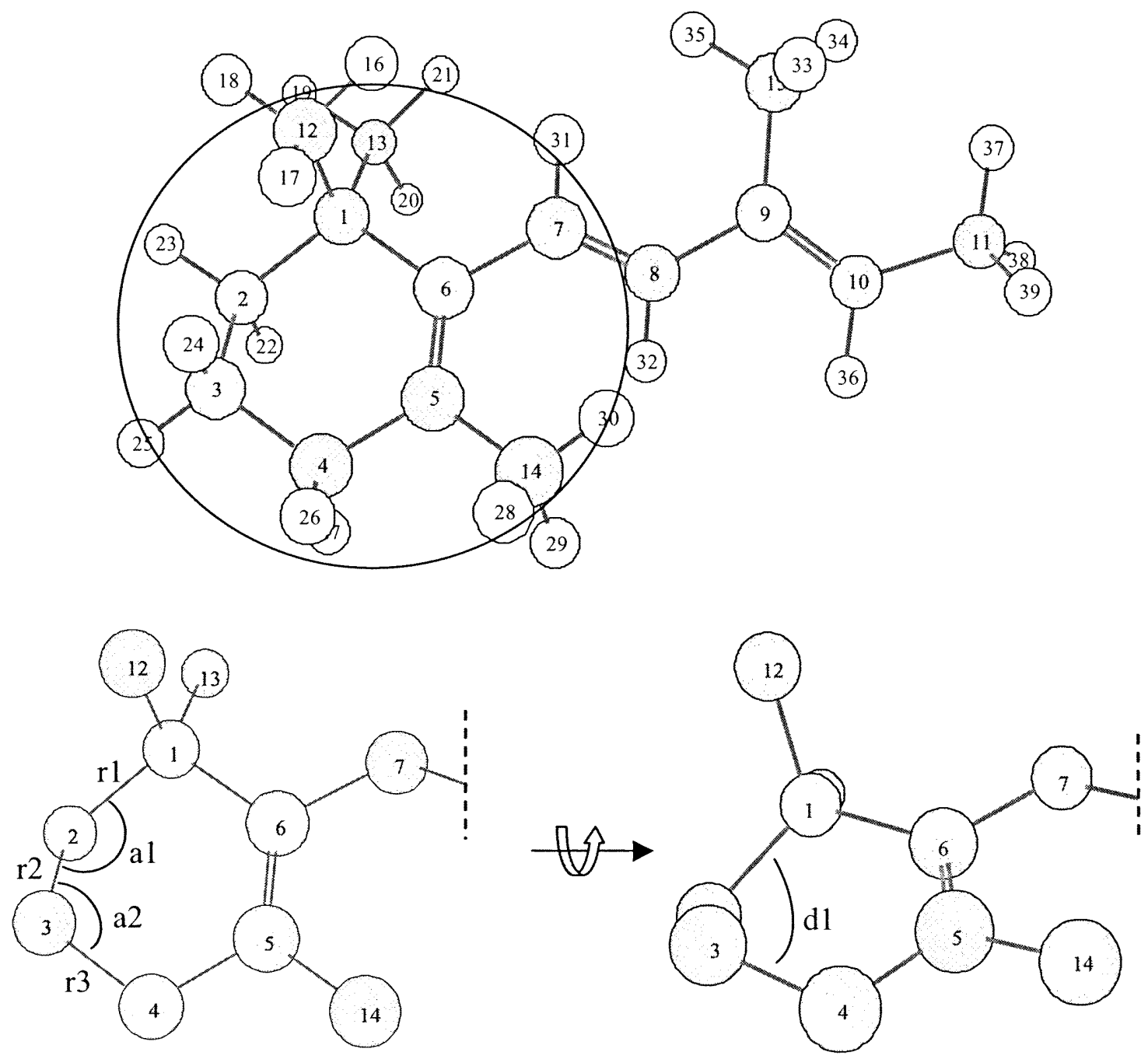

Figure 13. 3D-Structure of 11-apo- $\beta$-carotene showing selected bond lengths, bond angles and dihedral angles. 
The molecule specifications are given by the charge and spin multiplicity as two integers directly above the first line of the matrix. The spin multiplicity is calculated from the equation $2 \mathrm{~S}+1$, where $\mathrm{S}$ is the total spin for the molecule. Each unpaired electron contributes $+1 / 2$ to $S$ thus a system with no unpaired electrons (singlet) has a spin multiplicity of 1 and a system with one unpaired electrons (doublet) has a spin multiplicity of 2. The first line of the Z-matrix consists solely of the atomic symbol for the starting atom in the molecule, table 1.

Table 1. Z-matrix for 11-apo- $\beta$-carotene

\begin{tabular}{|c|c|}
\hline \#N b3lyp/6-31g* opt=(z-matrix) & $\begin{array}{l}\text { h } 13 \mathrm{r} 181 \text { al } 72 \mathrm{~d} 16 \\
\text { h } 13 \mathrm{r} 19 \text { a } 182 \mathrm{~d} 17\end{array}$ \\
\hline 01 & h 13 r20 1 a19 2 d18 \\
\hline c & h 2 r21 3 a20 4 d 19 \\
\hline c $1 \mathrm{rl}$ & h 2 r22 3 a 214 d 20 \\
\hline c 2 r2 $1 \mathrm{al}$ & h 3 r23 4 a 225 d 21 \\
\hline c 3 r3 2 a $21 \mathrm{~d} 1$ & h 3 r24 4 a23 5 d 22 \\
\hline c 4 r 43 a3 2 d 2 & h 4 r25 3 a 242 d 23 \\
\hline c $5 \mathrm{r} 54$ a $43 \mathrm{~d} 3$ & h 4 r26 3 a25 2 d24 \\
\hline c $6 \mathrm{r} 65 \mathrm{a} 54 \mathrm{~d} 4$ & h 14 r 275 a 264 d 25 \\
\hline c 7 r7 6 a $65 \mathrm{~d} 5$ & h 14 r 285 a 274 d 26 \\
\hline c 8 r8 7 a $76 \mathrm{~d} 6$ & h 14 r29 5 a 284 d27 \\
\hline c 9 r9 8 a8 7 d7 & h 7 r30 8 a $299 \mathrm{~d} 28$ \\
\hline c 10 r 109 a 98 d 8 & h 8 r31 9 a30 10 d29 \\
\hline c 1 r11 2 alo 3 d 9 & h 15 r32 9 a 3110 d 30 \\
\hline c 1 r12 2 al1 $3 \mathrm{~d} 10$ & h 15 r33 9 a32 $10 \mathrm{~d} 31$ \\
\hline c $5 \mathrm{r} 134$ a $123 \mathrm{~d} 12$ & h 15 r34 9 a33 $10 \mathrm{~d} 32$ \\
\hline c 9 r14 10 al3 $11 \mathrm{~d} 12$ & h 10 r35 9 a34 8 d33 \\
\hline h 12 r15 1 al4 2 d13 & h 11 r36 10 a35 9 d34 \\
\hline h 12 r161 a15 2 d14 & h 11 r37 10 a36 9 d35 \\
\hline h 12 r17 la162 d15 & h 11 r38 10 a37 $9 \mathrm{~d} 36$ \\
\hline
\end{tabular}

The second input line includes the atomic symbol of the second atom, the label of the atom it is bonded to (the first atom) and the label for the bond length given by the 
letter $r$ followed by an integer, in that order. The items are separated by spaces. The third input line locates the molecules position in the xy-plane. This input line will include the atomic symbol for the third atom directly attached to one of the previously specified atoms, the label for the atom it is bonded to and the bond length, the label of the other atom forming the bond angle and the label for the bond angle given by the letter a followed by an integer.

The position of all subsequent atoms are specified by its atomic symbol; an atom it is bonded to and the label for the bond length (r); a third atom bonded to it and the value of the resulting bond angle (a); and a forth atom bonded to either end of the previous chain and the value of the dihedral angle formed by the four atoms (d). Dihedral angles describe the angle the fourth atom makes with respect to the plane defined by the first three atoms. Dihedral angles are easy visualized using Newman projections, figure 14. Positive dihedral angles correspond to clockwise rotation in the Newman projection.
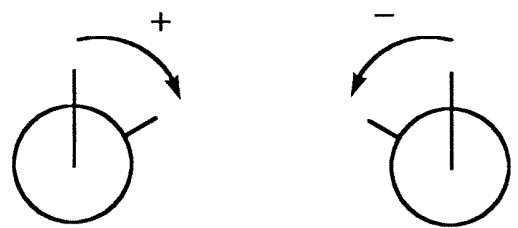

Figure 14. Newman projection for $\mathrm{C} 1-\mathrm{C} 2-\mathrm{C} 3-\mathrm{C} 4$ indicating the sign convention used

In a separate section below the complete z-matrix, the initial bond lengths, bond angles and dihedral angles are specified in the format $r l=$ followed by the optimized value. A blank line separates the two sections. The initial optimized parameters were obtained from Chemdraw after energy minimization. 


\subsubsection{Computational Methods}

The Becke 3-parameter density functional method using the Lee-Yang and Parr Correlation Functional (B3lyp) implemented on Gaussian 98 will be used to calculate the conformational energy curve for rotation of the carotenoid ring relative to a short polyene chain around the C6-C7 single bond as defined by its dihedral angle. It was be computationally inefficient to calculate the conformational barrier for the entire carotenoid structure so a model with a shortened polyene chain was used. Geometry optimization was initially performed for all degrees of freedom, including bond lengths, bond angles and dihedral angles. The dihedral angle between C5-C6-C7-C8 was fixed at $15^{\circ}$ intervals from $-180^{\circ}$ to $180^{\circ}$ while all other parameters were allowed to vary.

\subsection{Results}

The conformational energy barrier for the rotation of the end-ionone group in carotenoids was constructed from the relative energies obtained from Gaussian 98 at $30^{\circ}$ intervals. The dihedral angle at which the most stable conformation occurs is also given by Gaussian.

\subsubsection{Chain length}

The effect of chain length on the conformational barrier of carotenoids was investigated by the use of three structures varying in chain length, figure 15 . The conformational barrier for 11-apo- $\beta$-carotene, 13 -apo- $\beta$-carotene and 15 -apo- $\beta$-carotene is shown on figure 16 . 


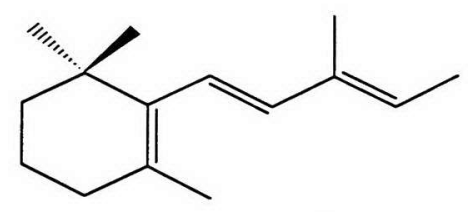

11 -apo- $\beta$-carotene<smiles>C/C=C/C=C(C)/C=C/C1=C(C)CCCC1(C)C</smiles>

13-apo- $\beta$-carotene

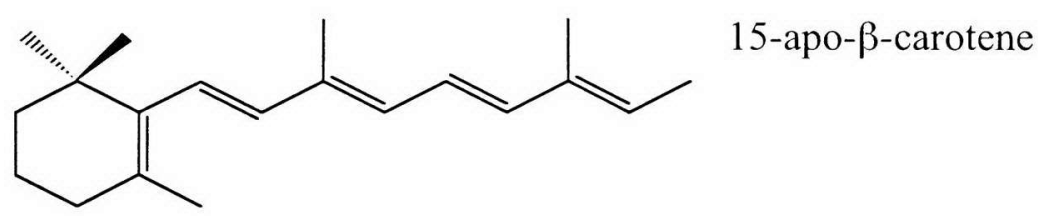

Figure 15. Structure of 11-apo- $\beta$-carotene $(O), 13$-apo- $\beta$-carotene $(\square)$ and 15-apo- $\beta$ carotene $(\triangle)$

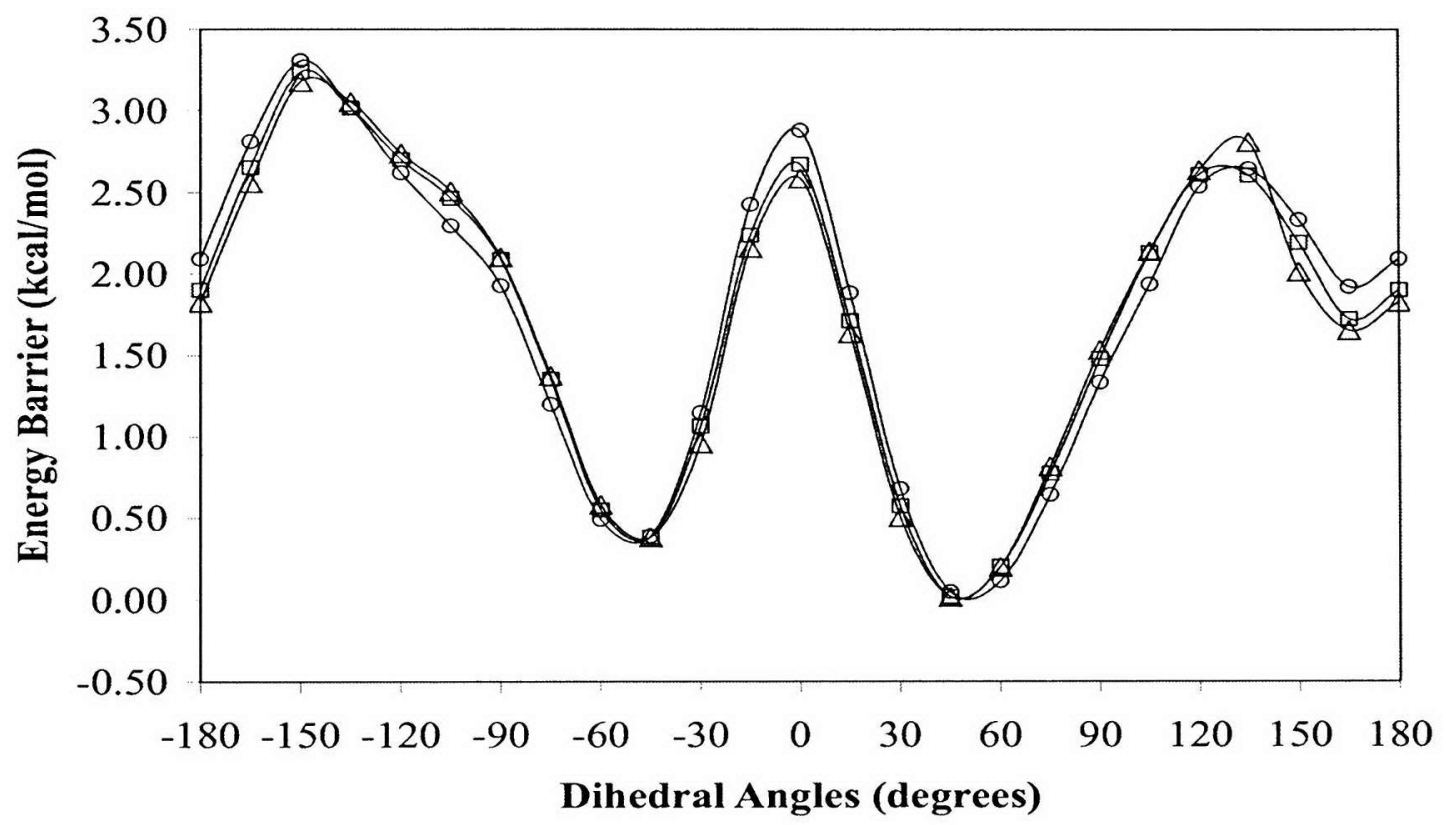

Figure 16. Conformational barrier of 11 -apo- $\beta$-carotene $(O), 13$-apo- $\beta$-carotene $(\square)$ and 15 -apo- $\beta$-carotene $(\triangle)$

The most stable conformation for the three apocarotenes occur within $1^{\circ}$ of each other, for 11 -apo- $\beta$-carotene at $49.2^{\circ}$, for 13 -apo- $\beta$-carotene at $48.2^{\circ}$ and for 15 -apo- $\beta$ - 
carotene at $47.8^{\circ}$. The increase in length and conjugation of the polyene chain decreases the dihedral angle at which the most stable conformer occurs. Similarly, the position of the second most stable conformation is also decreased in the series and occurs within $3.5^{\circ}$ of each other, at $-51.4,-49.2$ and $-47.9^{\circ}$, respectively. Symmetry is observed in the conformational barrier with respect to the $s$-cis conformation. Rotation of approximately $50^{\circ}$ clockwise or counterclockwise achieves two minima with an energy difference of $0.35 \mathrm{kcal} / \mathrm{mol}$ for 11 -apo- $\beta$-carotene, $0.33 \mathrm{kcal} / \mathrm{mol}$ for 13 -apo- $\beta$-carotene and 0.34 $\mathrm{kcal} / \mathrm{mol}$ for 15 -apo- $\beta$-carotene. The same symmetry is not observed with respect to the $s$-trans conformation, in which only one local minimum in the potential energy is observed at $165.6,167.8$ and $165.0^{\circ}$, respectively.

The increase in chain length does not greatly affect the position of the minima and maxima nor does it affects the overall conformational barrier. The energy difference between the most stable and the second most stable structures is nearly constant at 0.33 $0.35 \mathrm{kcal} / \mathrm{mol}$. The overall conformational barrier is slightly reduced from $3.25 \mathrm{kcal} / \mathrm{mol}$ to $3.18 \mathrm{kcal} / \mathrm{mol}$ for 13 -apo- $\beta$-carotene and $3.16 \mathrm{kcal} / \mathrm{mol}$ for 15 -apo- $\beta$-carotene. A distinguishable shoulder is observed for all structures at approximately $-110^{\circ}$ (quasi strans conformation). The cyclohexene ring is not planar and can adopt several ring conformations, whereas the nearly twisted chair conformation is the most stable. Of the two possible twist chair conformations, figure 17 , the apo- $\beta$-carotenes adopt conformation II more readily. 


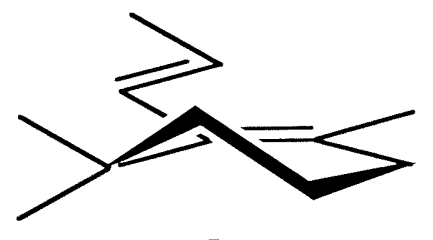

I

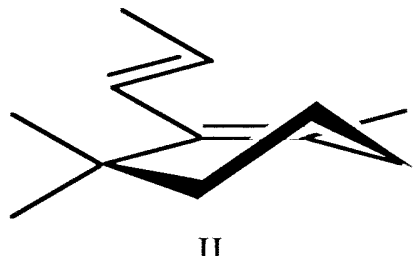

II

Figure 17. Twist-chair conformations possible for $\beta$-ionone rings

The ring puckering disrupts the quasi-s-trans conformation only in the (-)dihedral direction, causing the shoulder in the energy barrier observed in figure 16. In the $(+)$-dihedral direction carbon 1 is directed away from the polyene chain which prevents this steric distortion and allows a relative minimum to occur. In figure 12, the most stable conformation for the $\beta$-ring is observed.

\subsubsection{Chain Termination}

The effect of chain termination on the conformational barrier was investigated by comparing the energy diagram of 15 -apo- $\beta$-carotene to that of 15 -apo- $\beta$-carotenal. 15 apo- $\beta$-carotenal is commonly known as retinal, a precursor of vitamin A. Figure 18 shows the structure of 15 -apo- $\beta$-carotenal and figure 19 the conformational barrier for 15 -apo- $\beta$-carotenal along with that of 15 -apo- $\beta$-carotene for comparison.

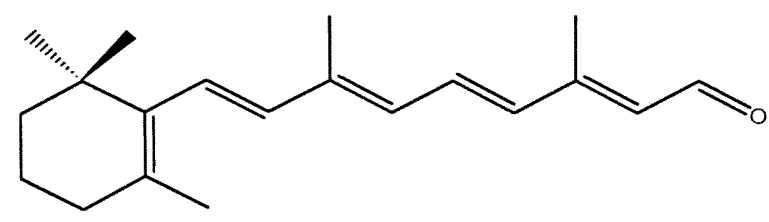

Figure 18. Structure of 15-apo- $\beta$-carotenal ( $\square)$ 


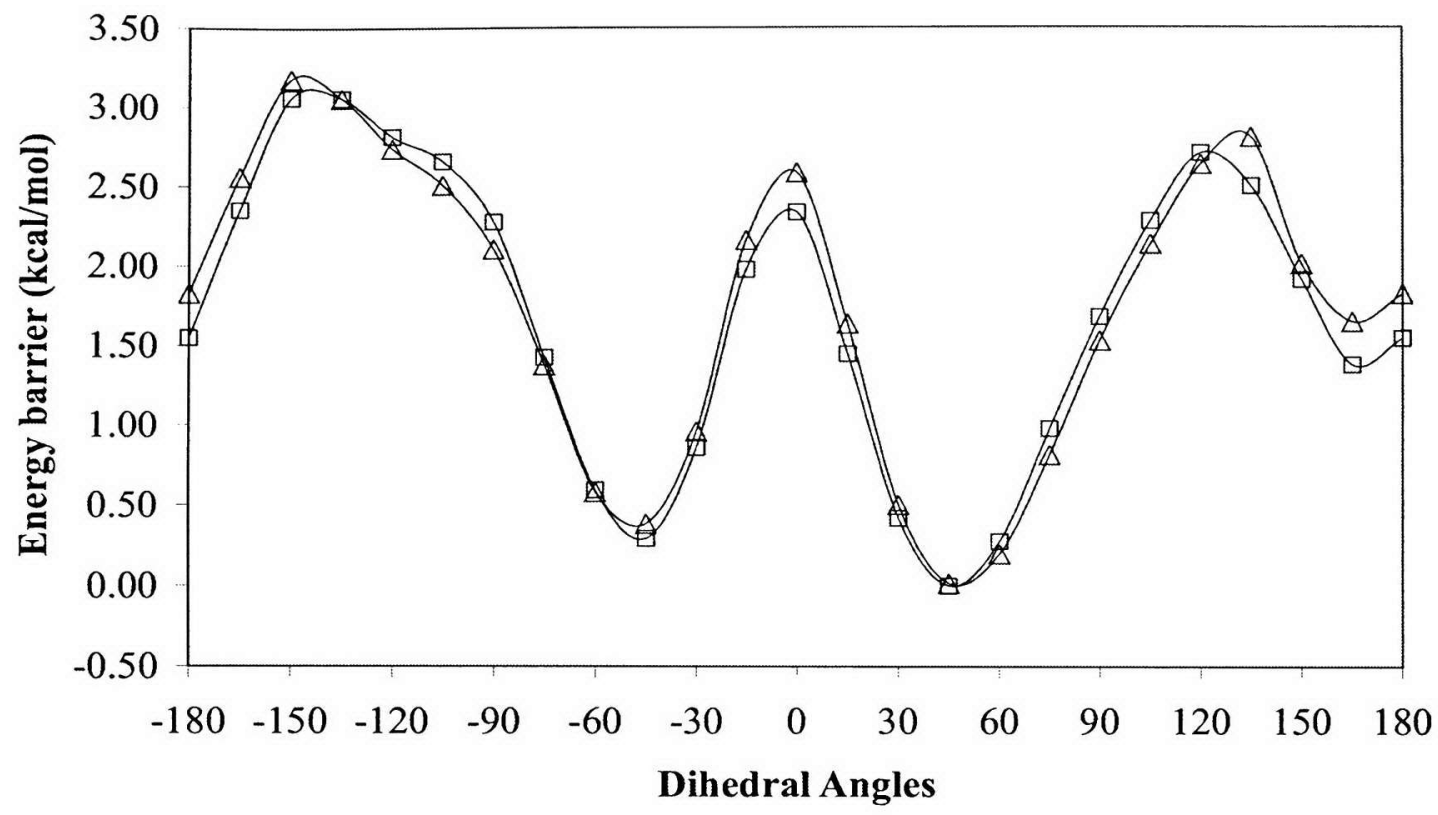

Figure 19. Conformational barrier of 15 -apo- $\beta$-carotene $(\triangle)$ and 15-apo- $\beta$-carotenal $(\square)$

The change in termination at carbon 15 insignificantly reduces the energy difference between the most stable and the second most stable conformation by 0.07 $\mathrm{kcal} / \mathrm{mol}$. The overall shape of the conformational barrier was considerably affected. The 15-apo- $\beta$-carotenal conformer with a dihedral angle of $167.8^{\circ}$ was stabilized by the variation in termination. The most stable conformation occurs at a dihedral angle of $47.8^{\circ}$ for 15 -apo- $\beta$-carotene and at $49.6^{\circ}$ for 15 -apo- $\beta$-carotenal and the second most stable conformation occurs at -47.9 and $-45.9^{\circ}$, respectively. The overall conformational barrier was reduced from 3.16 to $3.06 \mathrm{kcal} / \mathrm{mol}$. The shoulder in the conformational barrier is more pronounced in the apocarotenal than in the apocarotene. The changes in the conformational barrier, even though they are subtle, indicate a weak electronic stabilization of the pi system of the polyene chain by the carbonyl functional group. 


\subsubsection{Functional groups}

The combined effect of two functional groups, the ring hydroxyl and polyene terminating carbonyl group, on the conformational energy barrier was investigated by comparing the barrier of several $\beta$ - and $\varepsilon$-rings shown in figure 20 .

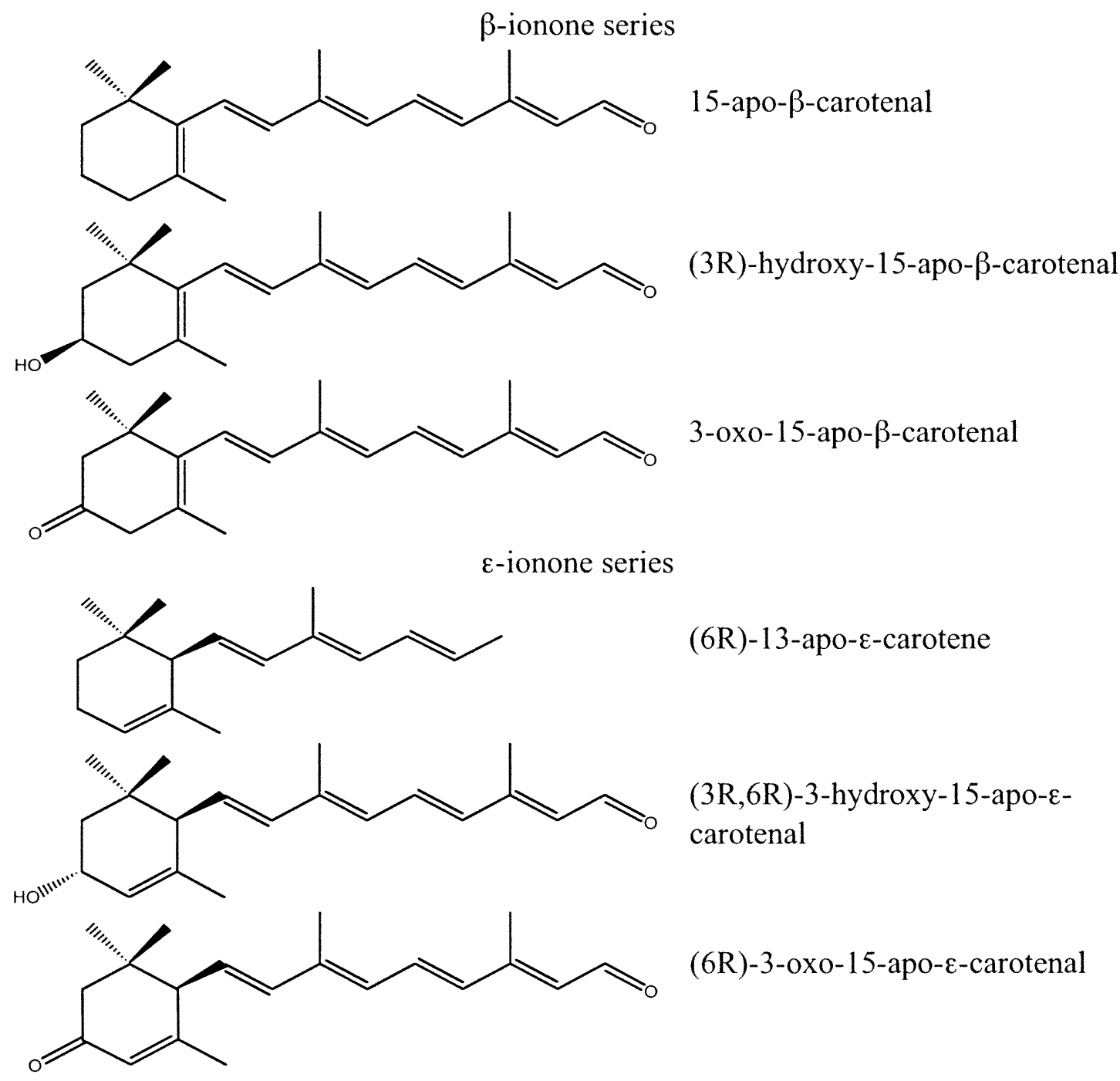

Figure 20. Structure of $\beta$-series: 15-apo- $\beta$-carotenal (O), (3R)-hydroxy-15-apo- $\beta$ carotenal $(\square)$ and 3-oxo-15-apo- $\beta$-carotenal $(+)$; and $\varepsilon$-series: (6R)-13-apo- $\varepsilon$-carotene $(\diamond),(3 R, 6 \mathrm{R})$-3-hydroxy-15-apo- $\varepsilon$-carotenal $(\triangle)$ and $(6 \mathrm{R})$-3-oxo-15-apo- $\varepsilon$-carotenal $(\times)$ 
Figure 21 shows the conformational barrier for the $\beta$-ionone ring series including that of 15 -apo- $\beta$-carotenal, (3R)-hydroxy-15-apo- $\beta$-carotenal and 3-oxo-15-apo- $\beta$ carotenal and figure 22 shows the conformational barrier for the $\varepsilon$-ionone ring series

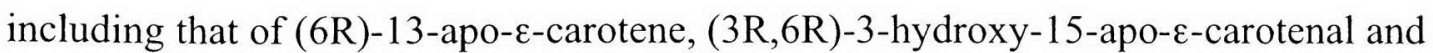
(6R)-3-oxo-15-apo- $\varepsilon$-carotenal. In the $\varepsilon$-ionone ring series, the conformational barrier of (6R)-13-apo-e-carotene was used for comparison. It was previously established that lengthening and changing the termination on the polyene chain does not significantly affect the conformational barrier.

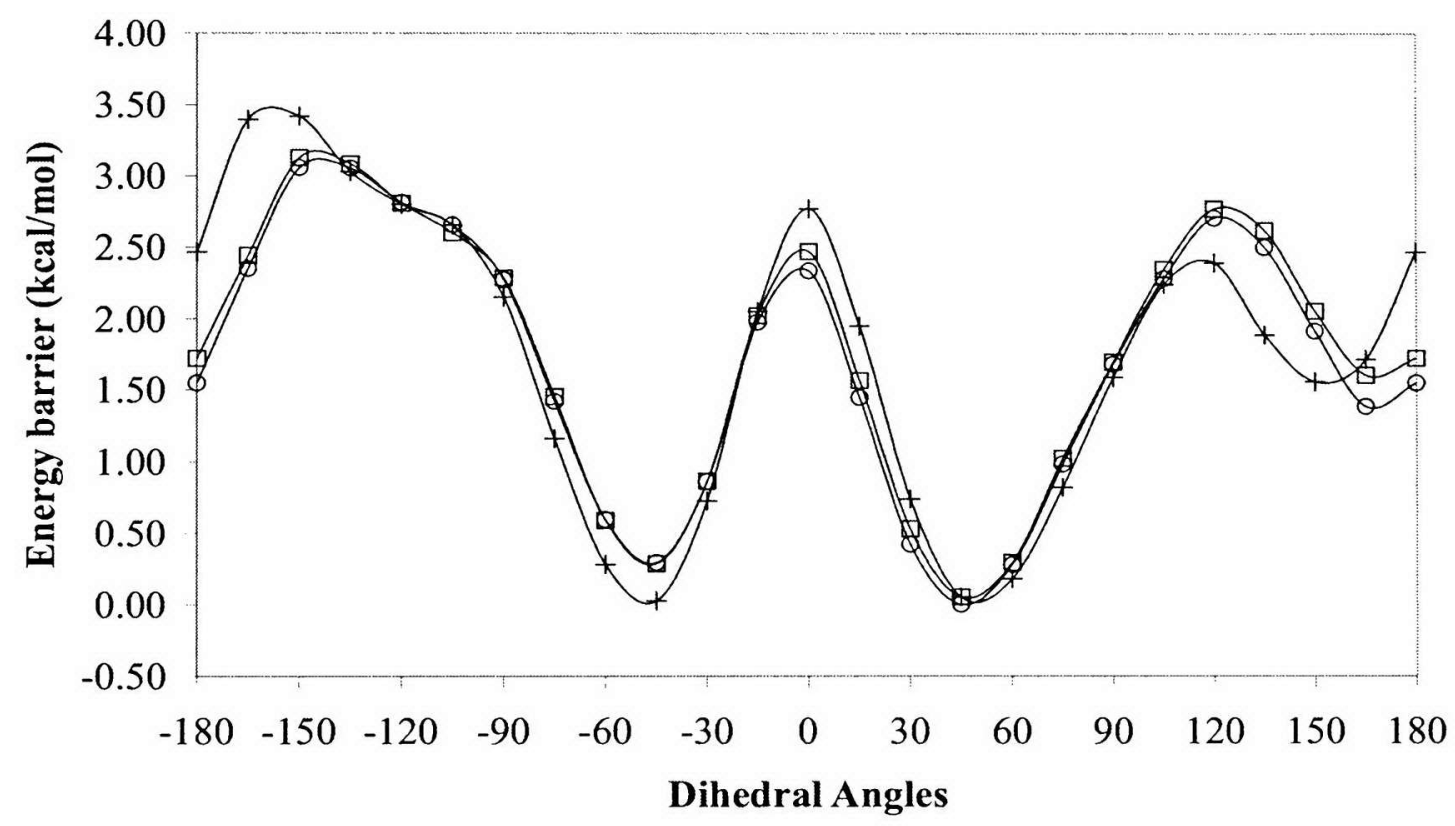

Figure 21. Conformational barrier of 15 -apo- $\beta$-carotenal (O), (3R)-hydroxy-15-apo- $\beta$ carotenal $(\square)$ and 3-oxo-15-apo- $\beta$-carotenal $(+)$ 


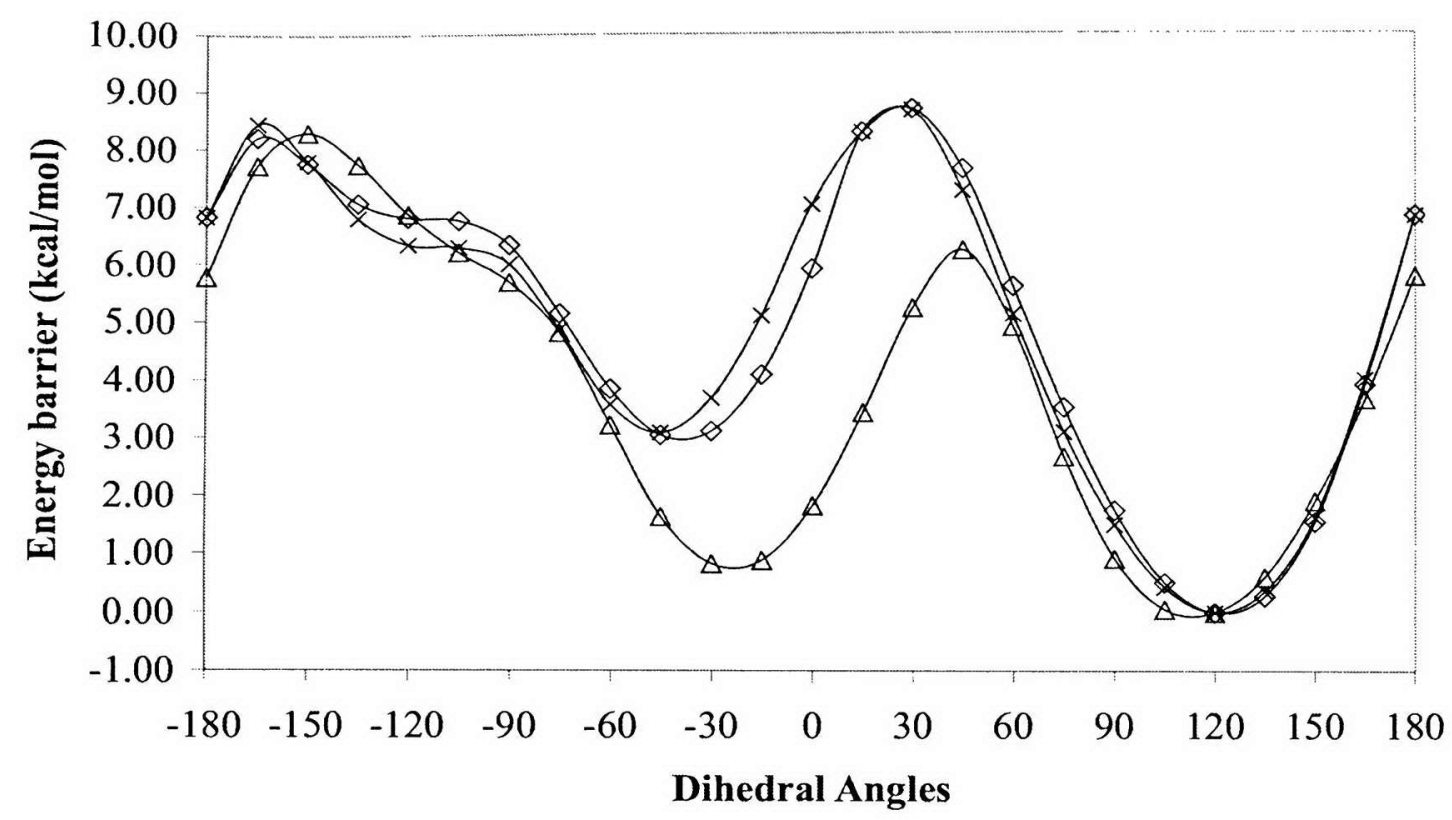

Figure 22. Conformational barrier of (6R)-13-apo- $\varepsilon$-carotene $(\diamond),(3 R, 6 R)$-3-hydroxy15-apo- $\varepsilon$-carotenal $(\triangle)$ and $(6 \mathrm{R})$-3-oxo-15-apo- $\varepsilon$-carotenal $(\times)$

The addition of a hydroxyl group at carbon 3 in the $\beta$-ionone ring does not greatly influence the overall shape of the conformational energy curve. The position of the minima in (3R)-hydroxy-apo- $\beta$-carotenal occurs at $46.7^{\circ}$ for the most stable structure and at $-47.4^{\circ}$ for the second most stable conformation. The energy difference among them was $0.24 \mathrm{kcal} / \mathrm{mol}$, only $0.03 \mathrm{kcal} / \mathrm{mol}$ lower than the energy difference for the two minima in 15 -apo- $\beta$-carotenal. The overall conformational barrier was $3.18 \mathrm{kcal} / \mathrm{mol}$, slightly but not significantly larger than that for 15 -apo- $\beta$-carotenal $(3.06 \mathrm{kcal} / \mathrm{mol})$. The conformational energy barrier for zeaxanthin was modeled by the conformational barrier of (3R)-hydroxy-apo- $\beta$-carotenal.

The conformational barrier for (6R)-3-oxo- 15 -apo- $\beta$-carotenal shows a similar conformational barrier to that observed for all other beta-ring carotenoids modeled. Two 
minima are observed at $47.3^{\circ}$ and $-49.8^{\circ}$ separated by $0.03 \mathrm{kcal} / \mathrm{mol}$. The small energy difference between the most stable and second most stable structure indicates the molecule adopts both conformers readily. The change in hybridization at carbon 3 from $\mathrm{sp}^{3}$ to $\mathrm{sp}^{2}$ situates the substituent planar with respect to the ring, reducing the steric interaction with the polyene chain. The overall conformational barrier for (6R)-3-oxo15 -apo- $\beta$-carotenal was $3.40 \mathrm{kcal} / \mathrm{mol}$, comparable to other apo- $\beta$-carotenals analyzed. The quasi-s-trans conformation in (6R)-3-oxo-15-apo- $\beta$-carotenal is higher in energy than in the other $\beta$-ionone structures, possible due to the conformational limitations as a result of the change in hybridization.

The conformational barrier for (3R,6R)-3-hydroxy-15-apo- $\varepsilon$-carotenal shows a minimum at $113.3^{\circ}$ and a second minimum at $-23.3^{\circ}$, only $0.92 \mathrm{kcal} / \mathrm{mol}$ in energy higher. Both (6R)-13-apo- $\varepsilon$-carotene and (6R)-3-oxo-15-apo- $\varepsilon$-carotenal show a significant energy difference between the two most stable structures of 3.05 and 3.06 $\mathrm{kcal} / \mathrm{mol}$, respectively. In contrast with these two structures, (3R,6R)-3-hydroxy-15-apo$\varepsilon$-carotenal readily adopts both conformations. The conformational barrier for 3-oxo-15apo- $\varepsilon$-carotenal showed two minima at 120.3 and -45.6 separated by $3.06 \mathrm{kcal} / \mathrm{mol}$. The position of the minima was in agreement with other apo- $\varepsilon$-carotenals analyzed. The

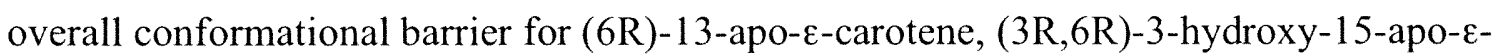
carotenal and (6R)-3-oxo-15-apo- $\varepsilon$-carotenal was $8.88,8.55$ and $8.68 \mathrm{kcal} / \mathrm{mol}$, respectively. $\varepsilon$-ionone rings show a distinguishable shoulder in the conformational barrier at approximately $-110^{\circ}$ similar to $\beta$-ionone rings. Substituents on the ring seem to stabilize the quasi-s-trans conformation. 


\subsubsection{End-groups}

The effect of the type of end-group, $\beta$ - or $\varepsilon$-ring, on the conformational barrier was investigated by comparing the energy diagram of 13 -apo- $\beta$-carotene with (6R)-13apo- $\varepsilon$-carotene in figure 23 , (3R)-hydroxy-15-apo- $\beta$-carotenal with $(3 R, 6 R)-3$-hydroxy15-apo- $\varepsilon$-carotenal in figure 24 ; and 3-oxo- 15 -apo- $\beta$-carotenal with (6R)-3-oxo-15-apo- $\varepsilon$ carotenal in figure 25. Epsilon rings, unlike beta rings, contain a stereocenter at carbon 6 which leads to at least two possible steromers. For simplicity, the $6 \mathrm{R}$ stereomer of the epsilon rings was used in every comparison. The structures of the apocarotenoids are shown in figures 15 and 20.

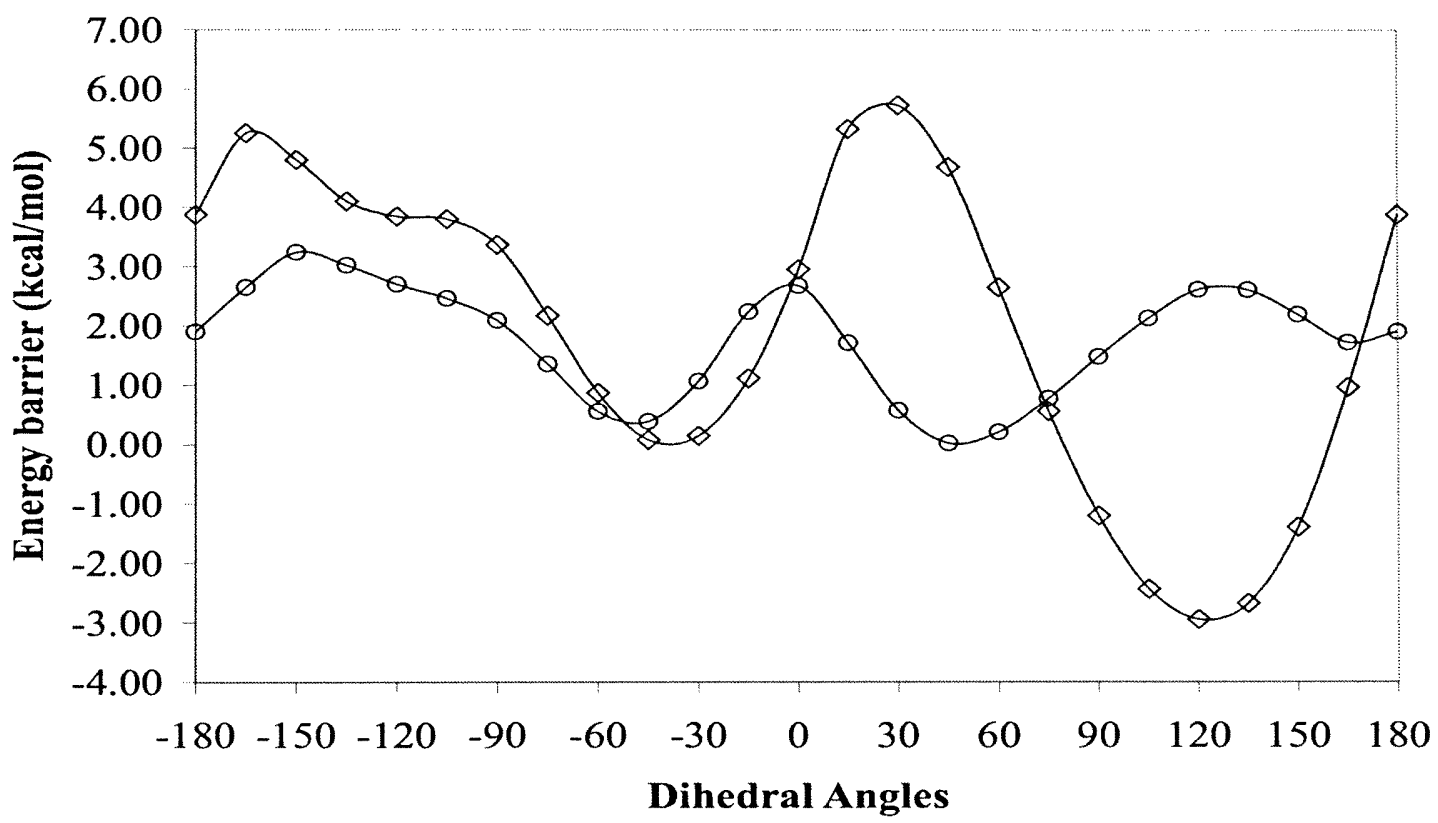

Figure 23. Conformational barrier of 13-apo- $\beta$-carotene $(O)$ and $(6 \mathrm{R})-13$-apo- $\varepsilon$-carotene $(\diamond)$ 


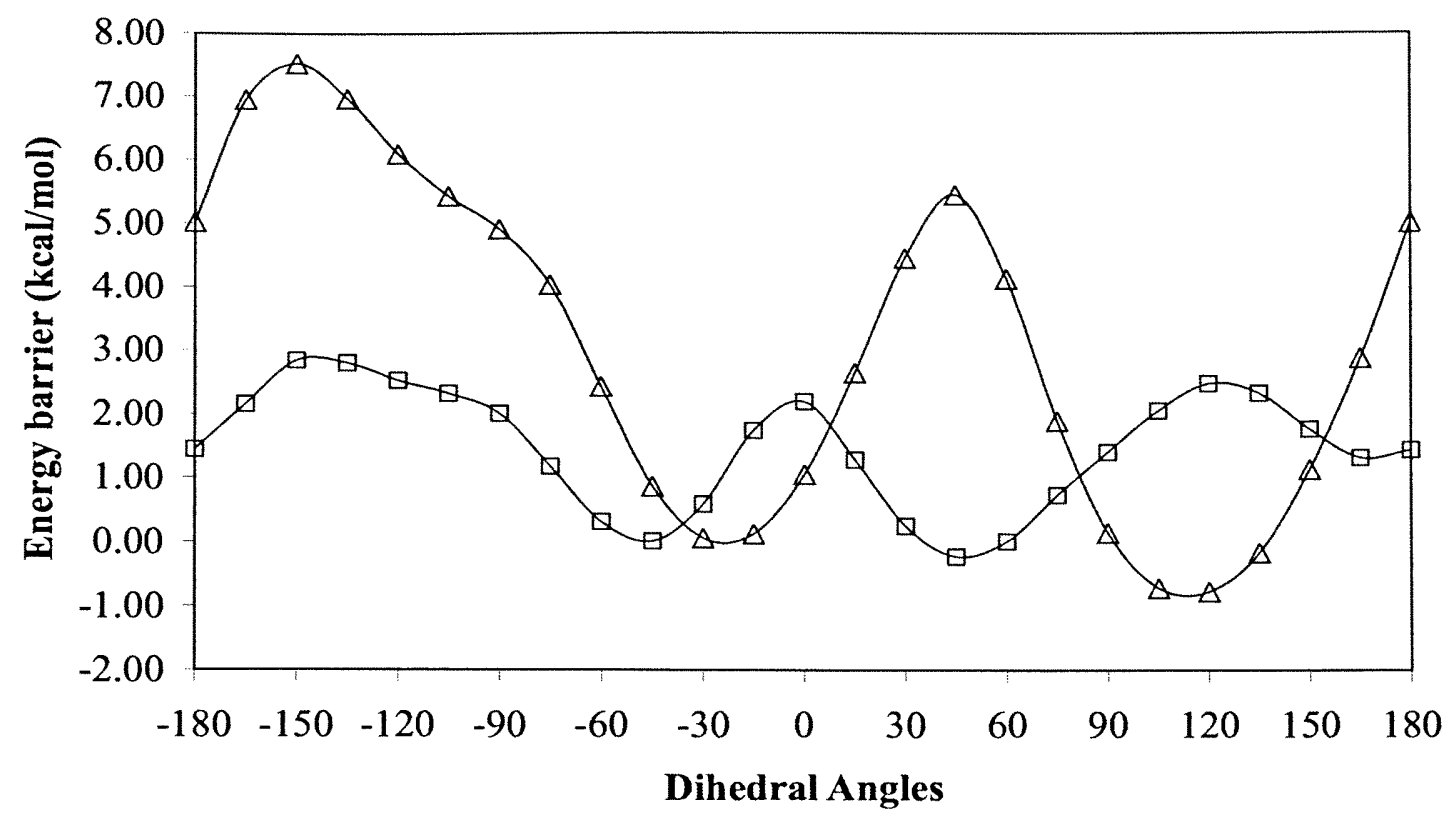

Figure 24. Conformational barrier of (3R)-hydroxy-15-apo- $\beta$-carotenal ( $\square$ ) and (3R,6R)-3-hydroxy-15-apo- $\varepsilon$-carotenal $(\triangle)$

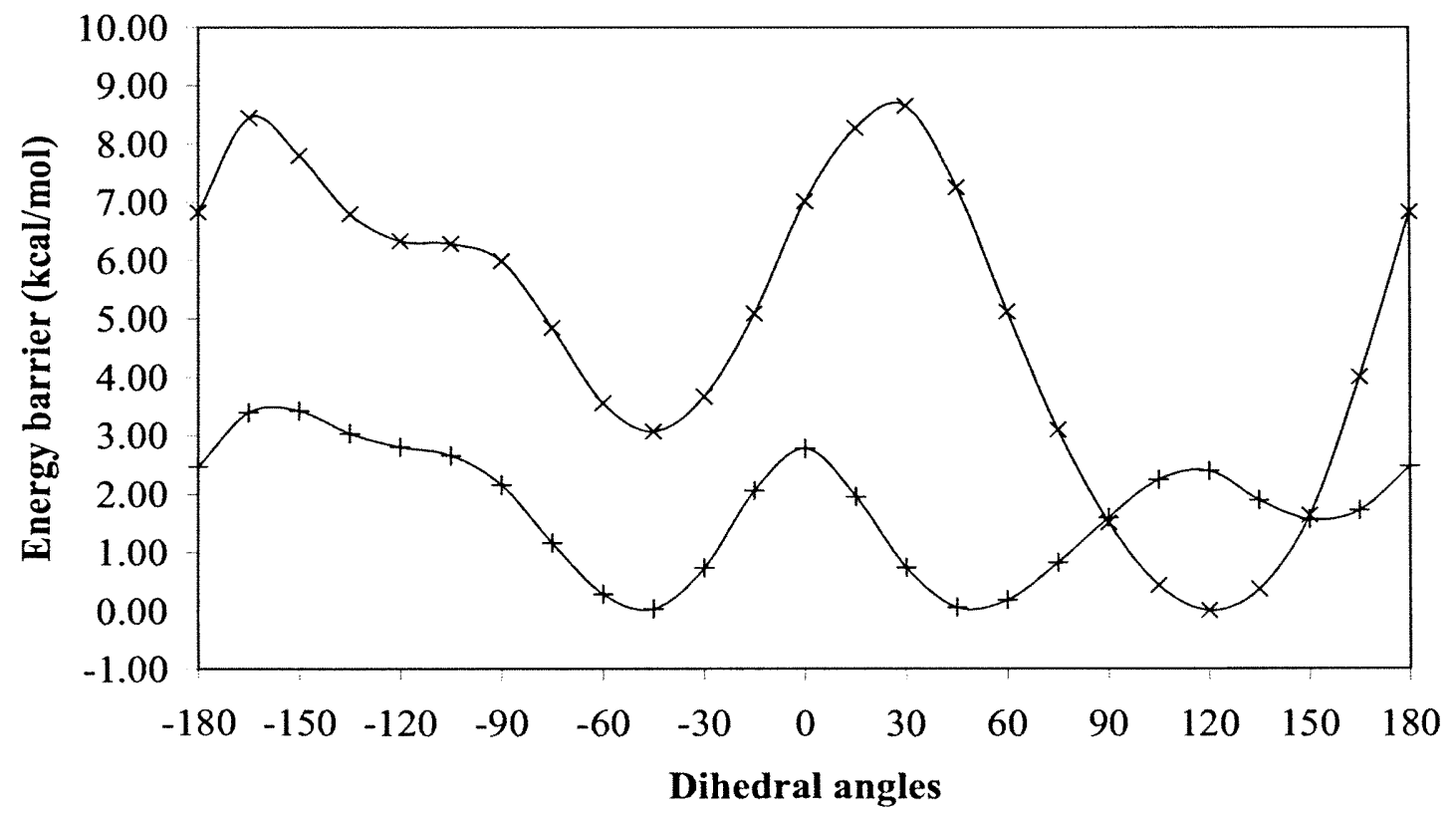

Figure 25. Conformational barrier of 3-oxo-15-apo- $\beta$-carotenal $(+)$ with (6R)-3-oxo-15apo- $\varepsilon$-carotenal $(\times)$ 
The conformational barriers for the $\varepsilon$-ring are dramatically different than that observed for the $\beta$-rings. In all of the $\varepsilon$-ionone ring systems, only one strong minimum in the potential curve was observed, occurring at approximately $120^{\circ}$. No symmetry in the potential curve is seen with respect to either $s$-cis or s-trans as is observed with $\beta$-ionone rings.

The overall conformational barrier for $\varepsilon$-ionone rings ranged in value from 8.55 to $8.88 \mathrm{kcal} / \mathrm{mol}$, significantly larger than that observed for $\beta$-ionone rings which ranged in value from 3.06 to $3.40 \mathrm{kcal} / \mathrm{mol}$. The energy difference between the most stable and the second most stable conformation was significantly larger for epsilon rings (0.92-3.06 $\mathrm{kcal} / \mathrm{mol})$ than for beta rings $(0.03-0.27 \mathrm{kcal} / \mathrm{mol})$. A striking similarity between the conformational barriers for the two types of rings is the shoulder for the quasi-s-cis conformation, as described above.

\subsubsection{Stereochemistry}

The effect of the different stereoisomers on the conformational barrier was investigated by comparing the energy diagram of (3R)-hydroxy-15-apo- $\beta$-carotenal with (3S)-hydroxy-15-apo- $\beta$-carotenal in figure 27 ; and (3R,6R)-3-hydroxy-15-apo- $\varepsilon$ carotenal, (3S,6R)-3-hydroxy-15-apo- $\varepsilon$-carotenal, (3S,6S)-3-hydroxy-15-apo- $\varepsilon$-carotenal and $(3 R, 6 S)-3$-hydroxy-15-apo- $\varepsilon$-carotenal in figure 28 . Figure 26 shows the two possible isomers of 3-hydroxy-15-apo- $\beta$-carotenal and the four possible isomers of 3hydroxy-15-apo- $\varepsilon$-carotenal. The conformational barrier of (3S)-hydroxy-15-apo- $\beta$ carotenal was used to model meso-zeaxanthin and (3S,3'S)-zeaxanthin while the 
conformational barrier of the diastereomers of 3-hydroxy-15-apo- $\varepsilon$-carotenal was used to model lutein, 3'-epilutein, 6'-epilutein, 3',6'-epilutein and 3,6'-epilutein, the diastereomers of lutein found in nature.

\section{3-hydroxy-15-apo- $\beta$-carotenal}<smiles>CC1=C(/C=C/C(C)=C/C=C/C(C)=C/C=C/C(C)=C/C=C/C(C)=C/C=O)C(C)(C)C[C@H](O)C1</smiles>

3-hydroxy-15-apo-e-carotenal

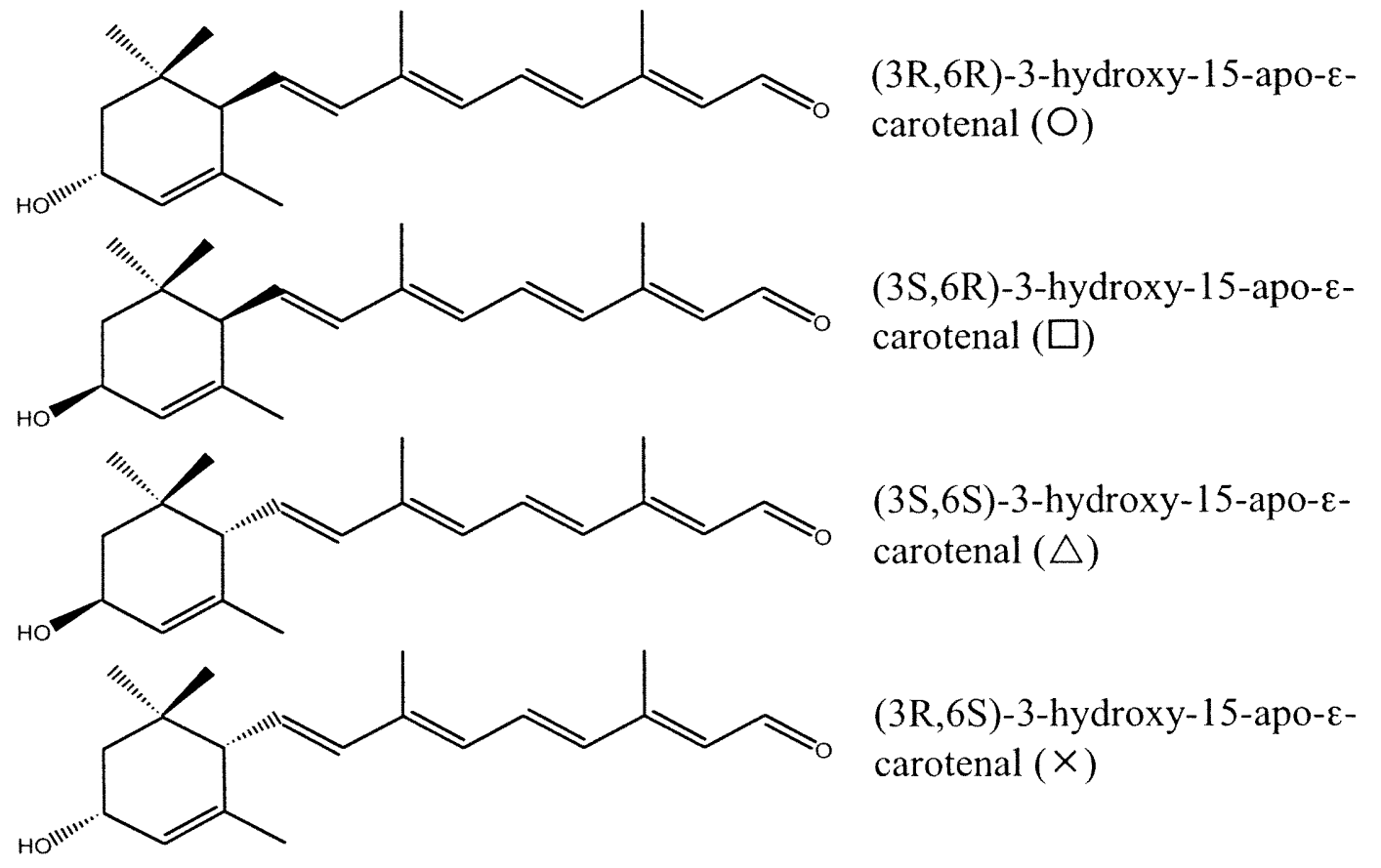

Figure 26. Possible isomers of 3-hydroxy-15-apo- $\beta$-carotenal and 3-hydroxy-15-apo- $\varepsilon$ carotenal 


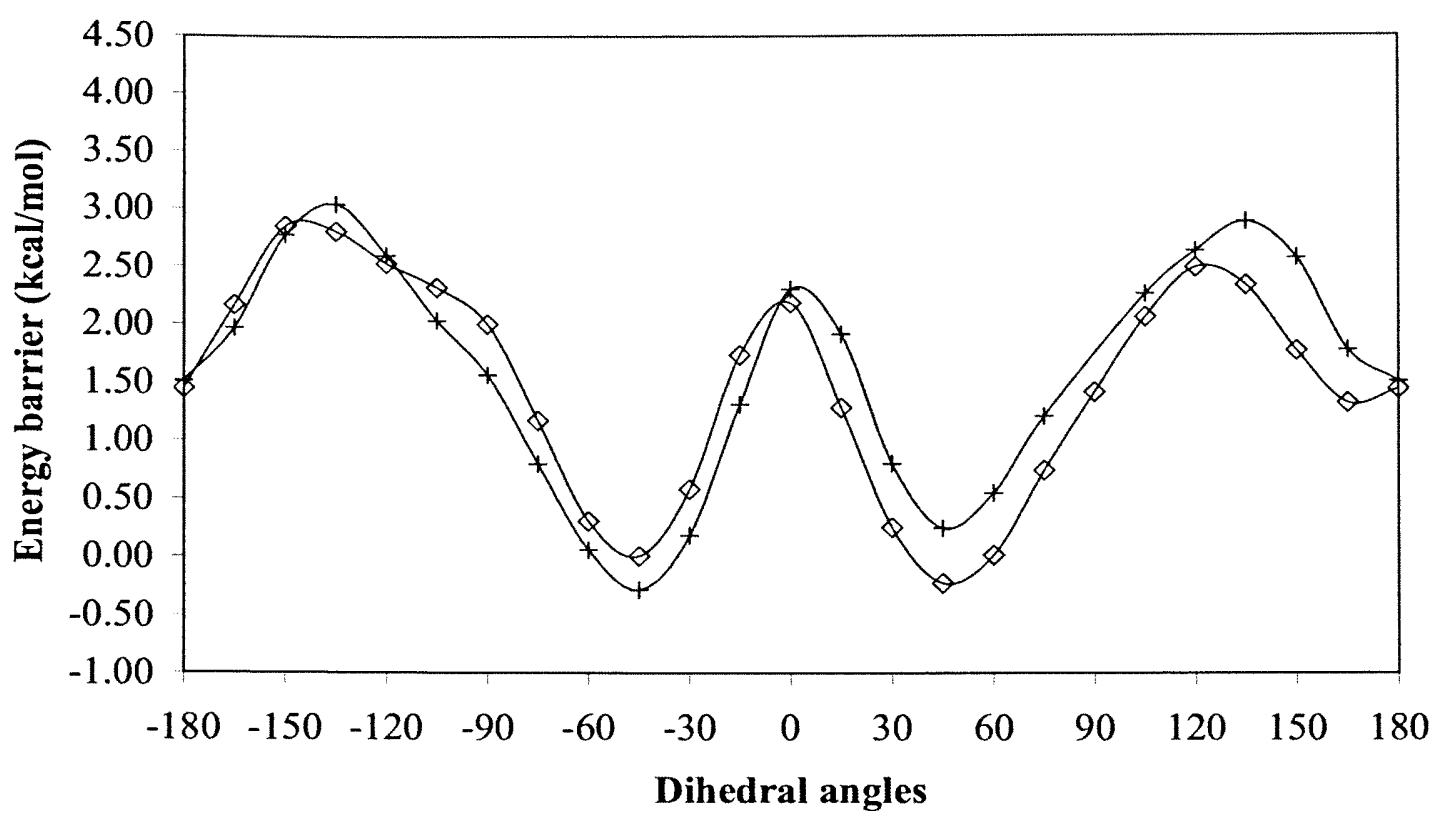

Figure 27. Conformational barrier of (3R)-hydroxy-15-apo- $\beta$-carotenal $(\diamond)$ and (3S)hydroxy-15-apo- $\beta$-carotenal $(+)$

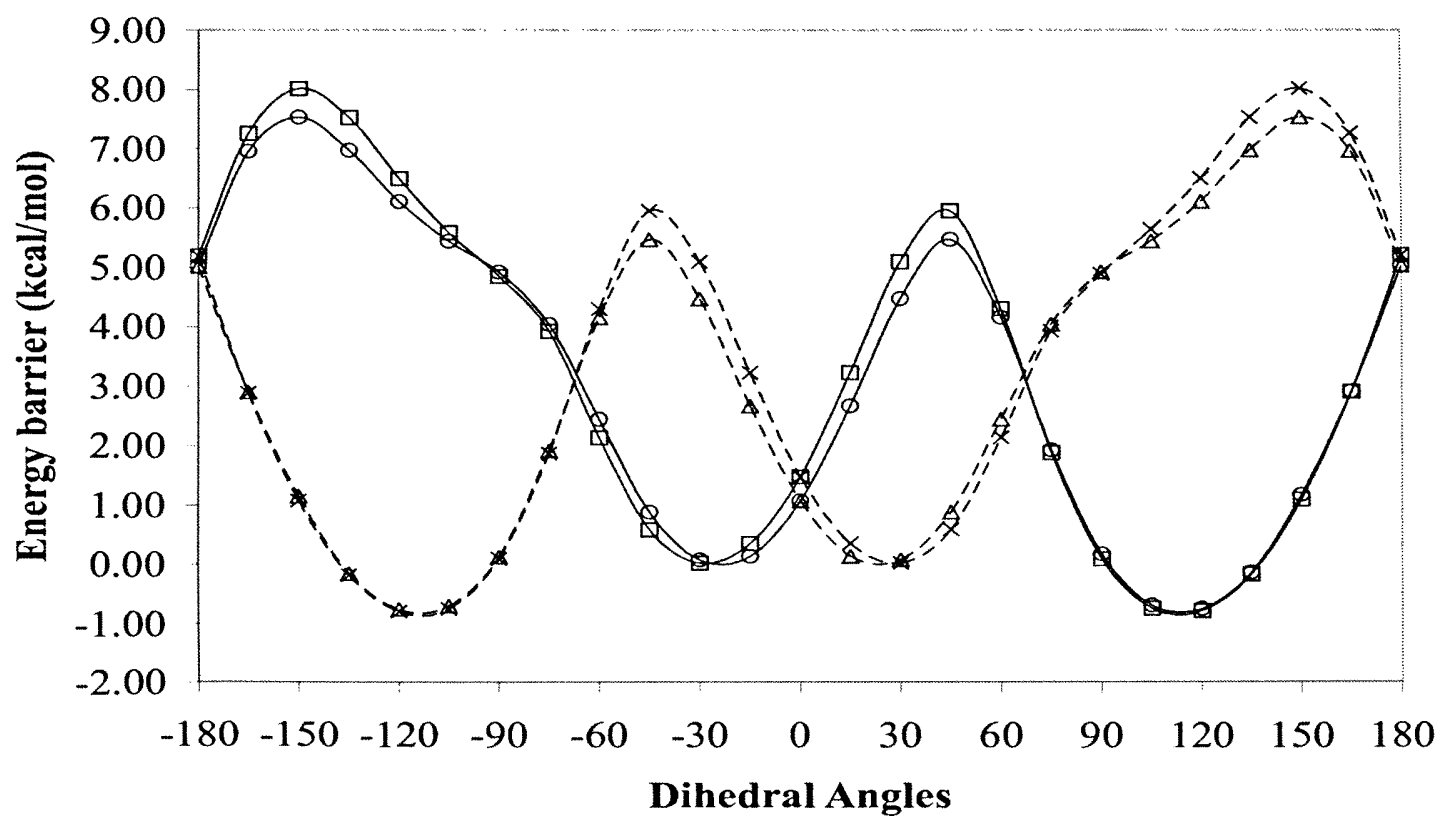

Figure 28. Conformational barrier of (3R,6R)-3-hydroxy-15-apo- $\varepsilon$-carotenal $(O)$, (3S,6R)-3-hydroxy-15-apo- $\varepsilon$-carotenal $(\square),(3 \mathrm{~S}, 6 \mathrm{~S})$-3-hydroxy-15-apo- $\varepsilon$-carotenal $(\triangle)$ and $(3 \mathrm{R}, 6 \mathrm{~S})$-3-hydroxy-15-apo- $\varepsilon$-carotenal $(\times)$ 
The conformational barrier for (3R)-3-hydroxy-15-apo- $\beta$-carotenal $(\diamond)$ differs from that of (3S)-3-hydroxy-15-apo- $\beta$-carotenal $(+)$ in the overall shape, the conformational energy barrier and in the energy difference between the most stable and the second most stable conformation. (3S)-3-hydroxy-15-apo- $\beta$-carotenal shows a minimum at $-46.3^{\circ}$ and a second minimum at $46.8^{\circ}$. The energy difference between the most stable and the second most stable conformation is $0.55 \mathrm{kcal} / \mathrm{mol}$ compared to 0.24 $\mathrm{kcal} / \mathrm{mol}$ for (3R)-3-hydroxy-15-apo- $\beta$-carotenal. The conformational barrier for (3R)-3hydroxy-15-apo- $\beta$-carotenal is $3.18 \mathrm{kcal} / \mathrm{mol}$ while that of (3S)-3-hydroxy- 15 -apo- $\beta$ carotenal is $3.35 \mathrm{kcal} / \mathrm{mol}$.

The conformational barrier for (3R,6R)-3-hydroxy-15-apo- $\varepsilon$-carotenal shows a minimum at $113.3^{\circ}$ and a second minimum at $-23.3^{\circ}$, only $0.92 \mathrm{kcal} / \mathrm{mol}$ in energy higher. The conformational barrier for $(3 \mathrm{~S}, 6 \mathrm{~S})$-3-hydroxy-15-apo-e-carotenal $(\triangle)$ is identical but reversed to that of $(3 R, 6 R)$-3-hydroxy-15-apo- $\varepsilon$-carotenal $(O)$, thus the stereocenter at carbon 6 dictates the energy barrier. As expected, the two enantiomers rotate in opposite directions to achieve the same conformation. The conformational barrier for (3S,6R)-3-hydroxy-15-apo- $\varepsilon$-carotenal ( $\square$ ) resembles that of (3R,6R)-3hydroxy-15-apo- $\varepsilon$-carotenal $(O)$ with the only difference in the position of the second most stable conformation, $-27.5^{\circ}$. As seen for the cis-enantiomers, in which the polyene chain and the substituent on carbon 3, the trans-enantiomers show an inversion of the conformational barrier. The energy difference between the most and second most stable structure is $0.92 \mathrm{kcal} / \mathrm{mol}$. The conformational barrier for the cis-enantiomers is 8.55 $\mathrm{kcal} / \mathrm{mol}$ while that of the trans-enantiomers is $9.05 \mathrm{kcal} / \mathrm{mol}$. 


\subsubsection{Discussion}

The observed position of the most stable and second most stable conformer along with the energy difference among them and the overall conformational barrier is summarized in table 2 .

Table 2. Summary of conformational barrier parameters

\begin{tabular}{|c|c|c|c|c|}
\hline Structure & $\begin{array}{l}\text { Most Stable } \\
\text { Geometry }\end{array}$ & \begin{tabular}{|c|} 
Second Most \\
Stable \\
Geometry \\
\end{tabular} & $\begin{array}{c}\text { Energy } \\
\text { Difference } \\
(\mathrm{kcal} / \mathrm{mol})\end{array}$ & $\begin{array}{c}\text { Conformational } \\
\text { Barrier } \\
(\mathrm{kcal} / \mathrm{mol})\end{array}$ \\
\hline 11 -apo- $\beta$-carotene & $49.2^{\circ}$ & $-51.4^{\circ}$ & 0.35 & 3.25 \\
\hline 13 -apo- $\beta$-carotene & $48.2^{\circ}$ & $-49.2^{\circ}$ & 0.33 & 3.18 \\
\hline 15-apo- $\beta$-carotene & $47.8^{\circ}$ & $-47.9^{\circ}$ & 0.34 & 3.16 \\
\hline 15 -apo- $\beta$-carotenal & $49.6^{\circ}$ & $-45.9^{\circ}$ & 0.27 & 3.06 \\
\hline $\begin{array}{l}\text { (3R)-hydroxy-15-apo- } \beta \text { - } \\
\text { carotenal }\end{array}$ & $46.7^{\circ}$ & $-47.4^{\circ}$ & 0.24 & 3.18 \\
\hline $\begin{array}{l}\text { (3S)-hydroxy-15-apo- } \beta \text { - } \\
\text { carotenal }\end{array}$ & -46.3 & 46.8 & 0.55 & 3.35 \\
\hline 3-oxo-15-apo- $\beta$-carotenal & $47.3^{\circ}$ & $-49.8^{\circ}$ & 0.03 & 3.40 \\
\hline (6R)-13-apo- $\varepsilon$-carotene & $122.5^{\circ}$ & $-39.6^{\circ}$ & 3.05 & 8.88 \\
\hline $\begin{array}{l}(3 \mathrm{R}, 6 \mathrm{R})-3 \text {-hydroxy-15-apo- } \\
\varepsilon \text {-carotenal }\end{array}$ & $113.3^{\circ}$ & $-23.3^{\circ}$ & 0.92 & 8.55 \\
\hline $\begin{array}{l}\text { (3S,6R)-3-hydroxy-15-apo- } \\
\varepsilon \text {-carotenal }\end{array}$ & $113.3^{\circ}$ & $-27.5^{\circ}$ & 0.92 & 9.05 \\
\hline $\begin{array}{l}\text { (3R,6S)-3-hydroxy-15-apo- } \\
\varepsilon \text {-carotenal }\end{array}$ & $-113.3^{\circ}$ & $27.5^{\circ}$ & 0.92 & 9.05 \\
\hline $\begin{array}{l}\text { (3S,6S)-3-hydroxy-15-apo- } \\
\varepsilon \text {-carotenal }\end{array}$ & $-113.3^{\circ}$ & $23.3^{\circ}$ & 0.92 & 8.55 \\
\hline $\begin{array}{l}\text { (6R)-3-oxo-15-apo- } \varepsilon- \\
\text { carotenal }\end{array}$ & $120.3^{\circ}$ & $-45.6^{\circ}$ & 3.06 & 8.68 \\
\hline
\end{tabular}

The conformational energy curve is greatly affected by the type of ring present in the carotenoid. A large barrier is observed for the interconversion of conformers in the epsilon rings $(8.55-9.05 \mathrm{kcal} / \mathrm{mol})$ when compared to beta rings $(3.06-3.40 \mathrm{kcal} / \mathrm{mol}$. The 
energy difference between the most stable and second most stable conformer in beta rings range from $0.03 \mathrm{kcal} / \mathrm{mol}$ for 3 -oxo- 15 -apo- $\beta$-carotenal to $0.35 \mathrm{kcal} / \mathrm{mol}$ for 11 -apo- $\beta$ carotene. The position of the most stable and second most stable conformers in beta rings is in agreement with previously reported data. [56] The conformational curve for all beta groups investigated possessed symmetry with respect to the $s$-cis conformation. The torsion angle for the two most stable geometries is approximately $\pm 46.7-49.2^{\circ}$, which indicates a preference for the s-cis conformer. The substituent present at $\mathrm{C} 3$ does not alter the position of the minima, but it does affect the energy between them. When a hydroxyl group is present, a slight decrease in the energy difference is observed. The effect of the substituent is even more pronounced for the presence of an oxo group at C3. Also, we must not forget that the change in hybridization at $\mathrm{C} 3$ may also affect the energy difference between the most stable and second most stable conformer.

In the case of the epsilon-rings, only one strong minimum is observed at 113.3$122.5^{\circ}$, as previously reported. [58] A pair of enantiomers such as (3R,6R)-3-hydroxy15-apo- $\varepsilon$-carotenal and (3R,6R)-3-hydroxy-15-apo- $\varepsilon$-carotenal have identical but reversed conformational barrier. Identical symmetry is observed in barrier for the pair of enantiomers, (3R,6S)-3-hydroxy-15-apo- $\varepsilon$-carotenal and (3S,6R)-3-hydroxy-15-apo- $\varepsilon$ carotenal. Among the four stereoisomers studied, the energy barrier for the trans isomers in which the 3-hydroxy and the polyene chain are trans to one another is slightly higher than that for the cis isomers. The stereocenter at C6 determines the direction of the conformational barrier. (3R,6R)-3-hydroxy-15-apo- $\varepsilon$-carotenal and (3S,6R)-3-hydroxy15-apo- $\varepsilon$-carotenal have similar energy barriers. 
The consequence of a high-energy barrier for rotation of the $\varepsilon$-ring system is that retinoids containing this structure will be more rigid than those possessing a $\beta$-ring. Accommodation of the $\varepsilon$-ring into non-ideal protein pockets would require that either the ring adopt a non-preferred conformational geometry or that the protein tense itself to an accommodating tertiary conformation. This accounts for the known specificity of photosynthetic proteins for zeaxanthin or lutein in specific sites. 


\section{CHAPTER III:}

\section{STUDY OF THE BIOAVAILABILITY OF XANTHOPHYLL ESTERS IN HUMANS}

\subsection{Overview}

The human diet supplies the necessary carotenoids to maintain a constant supply to the major tissues of the body in which carotenoids are accumulated such as the human macula and serum. The bioavailability of carotenoids is dependant on several factors including the carotenoid profile of the diet, the physical and chemical properties of the carotenoids, the release from the food matrix, transfer to lipid micelles, uptake by intestinal mucosal cells by passive diffusion, and transport to the lymph system. [59] Each step in the absorption of carotenoids influences the bioavailability and thus hindering the assessment. Numerous studies have measured the physiological concentrations of several carotenoids in serum in an attempt to determine the bioavailability of such carotenoids after supplementation. [60, 61] In the LUNA study, supplementation with $12 \mathrm{mg}$ of lutein and $1 \mathrm{mg}$ of zeaxanthin provided as esters along with other co-antioxidants resulted in an approximately four-fold increase in serum lutein concentration. In the LUXEA study, supplementation with $10 \mathrm{mg}$ of free lutein resulted in an approximately seven-fold increase in the serum lutein concentration. The variability in the results may be attributed to the supplement formulation.

In the current study, the bioavailability of a lutein ester supplement was determined by HPLC. The main objectives of this study were four-fold. First, determine the effect of low dose xanthophyll ester supplementation on the carotenoid serum 
response of 30 healthy individual as compared to placebo. Second, determine the concentration of the major serum carotenoids, specifically lutein, zeaxanthin, $\beta$-carotene, $\alpha$-carotene, $\alpha$-cryptoxanthin and $\beta$-cryptoxanthin, at baseline and post-supplementation and the effect of lutein supplementation on their concentration. Third, determine the concentration of four lutein metabolites at baseline and post-supplementation. Lastly, determine the relationship between the concentration of xanthophylls in serum and cholesterol, triglycerides, HDL, LDL, VLDL and C-reactive protein before and postsupplementation.

\subsection{Research Methodology}

\subsubsection{Internal Standard Preparation}

\section{Synthesis of Lutein}

Lutein used for the preparation of the internal standard, monopentyl lutein ether, was extracted from esterified carotenoids harvested from Marigold flowers (Targetes Erecta). The esterified carotenoids were dissolved in methanol and saponified for 12 hours by the addition of aqueous potassium hydroxide to produce a $4 \%$ solution in $10 \%$ deionized water. The reaction was performed in the dark under constant magnetic stirring. The reacted solution was filtered using a P8 qualitative filter (Fisher Scientific, $24.0 \mathrm{~cm}$ in diameter) to remove the esterified carotenoids still undissolved; and neutralized by the dropwise addition of concentrated glacial acetic acid (Fisher Scientific, 64-19-7).

The neutral solution was then evaporated using a rotary evaporator to a fourth of its volume and the carotenoid mixture extracted three times with equal volumes of 
methylene chloride (Fisher Scientific, 75-09-2) and deionized water. The organic layer was collected, dried using magnesium sulfate anhydrous (Fisher Scientific, 7487-88-9) and the solvent removed using a rotary evaporator.

\section{Column Chromatography for the separation of lutein}

The column packing was prepared by mixing $\mathrm{CaCO}_{3}$ (calcium carbonate, Fisher Scientific 471-34-1), MgO (magnesium oxide, light; Sigma-Aldrich 1309-48-4) and $\mathrm{Ca}(\mathrm{OH})_{2}$ (calcium hydroxide, Fisher Scientific 1305-62-0) in a 29.5, 6 and 5 ratio. The mixture was agitated vigorously and passed through an 80 -mesh sifter. The column was prepared in a $600 \mathrm{~mm}$ glass column with a 40-60 micron pore size glass fritted disc and PTFE Stopcock plug (Kontes, 420540). Hexane (Fisher Scientific, 110-54-3) was continuously added to prevent the packing material from drying.

The column was packed by adding a thin layer of washed sea sand (Fischer Scientific, 14808-60-7), $1 \mathrm{~cm}$ in height, and approximately $600 \mathrm{~g}$ of the pre-mixed packing material. The packing material was allowed to settle for several hours assisted by the continuous addition of hexane and pressurized air. Once the material became homogeneous without visible cracks, the level of the hexane was adjusted to $1 \mathrm{~cm}$ above the packing material. The dried carotenoid mixture was slowly added to the top of the column without disturbing the packing material, followed by a thin layer of sand, approximately $2 \mathrm{~cm}$ in height. The carotenoid mixture was prepared by dissolving approximately $50 \mathrm{mg}$ of carotenoids in $10 \mathrm{~mL}$ of methylene chloride, adding approximately $2 \mathrm{~g}$ of packing material and removing the solvent using rotary evaporation. 
The residue was scratched from the sides of the round-bottom flask and added directly to the column.

Hexane was used to elute the first yellow band containing the esterified carotenoids. Separately, a mixture of hexane, chloroform (Fischer Scientific, 67-66-3) and acetone (Fischer Scientific, 67-64-1) in a 3:2.4:0.5 ratio by volume was prepared and added to the column as to slowly adjust the solvent composition depending on the separation.

\section{Monopentyl lutein ether standard preparation}

Monopentyl lutein ether (MPL) was used as an internal standard for HPLC analysis (System II). $5 \mathrm{mg}$ of lutein was dissolved in $20 \mathrm{~mL}$ of 1-pentanol (Acros, 71-410) containing $1 \%$ by volume of concentrated hydrochloric acid (Fischer Scientific, 7647 01-0) and stirred magnetically for 4 hours in the dark. The solution was extracted 3 times with methylene chloride and deionized water, and purified by reverse phase HPLC (System I). MPL was then dissolved in ethanol to a fixed volume, and its concentration determined using a ultraviolet-visible Spectrophotomer.

\subsubsection{Serum sample preparation}

\section{Subjects}

30 healthy, non-smoker volunteers were recruited from the F.I.U. community using an institutional review board approved recruitment posting (Appendix I) and randomly assigned to one of the three study groups: placebo, low dose or high dose. The study included both males and females as well as members of minority populations. The 
study excluded: individuals who are smokers, pregnant or planning pregnancy, diabetics, hypertensive, those with gastrointestinal disorders and individuals taking statin drugs or other prescriptions chronically.

Subjects were interviewed and instructed on the research protocol, benefits and possible risks of the study. An institutional review board approved consent form (Appendix II) was required from each individual. No personal data with the exception of age and sex was acquired and retained for correlation to the experimental results.

\section{Study Supplements}

Study supplements were provided in a hard shell gelatine capsule containing esterified lutein extracted from marigold flowers (Targetes erecta) or placebo. The esterified lutein contained approximately $7 \%$ esterified zeaxanthin. The capsules were acquired from Biolut. The analysis of the capsule resulted in xanthophylls doses of $3 \mathrm{mg}$ of lutein equivalent per capsule for the low dose supplement and $6 \mathrm{mg}$ of lutein equivalent per capsule for the high dose supplement. Subjects were instructed to take the daily supplement with a meal at a regular time.

\section{Blood Collection}

$10 \mathrm{~mL}$ of venous blood were collected in Vacutainer separator tubes at the University Health Center before supplementation and every 2 weeks during the 8 -week intervention (total of 5 blood serum collections). The first and last blood collections were done after overnight fast for analysis of lipid parameters. Blood was allowed to clot for 
30 minutes and centrifuged for $10 \mathrm{~min}$ at $3000 \mathrm{rpm}$. The serum samples were stored at $80^{\circ} \mathrm{C}$ in $2 \mathrm{~mL}$ polypropylene tubes until extraction and analysis on HPLC (System II).

\section{Lipid Panel}

Fasting blood samples were collected before supplementation (day 0) and postsupplementation (day 60) and sent for analysis at a local clinical laboratory. The lipid parameters measured were: cholesterol, high-density lipoprotein (HLD), low-density lipoprotein (LDL), very low-density lipoprotein (VLDL), triglycerides and C-reactive protein.

\section{Serum sample extraction}

Serum samples were prepared according to previously established techniques. [62] The serum sample was removed from the freezer and thawed for 20 minutes. After vortexing the sample for 30 seconds, $200 \mu \mathrm{L}$ of serum and $20 \mu \mathrm{L}$ of monopentyl lutein ether dissolved in ethanol (AAPER, Absolute 200 proof) were combined in a $100 \times 13$ $\mathrm{mm}$ borosilicate glass tube with a Teflon lined screw cap. $2 \mathrm{~mL}$ of 1:1 methanol (Fischer Scientific, 67-56-1):deionized water mixture (v:v) was added to precipitate the serum proteins and the carotenoids extracted 3 times with $2 \mathrm{~mL}$ of hexane. After the addition of hexane, the mixture was vortexed for 1 minute and centrifuge for 5 minutes. The top hexane layer containing the dissolved carotenoids was drawn with a glass Pasteur pipette into a $2 \mathrm{~mL}$ polypropylene vial. The aliquots were combined and dried under a stream of nitrogen gas. The sample was re-dissolved in $40 \mu \mathrm{L}$ of ethanol and transferred 
to a $250 \mu \mathrm{L}$ polypropylene vial (Waters, WAT094172) for injection into HPLC (System II).

\subsubsection{Chromatographic Separations}

\section{System I}

MPL was purified using reverse phase HPLC on a system composed of a Thermo Finnigan Spectra System UV 1000 detector coupled to an LDC/Milton Roy Analytical Constametric 4000 multiple solvent delivery system equipped with a Phenomenex Ultracarb $10 \mu \mathrm{m}$ ODS column $(250 \times 21.20 \mathrm{~mm})$ and an injection loop volume of $10 \mathrm{~mL}$. The solvent composition was $85 \%$ acetonitrile (Fisher Scientific, $75-05-8$ ), $15 \%$ methanol (Fisher Scientific, 67-56-1) and 0.1\% triethylamine (Fisher Scientific, 121-44-8) which were mixed and degassed prior to introduction into the chromatographic system at a flow rate of $5 \mathrm{~mL} / \mathrm{min}$. The ultraviolet detector was set up at $450 \mathrm{~nm}$.

\section{System II}

The serum samples were analyzed using a Waters 2690 Alliance Separation module equipped with a Waters model 996 Photodiode Array Detector and a Waters 486 Tunable Absorbance Detector set at $450 \mathrm{~nm}$. Carotenoid separations were carried out on a reversed phase Phenomenex Ultracarb $3 \mu \mathrm{m}$ ODS $(150 \times 4.6 \mathrm{~mm})$ with a flow rate of 1 $\mathrm{mL} / \mathrm{min}$. The solvent composition used was $85 \%$ acetonitrile, $15 \%$ methanol, and $0.1 \%$ triethylamine by volume. Samples were run at ambient temperature, generally at $20^{\circ} \mathrm{C}$. $25 \mu \mathrm{L}$ of sample was injected into the system and ran for 60.0 minutes. 


\section{System III}

Carotenoid esters were analyzed using the chromatographic equipment described for system II with a YMC $3 \mu \mathrm{m} \mathrm{C} 30$ Carotenoid Column $(2.0 \times 250 \mathrm{~mm})$. A gradient between solvent A ( $81 \%$ methanol, $4 \%$ deionized water and $15 \%$ methyl tert-butyl ether, Fisher Scientific, 1634-04-4) and solvent B (6\% methanol, 4\% deionized water and 90\% methyl-tert-butyl ether) was used for elution, figure 29 , delivered at a flow rate of 0.3 $\mathrm{mL} / \mathrm{min}$. The column temperature was adjusted to $35^{\circ} \mathrm{C} .25 \mu \mathrm{L}$ of sample dissolved in ethanol was injected into the system and ran for 70.0 minutes.

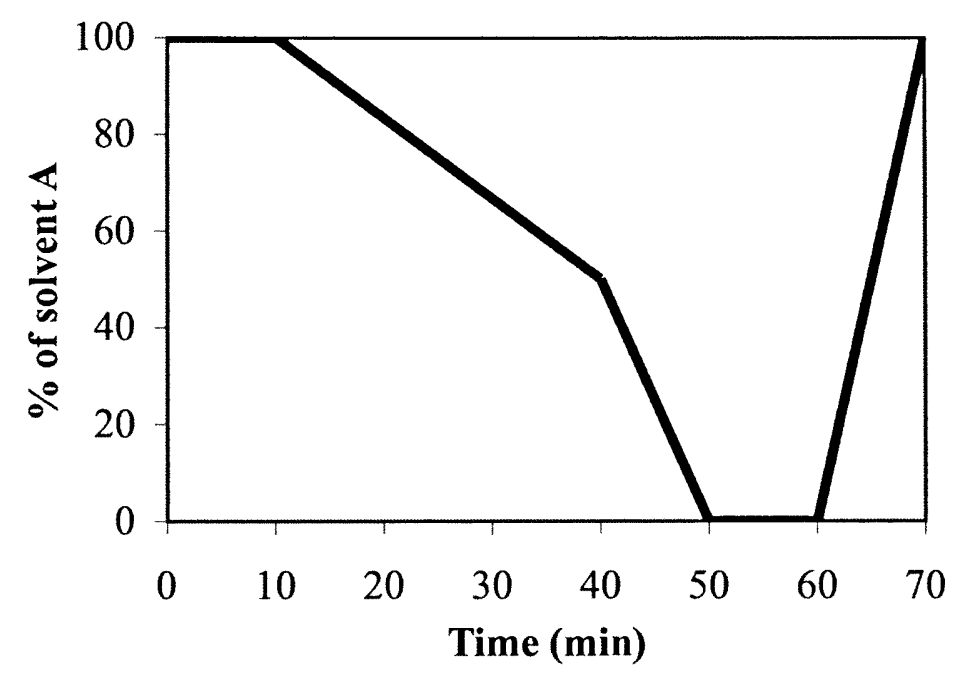

Figure 29. HPLC gradient for the separation of carotenoid ester by System III (solvent A: $81 \%$ methanol, $4 \%$ deionized water and $15 \%$ methyl tert-butyl ether, and solvent B:6\% methanol, $4 \%$ deionized water and $90 \%$ methyl-tert-butyl ether

\subsubsection{Ultraviolet-visible Spectrophotometer}

The concentration of MPL was measured using a Shimadzu double beam UVVisible Scanning Spectrophotometer (UV-2101 PC). Mono-pentyl lutein ether (Internal Standard) was dissolved in ethanol and scanned from 650 to $300 \mathrm{~nm}$. The ultraviolet- 
visible spectrum was measured in a UV self-masking micro cell with PTFE stopper (NSG precision cells, 30MUV10). Beer's law was used to determine the concentration. The molar absorptivity of MPL ( $\varepsilon$ ) is $1.45 \times 10^{5} \mathrm{M}^{-1} \cdot \mathrm{cm}^{-1}$ at $450 \mathrm{~nm}$.

\subsubsection{Statistical Analysis}

The data including the serum carotenoid concentrations and lipid parameters was analyzed using the Statistical Package for the Social Sciences (SPSS). Descriptive statistics including means and standard deviations were used to analyze the variation in serum carotenoids and lipid parameters. Two-way analysis of variance and independent t-test was used to compare differences in carotenoid serum concentration between the placebo and the supplementation groups and to compare the lipid parameters among the groups. Results were considered statistically significant at $p<0.05$. Spearman's correlations were performed to establish the relationship between serum carotenoids and lipid parameters.

\subsection{Results}

\section{Baseline characteristics}

Thirty subjects from the F.I.U. community participated in the study. The baseline characteristics of the three groups in the study along with baseline values of serum carotenoids are shown in table 2. The age range of the participants was from 18 to 62 years with a mean age of $24.9 \pm 9.7$ years. The majority of the subjects, $90 \%$ or 27 subjects, were between the ages of 18 and 29 years. No statistical differences, as determined by one-way ANOVA, were observed in terms of age and the female-to-male 
ratio. 10 males and 20 females participated in the study, equally distributed among the groups, table 3. The placebo and low dose group each included $70 \%$ females and the high dose included $60 \%$ females.

Table 3. Baseline characteristics for supplemented subjects (mean \pm standard deviation)

\begin{tabular}{|lccc|}
\hline & Placebo $(\mathrm{n}=10)$ & Low dose $(\mathrm{n}=10)$ & High dose $(\mathrm{n}=10)$ \\
\hline Age (years) & $22.3 \pm 4.64$ & $26.4 \pm 12.9$ & $26.0 \pm 10.3$ \\
Female:male & $7: 3$ & $7: 3$ & $6: 4$ \\
& & & \\
Lipid parameters & & & \\
Cholesterol (mg/dL) & $149.5 \pm 22.6$ & $178.0 \pm 33.6^{*}$ & $191.6 \pm 33.9 *$ \\
Triglycerides (mg/dL) & $62.4 \pm 15.3$ & $85.1 \pm 46.4$ & $96.8 \pm 48.9$ \\
HDL Cholesterol (mg/dL) & $52.3 \pm 5.3$ & $57.3 \pm 11.2$ & $50.6 \pm 12.6$ \\
LDL (mg/dL) & $84.5 \pm 22.4$ & $103.6 \pm 19.4$ & $121.8 \pm 24.8$ \\
VLDL (mg/dL) & $12.7 \pm 3.1$ & $17.1 \pm 9.4$ & $19.2 \pm 9.8$ \\
C-reactive protein & $0.09 \pm 0.07$ & $0.20 \pm 0.30$ & $0.14 \pm 0.11$ \\
& & & \\
Major Serum carotenoids & & & \\
Lutein (nmol/dL) & $15.74 \pm 6.69$ & $14.77 \pm 3.77$ & $16.89 \pm 8.85$ \\
Zeaxanthin (nmol/dL) & $5.04 \pm 1.77$ & $6.49 \pm 2.56$ & $6.55 \pm 4.07$ \\
$\alpha$-Cryptoxanthin (nmol/dL) & $2.98 \pm 1.68$ & $3.34 \pm 2.00$ & $3.06 \pm 2.12$ \\
$\beta$-Cryptoxanthin (nmol/dL) & $10.33 \pm 8.98$ & $13.20 \pm 9.88$ & $13.85 \pm 13.39$ \\
$\alpha$-Carotene (nmol/dL) & $2.96 \pm 2.49$ & $3.24 \pm 2.78$ & $5.19 \pm 6.23$ \\
$\beta$-Carotene (nmol/dL) & $8.63 \pm 7.63$ & $13.59 \pm 14.52$ & $13.04 \pm 13.60$ \\
\hline
\end{tabular}

* $\mathrm{t}$-test for equality of means indicate significant difference when compared to baseline concentration $(\mathrm{p}<0.05)$

The cholesterol levels for the participants ranged from 122 to $262 \mathrm{mg} / \mathrm{dL}$ with a mean serum cholesterol level of $173.0 \pm 34.4 \mathrm{mg} / \mathrm{dL}$. The baseline cholesterol levels of the placebo group significantly differed from both the low and the high dose supplementation group at the $\mathrm{p}<0.05$ level, as determined by one-way ANOVA. The mean cholesterol level for the placebo group was $149.5 \pm 22.6 \mathrm{mg} / \mathrm{dL}$, for the low dose 
group $178.0 \pm 33.6 \mathrm{mg} / \mathrm{dL}$ and for the high dose $191.6 \pm 33.9 \mathrm{mg} / \mathrm{dL}$. The statistical differences in the baseline cholesterol levels within the groups, prevented a comparison with post-supplementation cholesterol levels.

Pearson correlations between the baseline serum lutein concentration and the lipid parameters revealed a positive linear correlation at $\mathrm{p}<0.05$ between the lutein concentration and the serum concentrations of cholesterol, figure 30 , HDL, figure 31 , and LDL, figure 32 , levels for the males but not for the females or when all subjects where combined. The individual Pearson's product momentum correlation coefficients, $r$, are indicated next to each linear trend line and denoted with an asterisk to indicate significance at $p<0.05$. Among the females, a greater variability was observed in the serum parameters and in the serum carotenoid concentration.

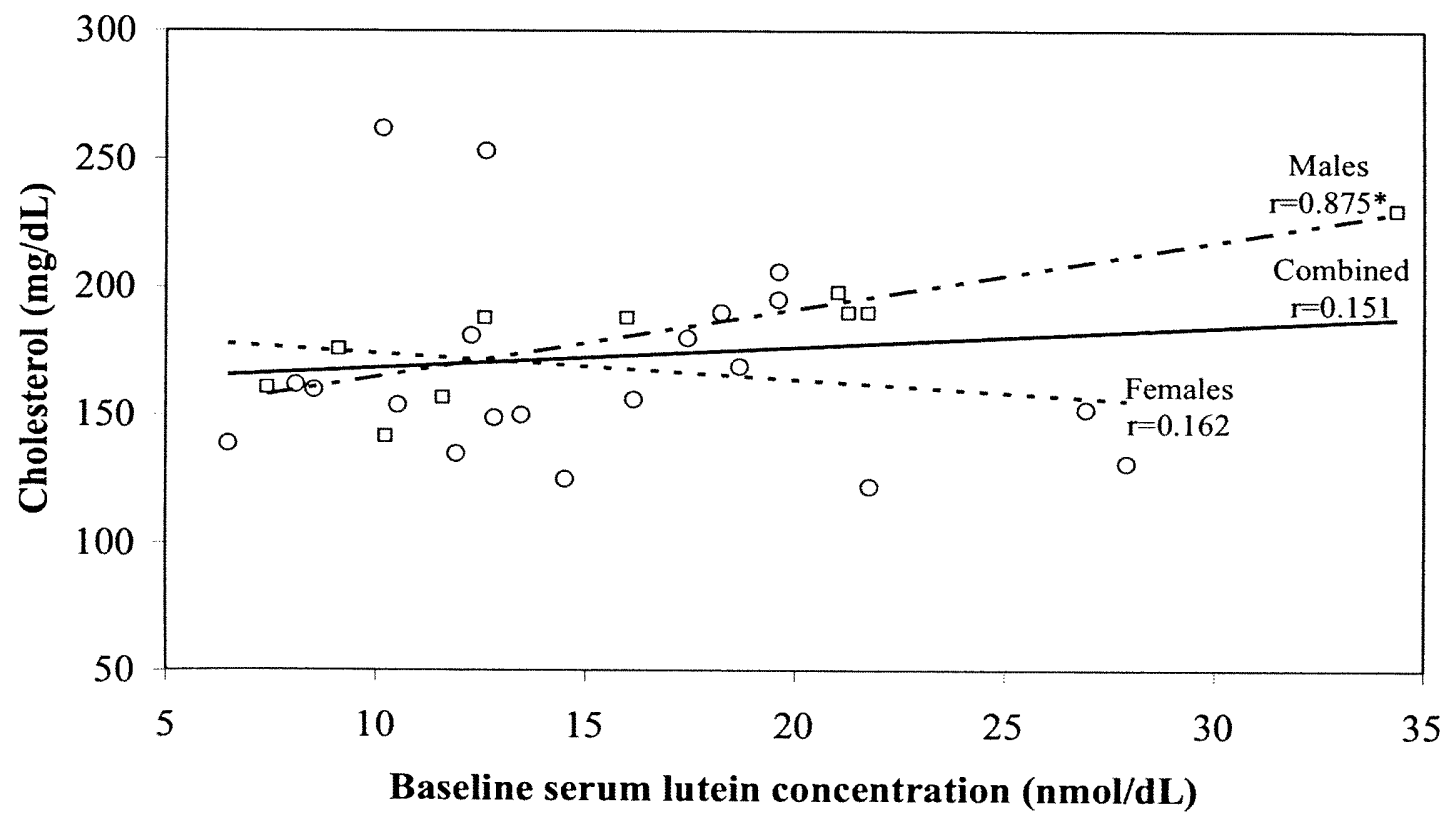

Figure 30. Correlation between serum lutein concentration and cholesterol for females $\mathrm{r}=0.162(\mathrm{O})$, males $\mathrm{r}=0.875^{*}(\square)$ and combined $\mathrm{r}=0.151$ 


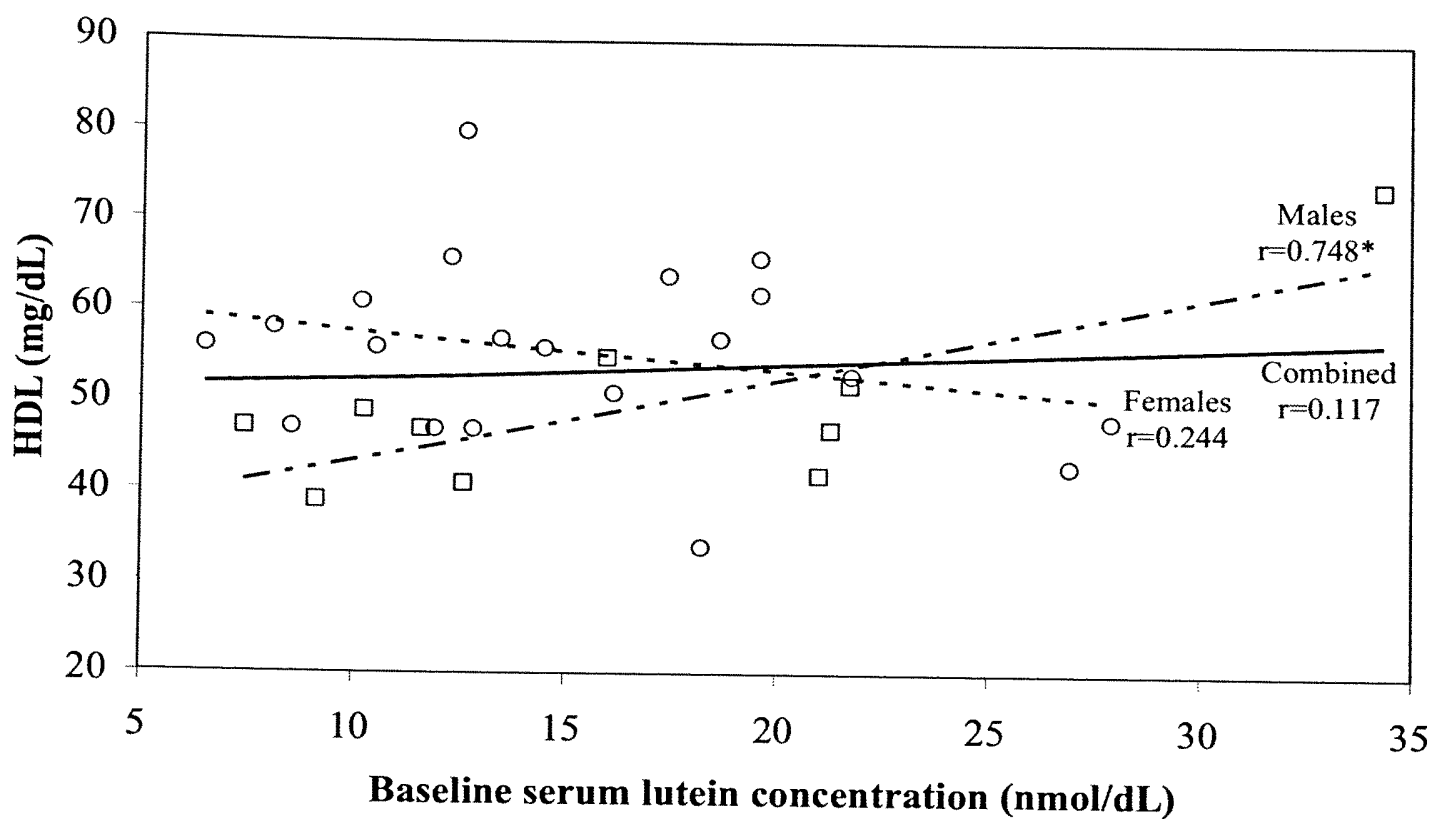

Figure 31. Correlation between serum lutein concentration and HDL for females $r=0.244$ $(\mathrm{O})$, males $\mathrm{r}=0.748^{*}(\square)$ and combined $\mathrm{r}=0.117$

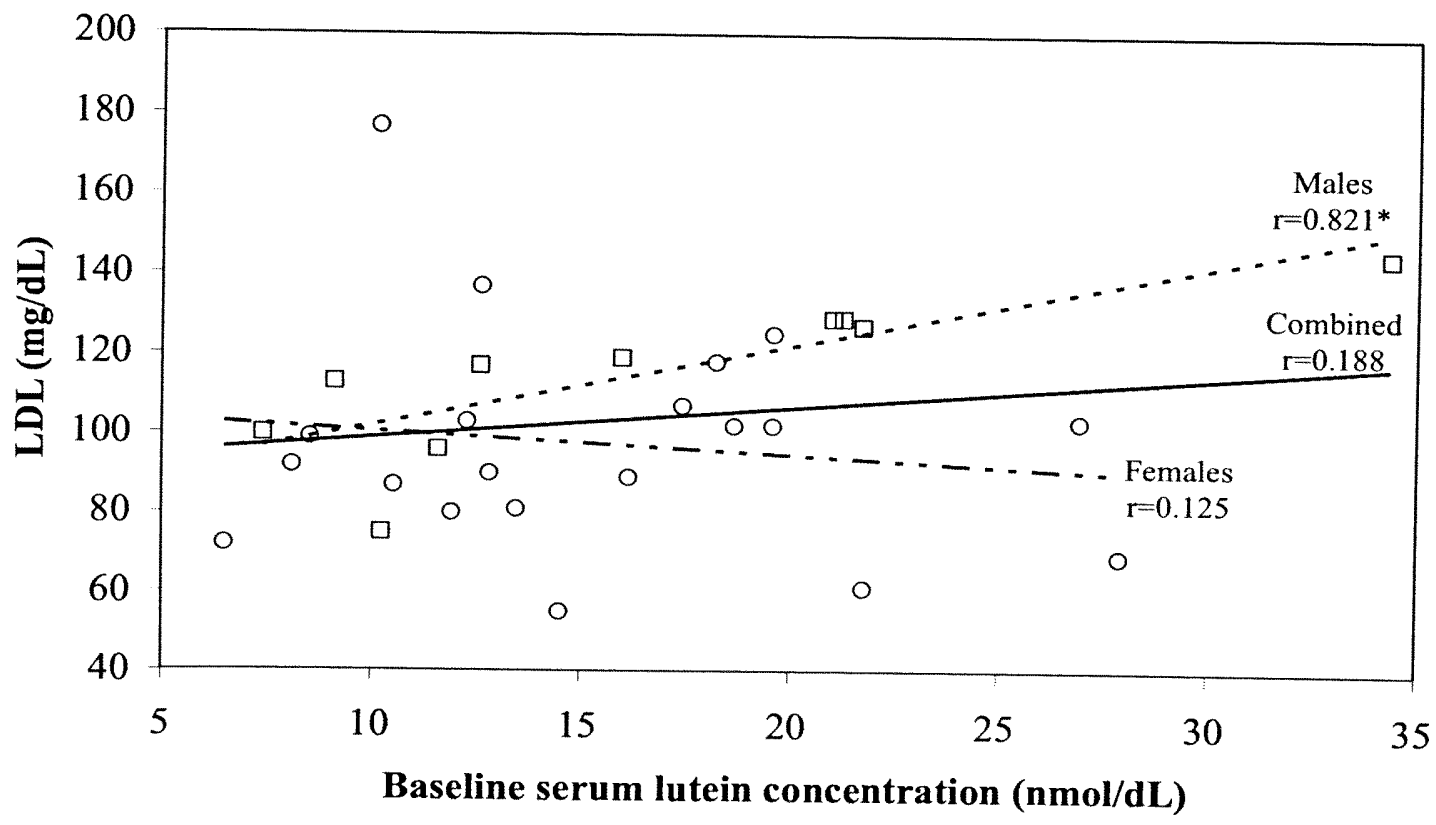

Figure 32. Correlation between serum lutein concentration and LDL for females $r=0.125$ $(\mathrm{O})$, males $\mathrm{r}=0.821^{*}(\square)$ and combined $\mathrm{r}=0.188$ 
The Pearson's product momentum correlation coefficients and linear trend line indicates that the male subjects with higher cholesterol, HDL and LDL exhibit higher serum lutein concentrations at baseline. No correlation was observed with other serum carotenoids.

The mean serum triglycerides in the study was $81.4 \pm 41.2 \mathrm{mg} / \mathrm{dL}$, the mean HDL cholesterol was $53.4 \pm 10.2 \mathrm{mg} / \mathrm{dL}$, the mean LDL level was $103.3 \pm 26.5 \mathrm{mg} / \mathrm{dL}$ and the mean VLDL level was $16.3 \pm 8.2 \mathrm{mg} / \mathrm{dL}$. No significant differences were observed for the baseline levels of triglycerides, HDL cholesterol, LDL and VLDL within the groups at the $\mathrm{p}<0.05$.

The serum concentration of lutein ranged from 7.41 to $34.34 \mathrm{nmol} / \mathrm{dL}$, with a mean of $15.79 \pm 6.43 \mathrm{nmol} / \mathrm{dL}$. The mean serum concentration of zeaxanthin, $\alpha$ cryptoxanthin and $\beta$-cryptoxanthin was $6.03 \pm 2.80,3.13 \pm 1.88$ and $12.46 \pm 10.65$ $\mathrm{nmol} / \mathrm{dL}$ respectively. As in the case of lutein, the responses varied widely within each group. The mean serum concentration of $\alpha$-carotene, $\beta$-carotene and cis- $\beta$-carotene was $3.77 \pm 4.11,11.75 \pm 11.56$ and $2.40 \pm 1.12 \mathrm{nmol} / \mathrm{dL}$, respectively. No significant differences were observed between the carotenoid serum concentrations among the three groups.

\section{Analysis of xanthophyll esters supplement}

The analysis of the xanthophyll esters supplement was carried out by System III. The HPLC chromatogram of the supplement, figure 33, indicate the presence of multiple fatty acid ester components known to be naturally produced by marigold flowers, the source of the supplements used. [28] 


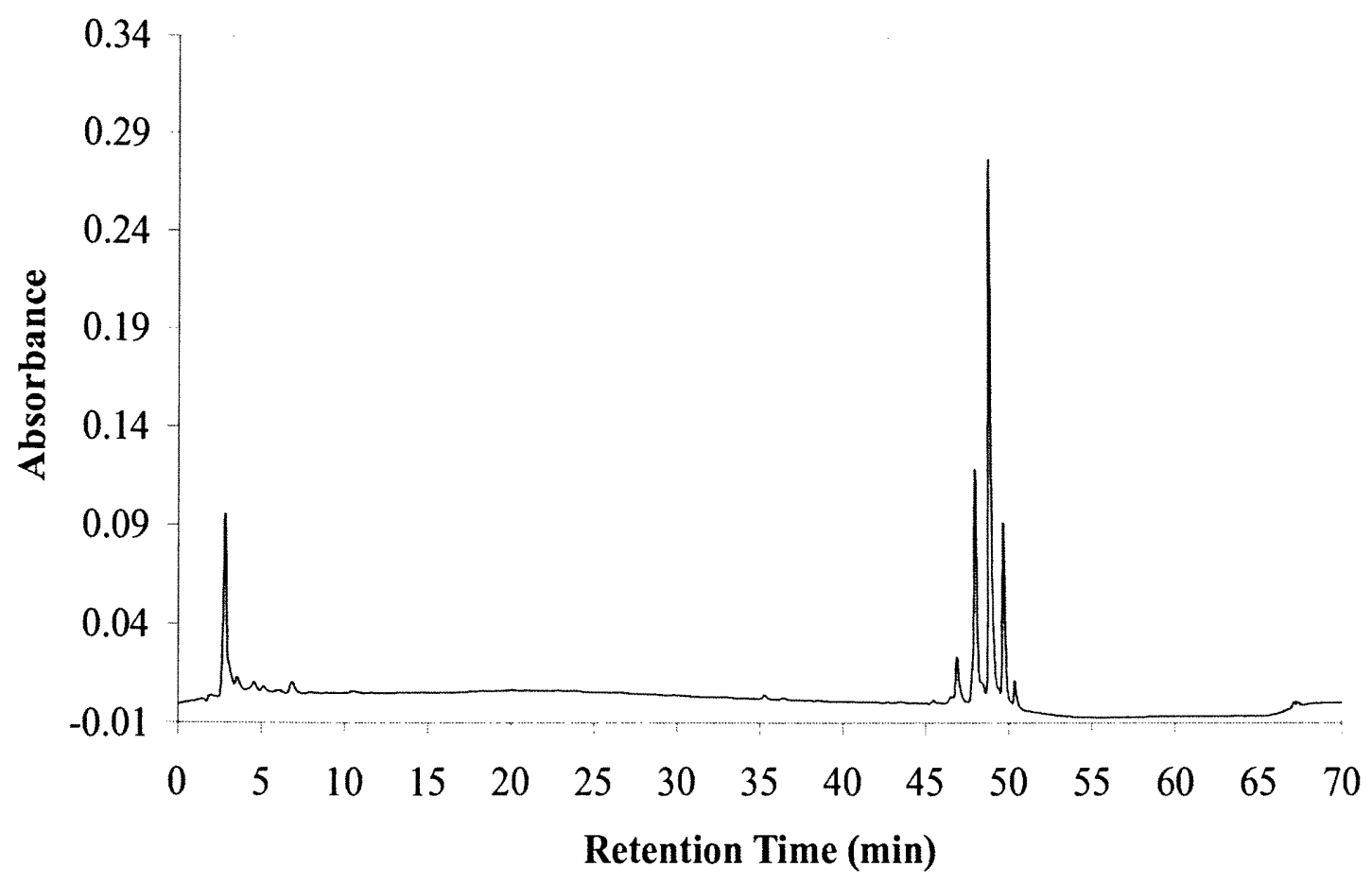

Figure 33. HPLC chromatogram of xanthophyll esters supplement

The UV-visible spectra of the individual components, ranging in retention time from 46.9 to $50.4 \mathrm{~min}$, indicate the presence of five different lutein diesters. The wavelength of maximum absorbance for all components ranged from 446.8 and 447.2 $\mathrm{nm}$, consistent with that observed for lutein. Esterification does not alter the chromophore present in the carotenoid, therefore $\lambda_{\max }$ for the lutein diesters equal that of lutein. In between the main peaks, small overlapping peaks were observed and identified as the corresponding zeaxanthin diesters which are known to occur naturally in marigold flowers (Targetes erecta) in approximately 7\%. [28] The main source of the xanthophyll diester supplements was marigold flowers. 


\section{Spectroscopic characterization of serum components}

The HPLC chromatogram recorded by System II of a typical serum sample at baseline is shown in figure 34. The identity, retention time and retention factor for each component is described in table 4.

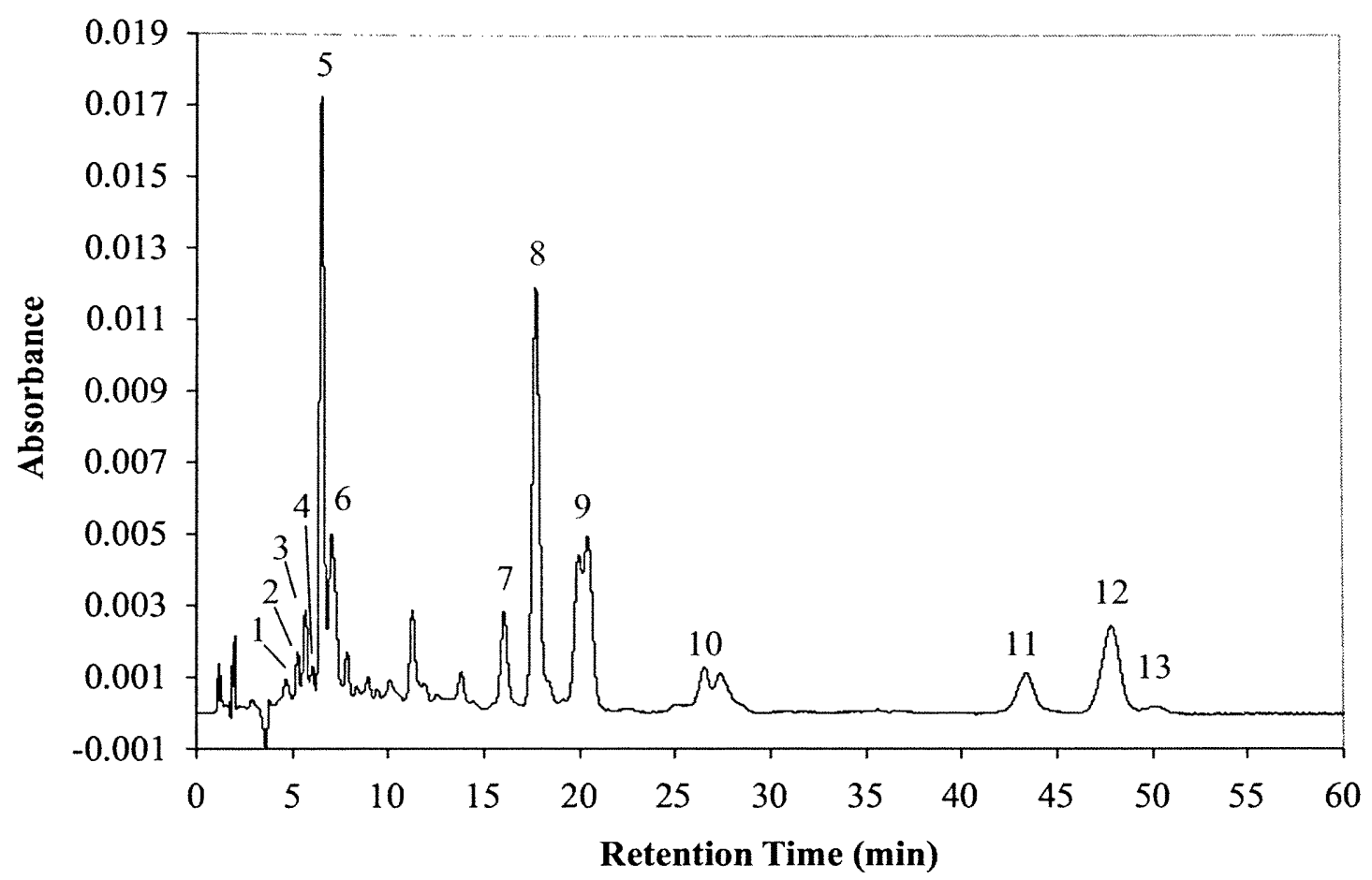

Figure 34. HPLC chromatogram of a typical serum response at baseline (Subject 5, high dose group). 1: lutein metabolite, 2: lutein metabolite, 3: lutein metabolite, 4: lutein metabolite, 5: lutein, 6: zeaxanthin, 7: $\alpha$-cryptoxanthin, 8: $\beta$-cryptoxanthin, 9: MPL (internal standard), 10: lycopene stereoisomers, 11: $\alpha$-carotene, 12: $\beta$-carotene, 13: cis- $\beta$ carotene

The concentration of each component was determined by comparing the area under each peak with the area of the internal standard monopentyl lutein ether (MPL), peak 9. MPL is composed of two overlapping peaks corresponding to the diastereomers 
of MPL, monopentyl (3R,3'R,6'R)-lutein ether and monopentyl (3R,3'S,6'R)-lutein ether produced during the synthesis reaction. The acid-catalyzed ether formation of MPL produces minor oxidation and dehydration products which were removed by HPLC (System I). The two broad peaks eluting between minutes 25.5 and 28 and labeled peak 10 in the chromatogram comprise the unresolved lycopene stereoisomers present in serum. The all-trans-lycopene and 9-, 13- and 15-cis-lycopene have been identified in serum. $[49,63]$

Table 4. Retention time (Rt) and retention factor $\left(\mathrm{k}^{\prime}\right)$ of carotenoids in human serum

\begin{tabular}{|clcc|}
\hline Peak no. & Compound & $\begin{array}{c}\text { Retention time } \\
(\mathrm{min})\end{array}$ & $\begin{array}{c}\text { Retention factor } \\
\left(\mathrm{k}^{\prime}\right)\end{array}$ \\
\hline 1 & Lutein metabolite 1 & 4.61 & 1.42 \\
2 & Lutein metabolite 2 & 5.21 & 1.74 \\
3 & Lutein metabolite 3 & 5.61 & 1.95 \\
4 & Lutein metabolite 4 & 5.98 & 2.14 \\
5 & Lutein & 6.43 & 2.38 \\
6 & Zeaxanthin & 6.95 & 2.65 \\
7 & $\alpha$-Cryptoxanthin & 15.98 & 7.39 \\
8 & $\beta$-Cryptoxanthin & 17.64 & 8.26 \\
9 & Mono-pentyl lutein ether (MPL) & $19.88,20.38$ & $9.44,9.70$ \\
10 & Lycopene isomers & $25.5-28.0$ & - \\
11 & $\alpha$-Carotene & 43.29 & 21.74 \\
12 & $\beta$-Carotene & 47.77 & 24.09 \\
13 & cis- $\beta$-Carotene & 50.21 & 25.37 \\
\hline
\end{tabular}

The retention factor of the serum carotenoids ranged in value from 1.42 to 25.37 . Retention factors measure the migration rate of the analyte on the column and are a good indication that the proper solvent composition was used. 
The identity of each component was confirmed by their UV-visible spectrum given in figure 35 for peak 1 and 2, figure 36 for peak 3 and 4 , figure 37 for peak 5 and 6 , figure 38 for peak 7 and 8 and figure 39 for peak 9 and 12; by their retention times and by comparison with standard solutions when they were available. The serum carotenoids described below refer to the all-trans carotenoids unless specified otherwise. The concentration of the components under peaks 10, 11 and 13 was too low to obtain defined UV-visible spectrum.
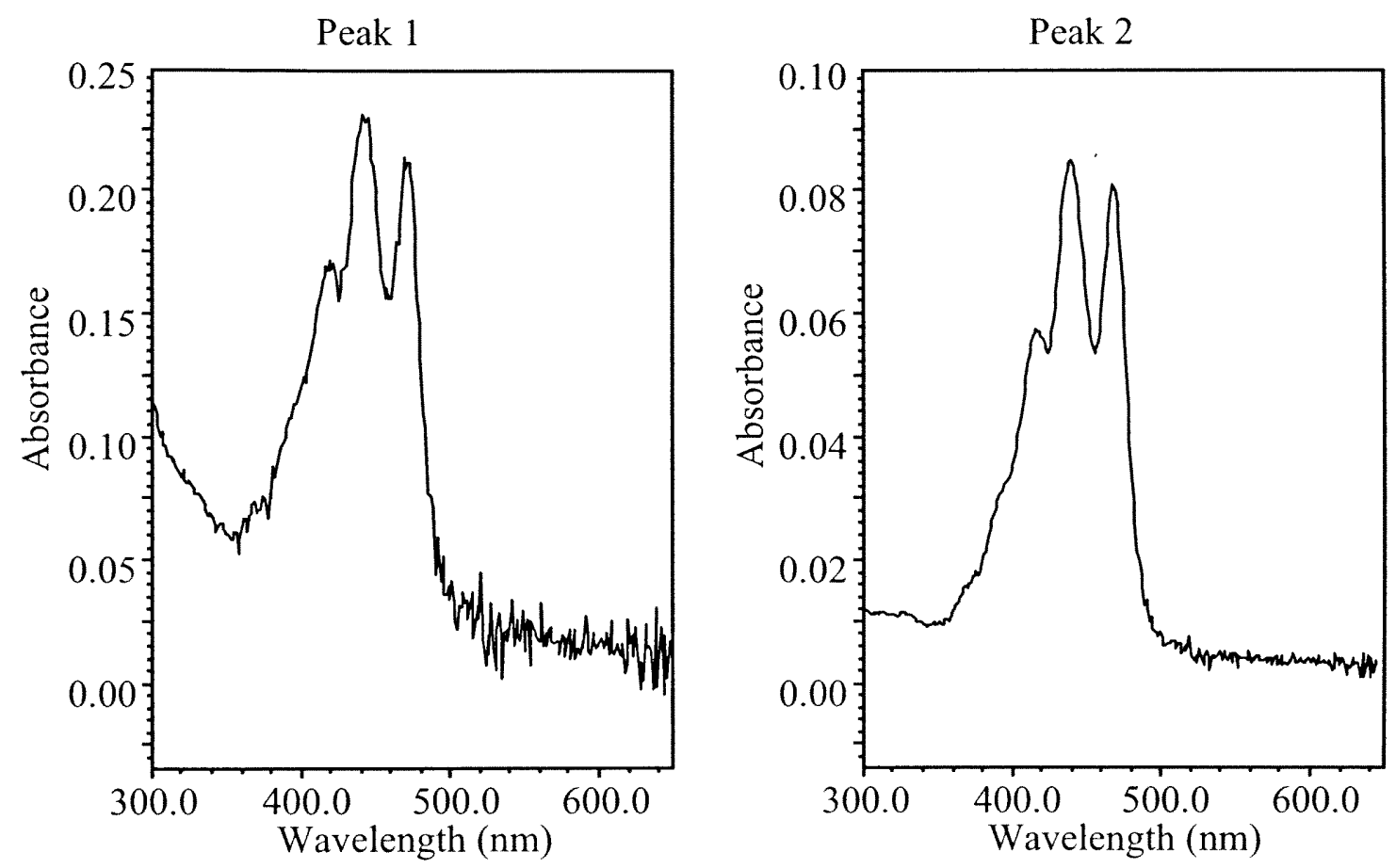

Figure 35. Ultraviolet-visible spectrum of peak 1 and 2

The UV-visible spectrum of peak 1 shows the maximum absorbance at $\lambda_{\max }=$ $441.5 \mathrm{~nm}$ (Band II) and a second maximum absorbance at $\lambda=471.6 \mathrm{~nm}$ (Band III). The 
$\% \mathrm{III} / \mathrm{II}$ of $73.2 \%$ is indicative of two $\varepsilon$-ionone rings or a $\beta$ - and an $\varepsilon$-ionone ring in the structure. The UV/visible spectrum of peak 2 shows the maximum absorbance at $\lambda_{\max }=$ $441.5 \mathrm{~nm}$ (Band II) and a second maximum absorbance at $\lambda=469.8 \mathrm{~nm}$ (Band III). The $\%$ III/II of $84.6 \%$ is indicative of two $\varepsilon$-ionone rings or a $\beta$ - and an $\varepsilon$-ionone ring in the structure. Rajendran et al tentatively identified peak 1 through 4 as cis-isomers of lutein based on their Q-ratios, the ratio of the cis-peak to the main absorption band in the UVvisible spectra. [64]

Peak 3

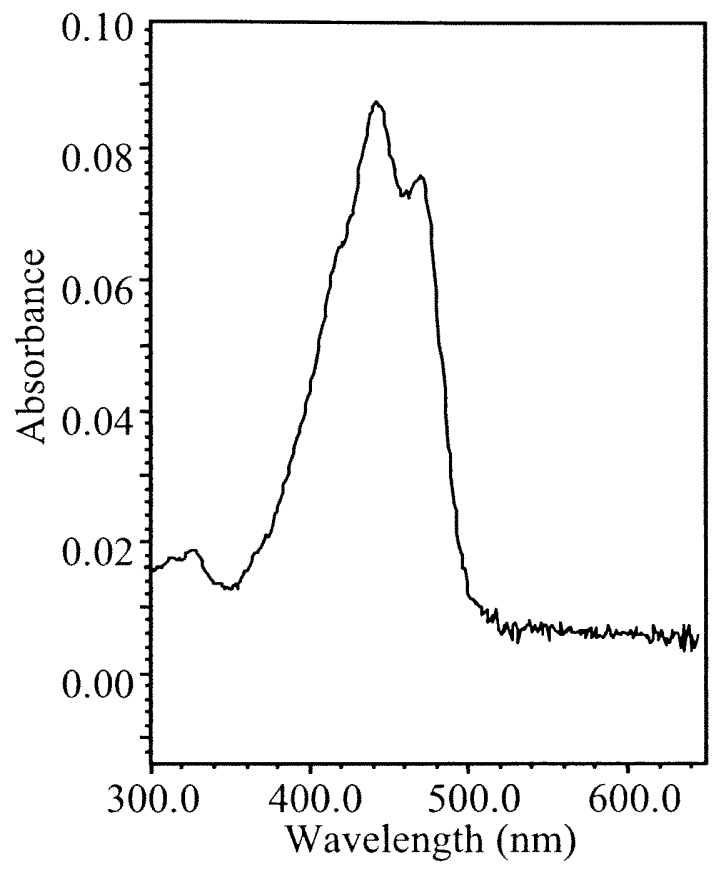

Peak 4

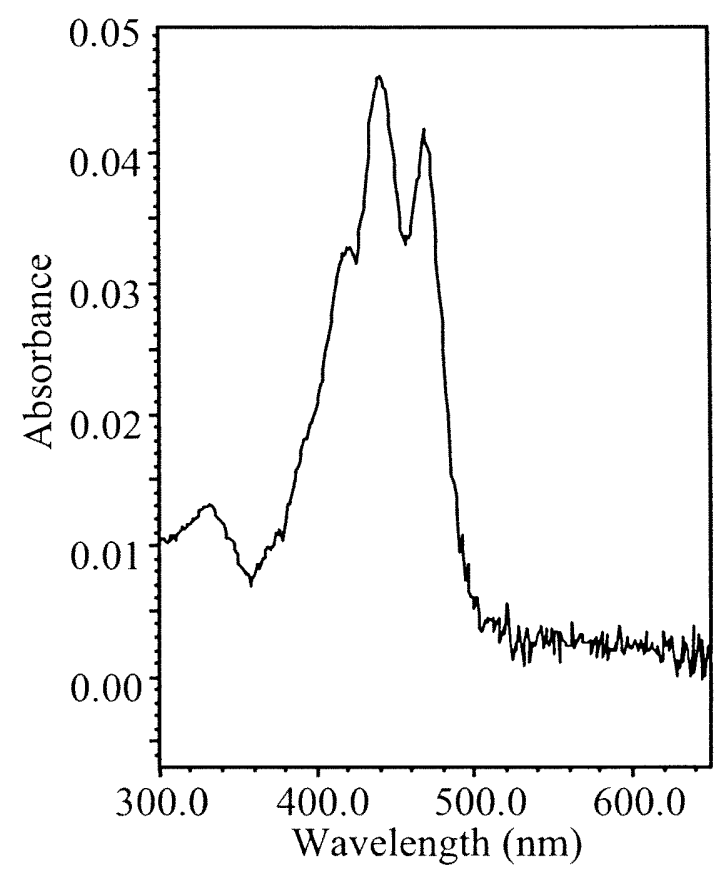

Figure 36. Ultraviolet-visible spectrum of peak 3 and 4

The UV-visible spectrum of peak 3 shows the maximum absorbance at $\lambda_{\max }=$ $445.1 \mathrm{~nm}$ (Band II) and a second maximum absorbance at $\lambda=473.4 \mathrm{~nm}$ (Band III). The 
$\% \mathrm{IIL} / \mathrm{II}$ of $15.7 \%$ is indicative of one $\varepsilon$-ionone and one $\beta$-ionone ring in the structure.

Peak 3 has been previously determined to be oxo-lutein (3-hydroxy- $\beta, \varepsilon$-carotene- $3^{\prime}$ one)... The UV/visible spectrum of peak 4 shows the maximum absorbance at $\lambda_{\max }=441.5$ $\mathrm{nm}$ (II) and a second maximum absorbance at $\lambda=469.8 \mathrm{~nm}$ (III). The $\%$ III/II of $65.9 \%$ is indicative of two $\varepsilon$-ionone rings or a $\beta$-and an $\varepsilon$-ionone ring in the structure.

Peak 5

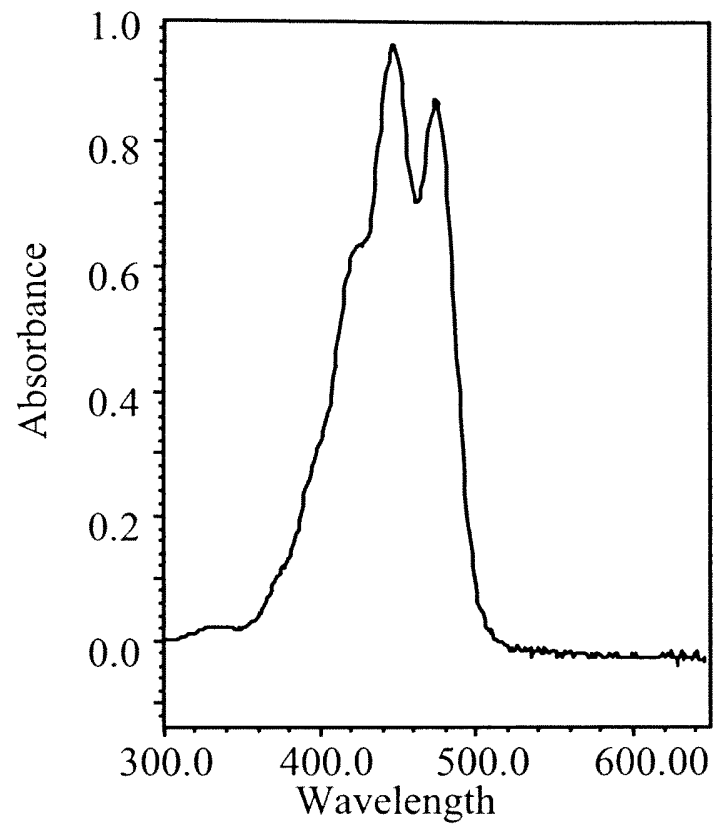

Peak 6

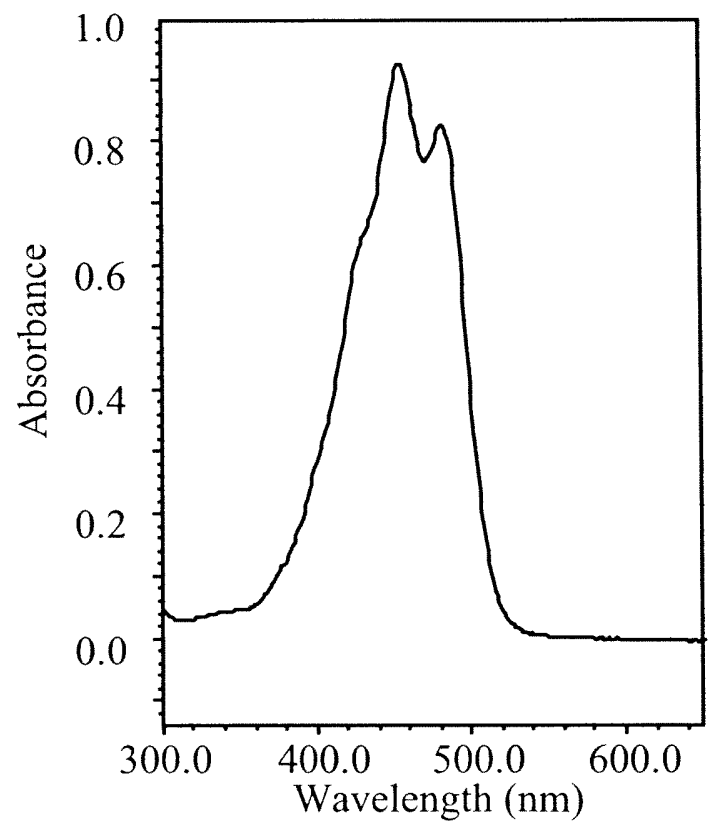

Figure 37. Ultraviolet-visible spectrum of peak 5 and 6

The UV-visible spectrum of peak 5 shows the maximum absorbance at $\lambda_{\max }$ of $447.3 \mathrm{~nm}$ (Band II) and a second maximum absorbance at $\lambda=475.6 \mathrm{~nm}$ (Band III). The $\% \mathrm{III} / \mathrm{II}$ of $56 \%$ and the retention time is consistent with that obtained for the lutein standard. The UV-visible spectrum of peak 6 shows the maximum absorbance at $\lambda_{\max }$ of 
$453.5 \mathrm{~nm}$ (Band II) and a second maximum absorbance at $\lambda=479.3 \mathrm{~nm}$ (Band III). The $\% \mathrm{III} / \mathrm{II}$ of $28 \%$ and the retention time is consistent with that obtain for the zeaxanthin standard. At higher serum lutein concentrations, obtained after 30 days of supplementation in both the low and high dose group, a peak consistent with cis-lutein was observed overlapping with the zeaxanthin peak.
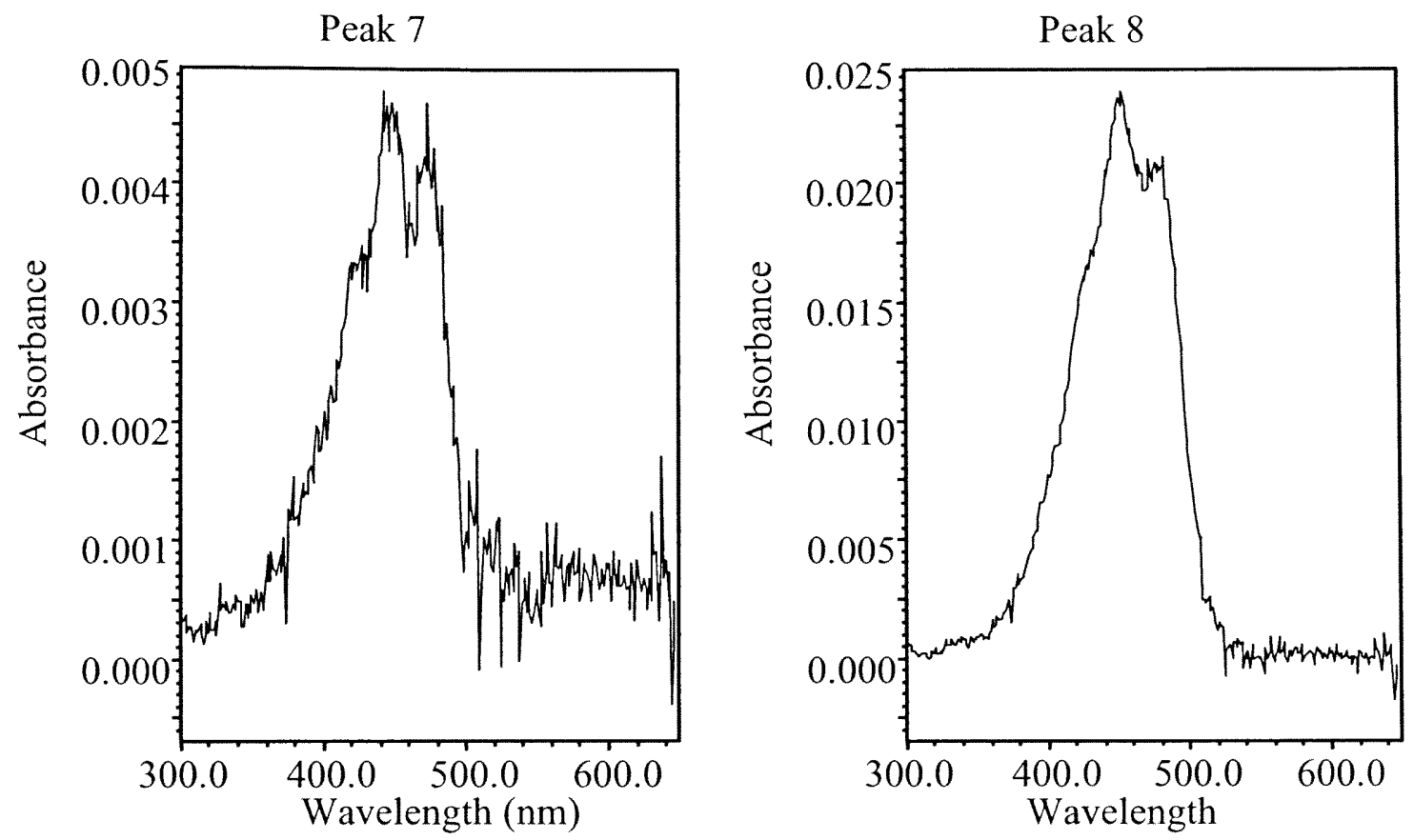

Figure 38. Ultraviolet-visible spectrum of peak 7 and 8

The UV-visible spectrum of peak 7 shows the maximum absorbance at $\lambda_{\max }=446.1 \mathrm{~nm}$ (Band II) and a second maximum absorbance at $\lambda=474.8 \mathrm{~nm}$ (Band III). The $\% \mathrm{III} / \mathrm{II}$ of $67 \%$ is consistent with the presence of a $\beta$-ring and an $\varepsilon$-ring and the retention time is consistent with that expected for $\alpha$-cryptoxanthin. The UV-visible spectrum of peak 8 shows the maximum absorbance at $\lambda_{\max }=449.8 \mathrm{~nm}$ (Band II) and a 
second maximum absorbance at $\lambda=477.2 \mathrm{~nm}$ (Band III). The $\% \mathrm{III} / \mathrm{II}$ of $21 \%$ is consistent with that of two $\beta$-rings and the retention time is consistent with that expected for $\beta$ cryptoxanthin.
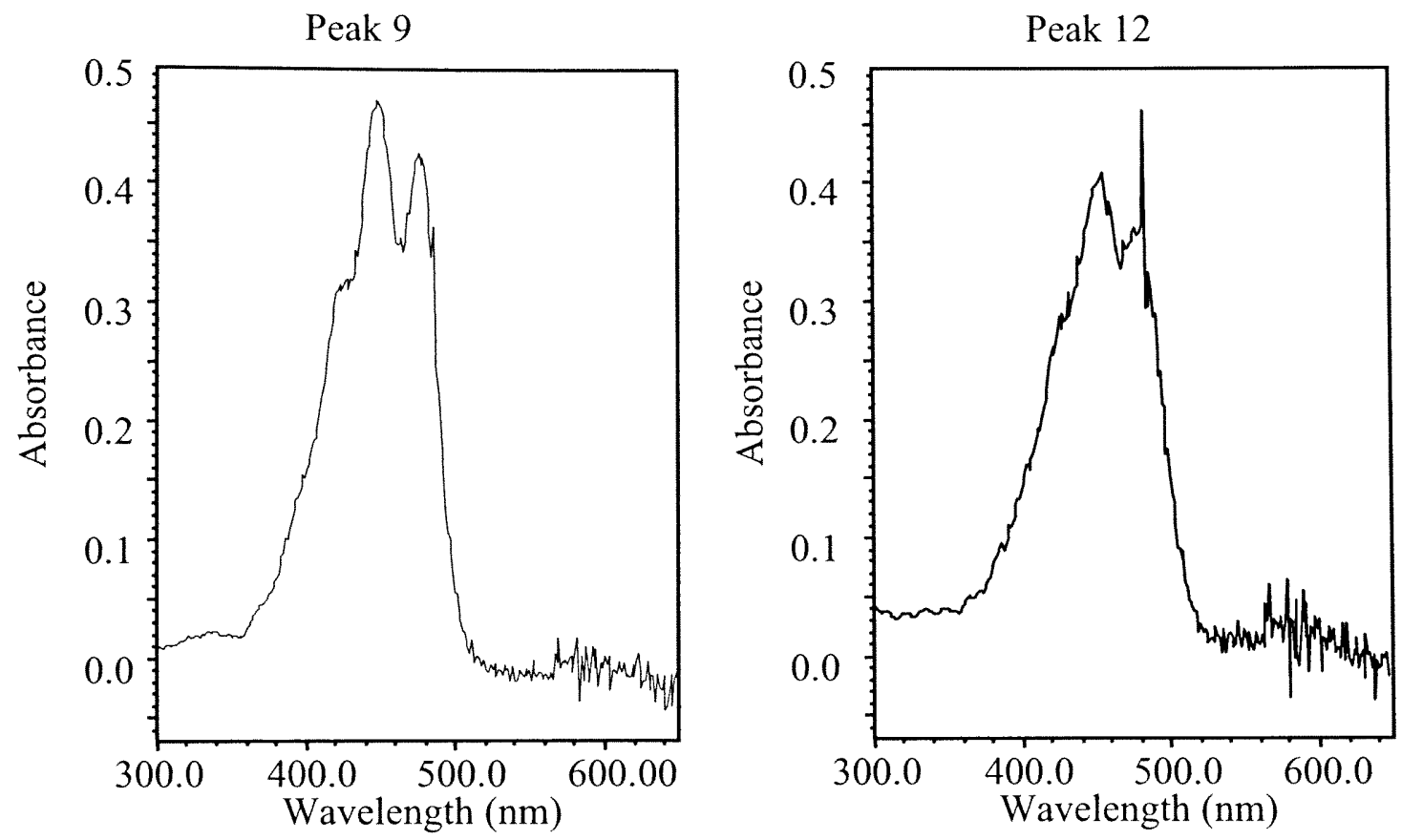

Figure 39. Ultraviolet-visible spectrum of peak 9 and 12

The UV-visible spectrum of MPL is identical to that of lutein, figure 37.

Derivatization at $\mathrm{C}^{\prime}$ ' does not affect conjugation at the polyene chain, thus it does not affect the UV-visible spectrum. Peak 9 shows a maximum absorbance at $\lambda_{\max }=447.5 \mathrm{~nm}$ (Band II), a second maximum absorbance at $\lambda=475.9 \mathrm{~nm}$ (Band III) and a $\%$ III/II of $61 \%$. Peak 12 shows a maximum absorbance at $\lambda_{\max }=450.8 \mathrm{~nm}$ (Band II) and a second maximum absorbance at $\lambda=478.2 \mathrm{~nm}$ (Band III). The $\% \mathrm{III} / \mathrm{II}$ of $61 \%$ indicates the 
presence of two $\beta$-rings and the retention time is consistent with that obtained for the $\beta$ carotene standard.

\section{Supplementation response}

The HPLC chromatogram of a serum sample in the high dose group after supplementation is shown in figure 40 .

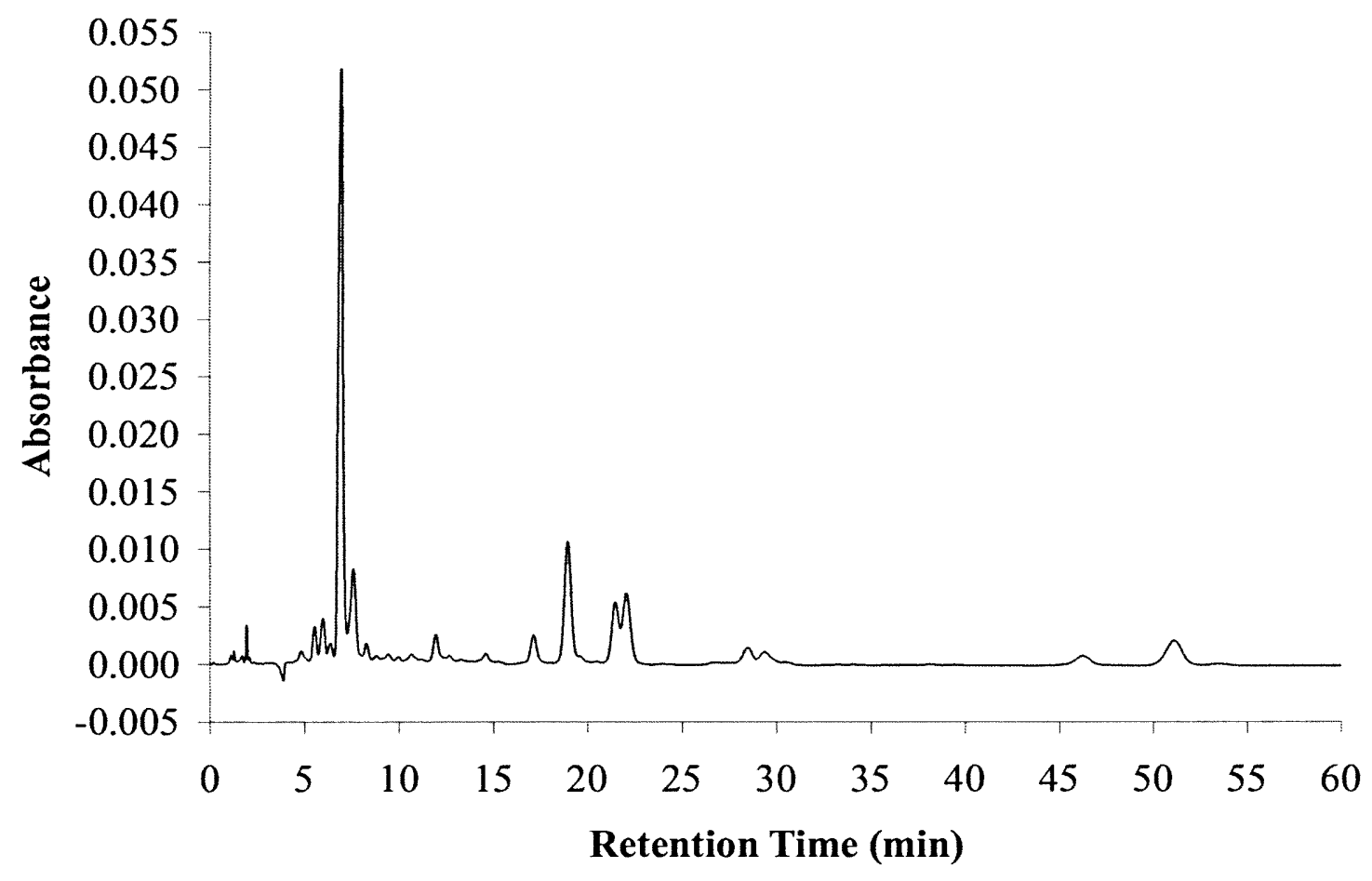

Figure 40. HPLC chromatogram of a typical serum response in the high dose group after supplementation (Subject 5)

A marked increase in the serum concentration of lutein was observed after supplementation in both the low dose and the high dose groups, figure 41 . The increase reached a plateau concentration after day 15 , with a mean concentration of $34.28 \pm 17.96$ 
and $71.41 \pm 35.98 \mathrm{nmol} / \mathrm{dL}$ for the low dose and high dose group, respectively. The error bars indicate the variability within the groups. The serum lutein concentration of the low dose and high dose groups was significantly different from the placebo group $(\mathrm{p}<0.05)$ at every supplemented serum collection (day 15 to day 60 ). The serum lutein concentration was significantly different for the low and high dose supplementation group at day 15,30 and 45. At day 60 , the serum lutein concentration of the high dose was higher that the serum lutein concentration for the low dose group but it did not reach statistical significance at $p<0.05$. The decrease in serum concentration for the high dose at day 60 was attributed to decreasing compliance among the subjects as the study progressed.

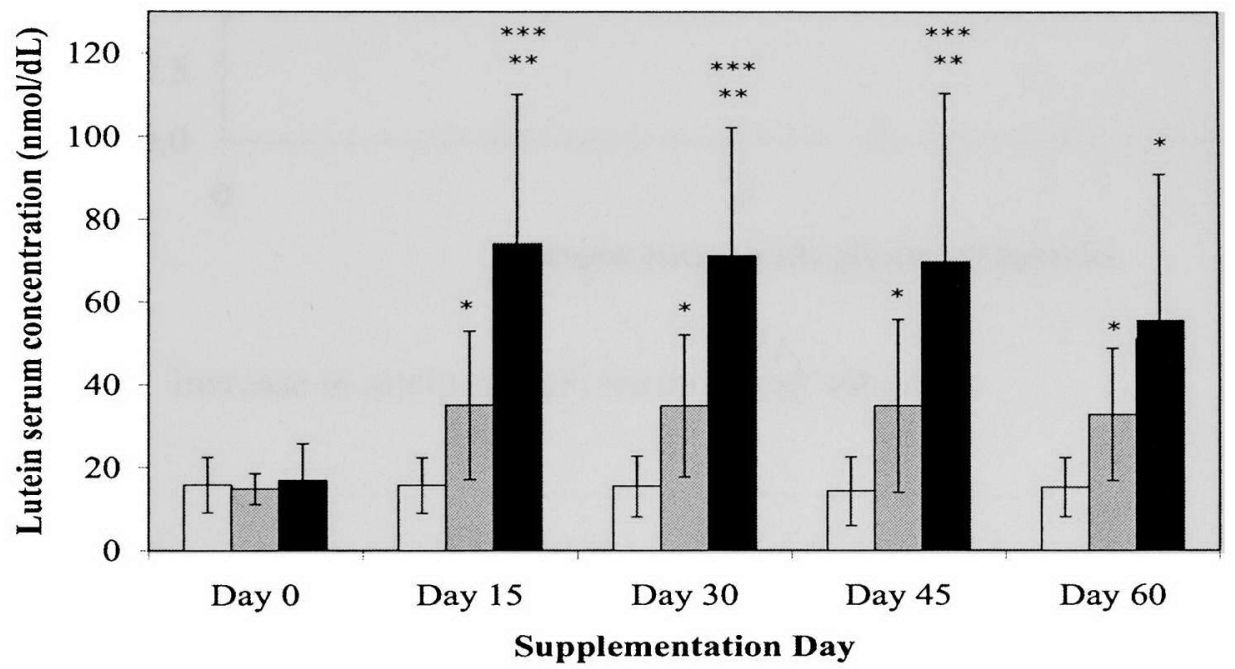

Figure 41. Mean $( \pm \mathrm{SD})$ serum lutein concentration for each group: placebo in white, low dose in gray and high dose in black

* Significant difference when compared to baseline concentration $(p<0.05),{ }^{* *} p<0.002$ $* * *$ Significant difference when compared to low dose concentration $(\mathrm{p}<0.05)$ 
The increase in concentration of lutein was proportional to the dose supplemented, figure 42 . In the low dose group an approximately 2 -fold increase was observed while in the high dose group an approximately 4-fold increase was observed.

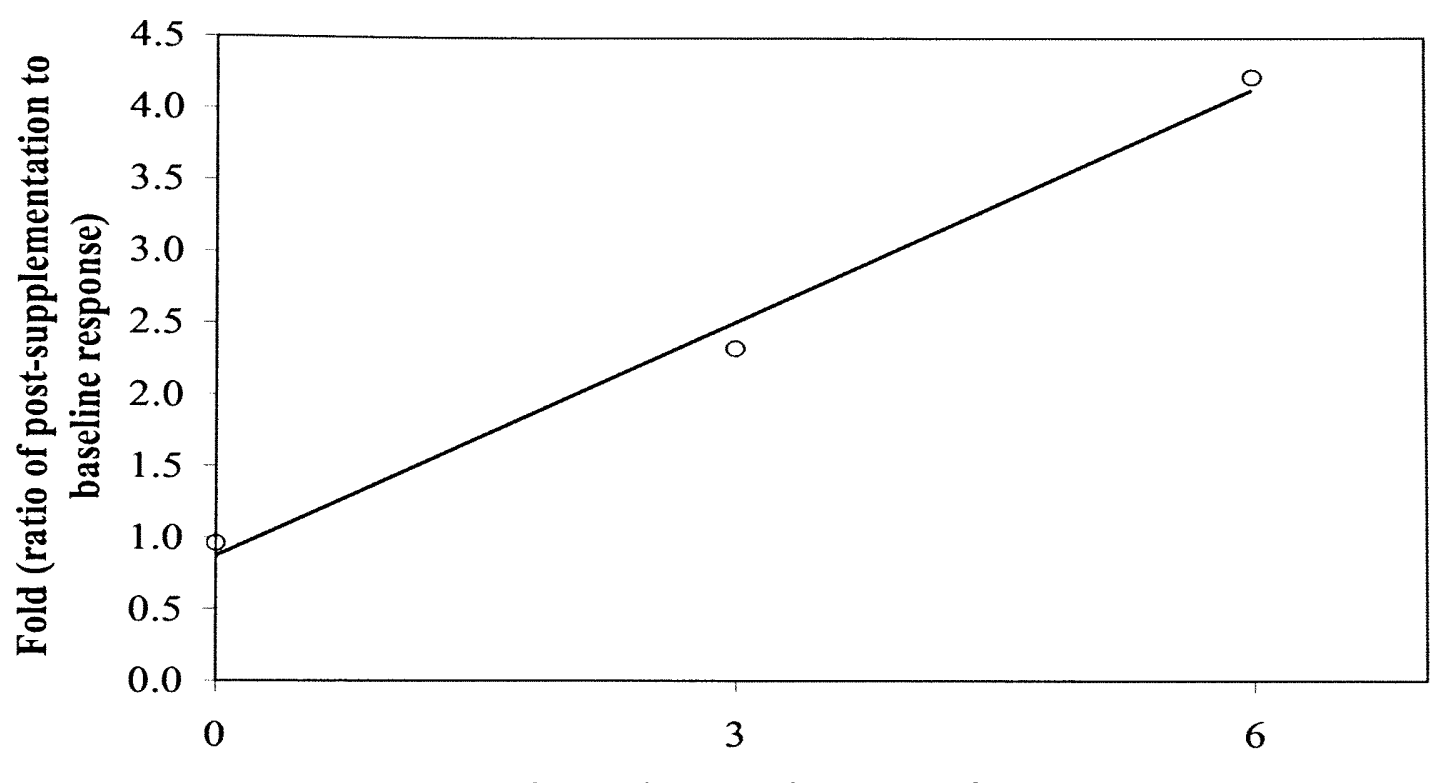

Dose (mg equivalents of lutein)

Figure 42. Increase in lutein serum concentration with dose

Pearson's correlations after adjusting for the different supplementation doses revealed a correlation between the final serum lutein concentration and the baseline concentrations of triglycerides, figure 43 , HDL, figure 44, VLDL, figure 45 and Creactive protein, figure 46 for the males at $\mathrm{p}<0.05$. No correlation was observed for the females or when all subjects were combined. Among the females, a greater variability was observed in the serum parameters and in the serum carotenoid concentration. No correlation was observed with other serum carotenoids. 


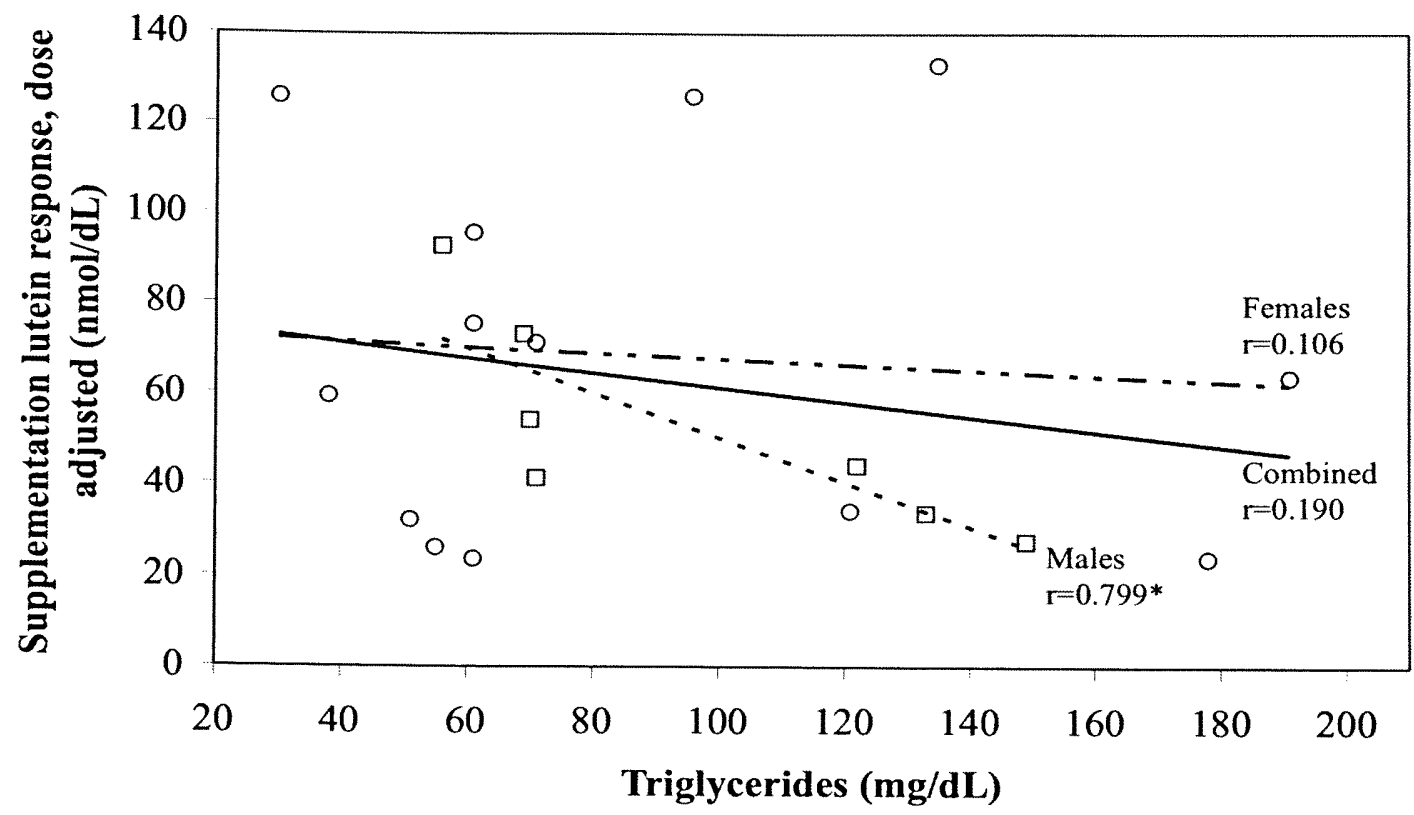

Figure 43. Correlation between post-supplementation serum lutein concentration and baseline triglycerides concentration for females $r=0.106(O)$, males $r=0.799 *(\square)$ and combined $\mathrm{r}=0.190$

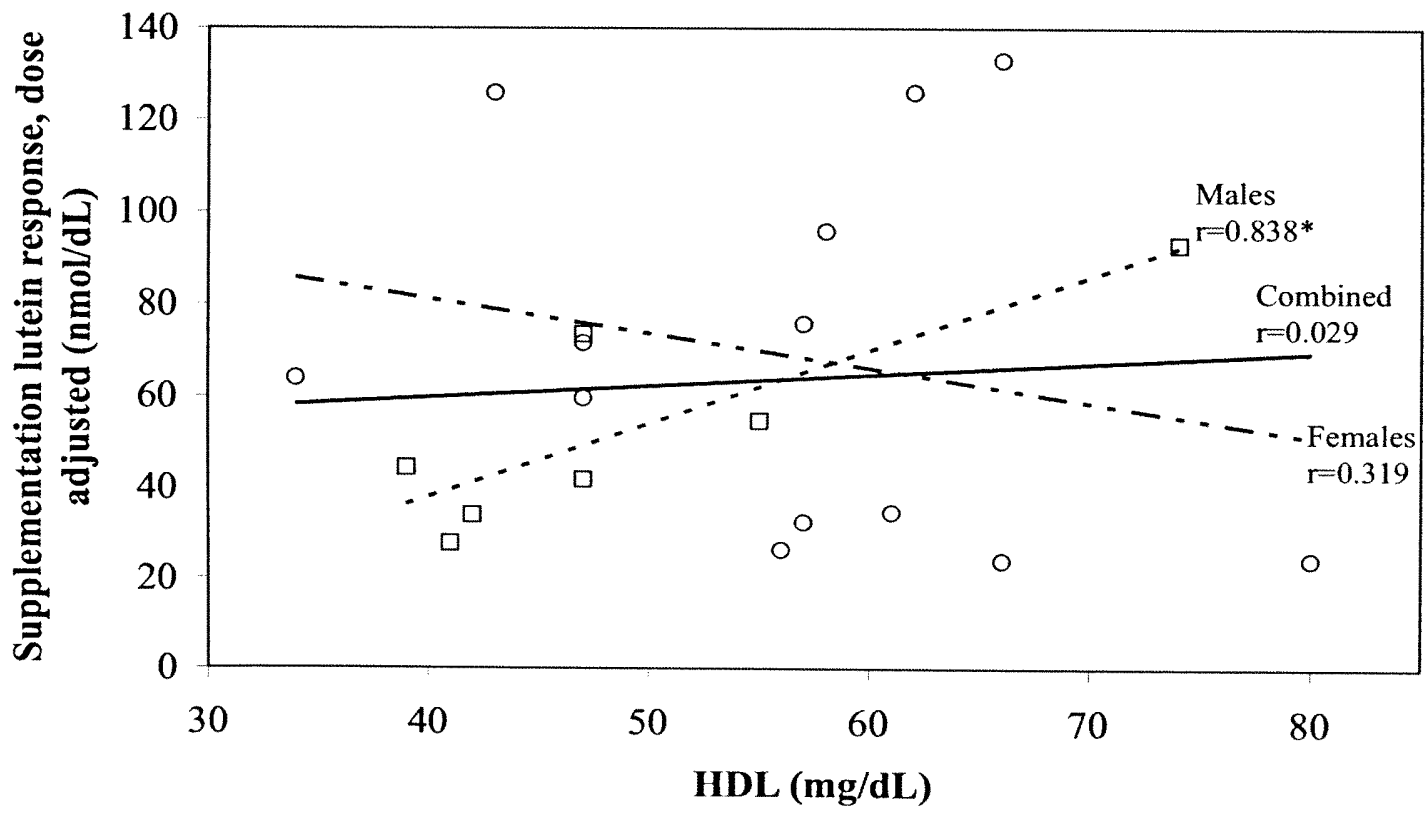

Figure 44. Correlation between post-supplementation serum lutein concentration and baseline HDL concentration for females $r=0.319(O)$, males $r=0.838^{*}(\square)$ and combined $\mathrm{r}=0.029$ 


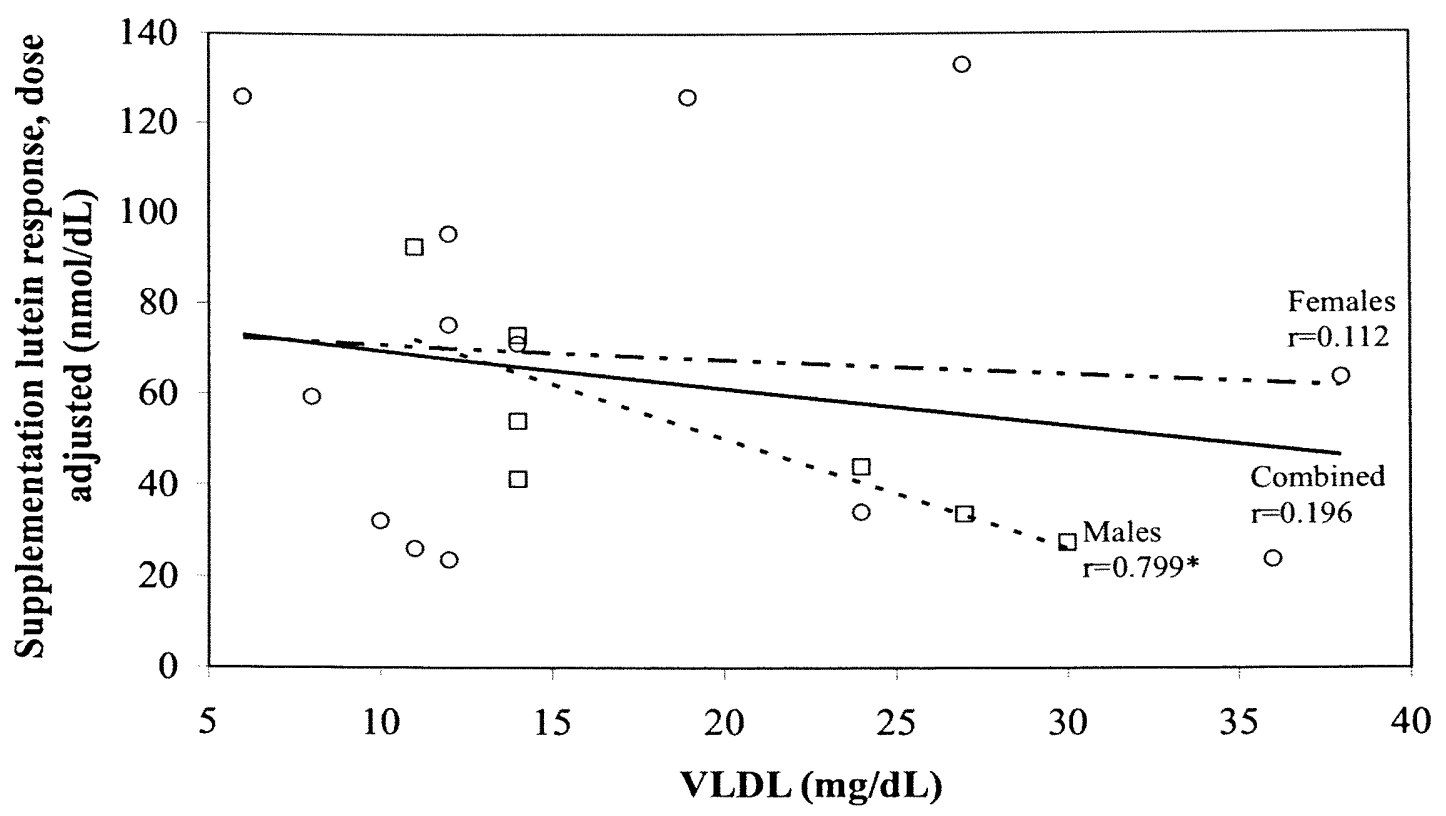

Figure 45. Correlation between post-supplementation serum lutein concentration and baseline VLDL concentration for females $r=0.112(O)$, males $r=0.799^{*}(\square)$ and combined $\mathrm{r}=0.196$

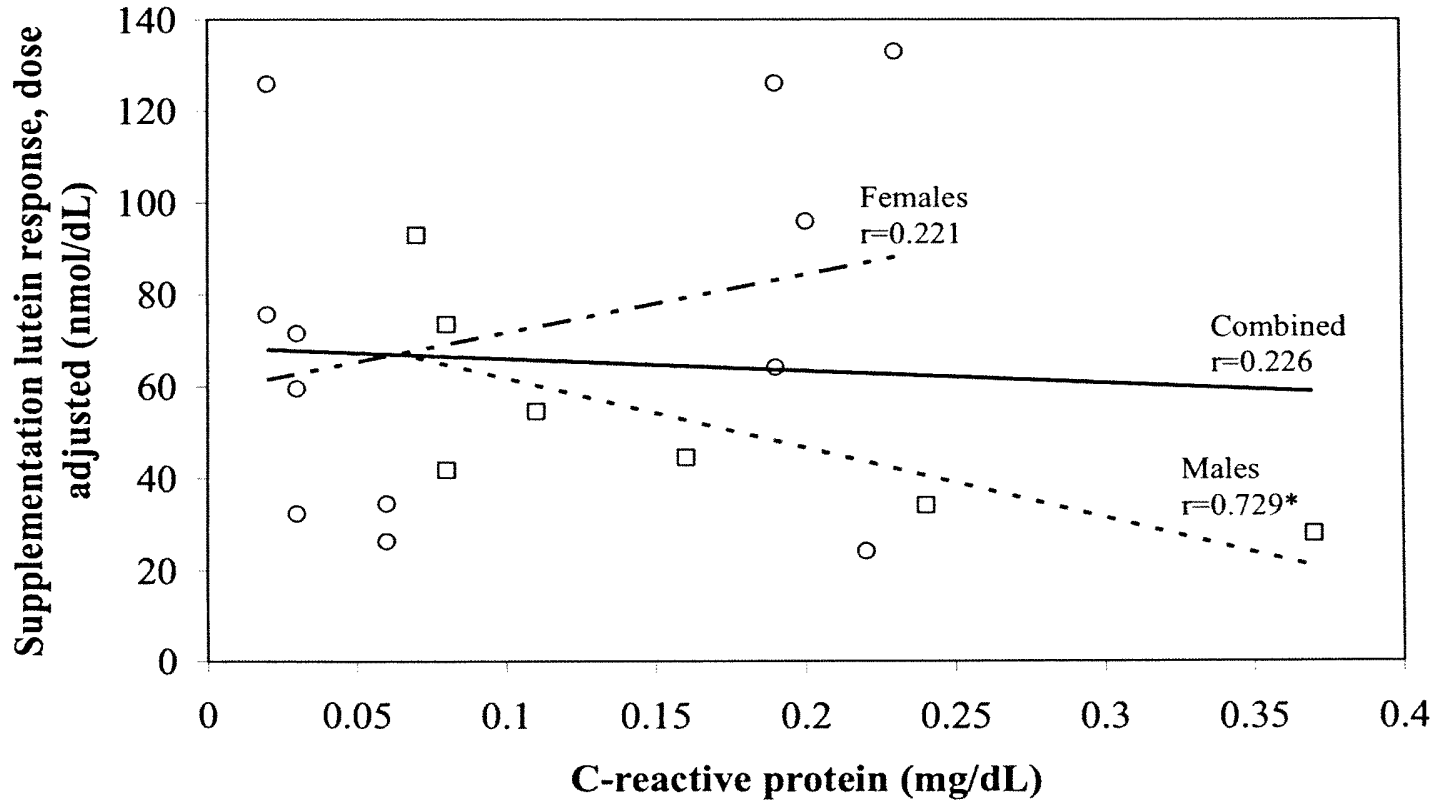

Figure 46. Correlation between post-supplementation serum lutein concentration and baseline $C$-reactive protein concentration for females $p=0.221(O)$, males $p=0.729^{*}(\square)$ and combined $\mathrm{p}=0.226$ 
The Pearson's product momentum correlation coefficients are given next to the linear trend lines and they indicate that the baseline serum concentration of triglycerides, HDL, VLDL and C-reactive protein are correlated with the supplementation response.

Male subjects with higher triglycerides, VLDL and C-reactive protein were lower responders while subjects with lower HDL were lower responders.

The serum concentration of zeaxanthin also increased proportional to dose, figure 47. The baseline serum concentration of all supplementation groups did not differ significantly. A decrease in zeaxanthin serum concentration was observed at day 45 for all groups, this was attributed to overlap with lutein cis peaks at increasing lutein concentrations. Asterisks indicate significant difference at $\mathrm{p}=0.05$ and/or $\mathrm{p}=0.01$.

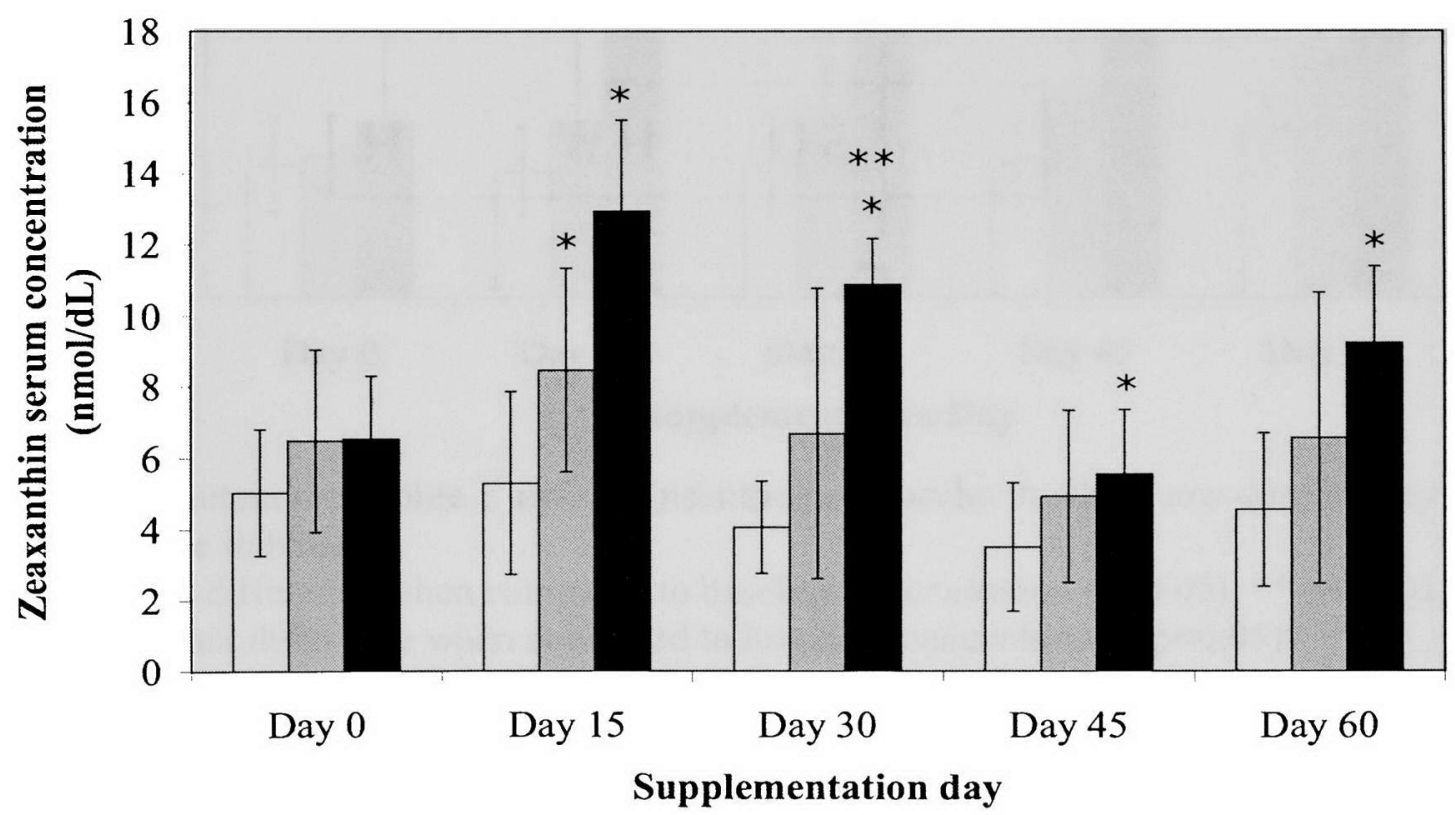

Figure 47. Mean $( \pm \mathrm{SD})$ serum zeaxanthin concentration for each group: placebo in white, low dose in gray and high dose in black

* Significant difference when compared to baseline concentration $(p<0.05)$, ** Significant difference when compared to low dose concentration $(\mathrm{p}<0.05)$ 
The serum concentration of zeaxanthin increased from an average baseline of 6.03 $\pm 2.80 \mathrm{nmol} / \mathrm{dL}$ to $8.03 \pm 2.70$ and $12.23 \pm 5.85 \mathrm{nmol} / \mathrm{dL}$ for the low and high supplementation groups, respectively. The serum concentration of four lutein metabolites also increased proportional to dose labeled lutein metabolite 1 through 4 , figures 48 to 51 . The serum concentration of the lutein metabolites for all groups did not differ significantly at baseline.

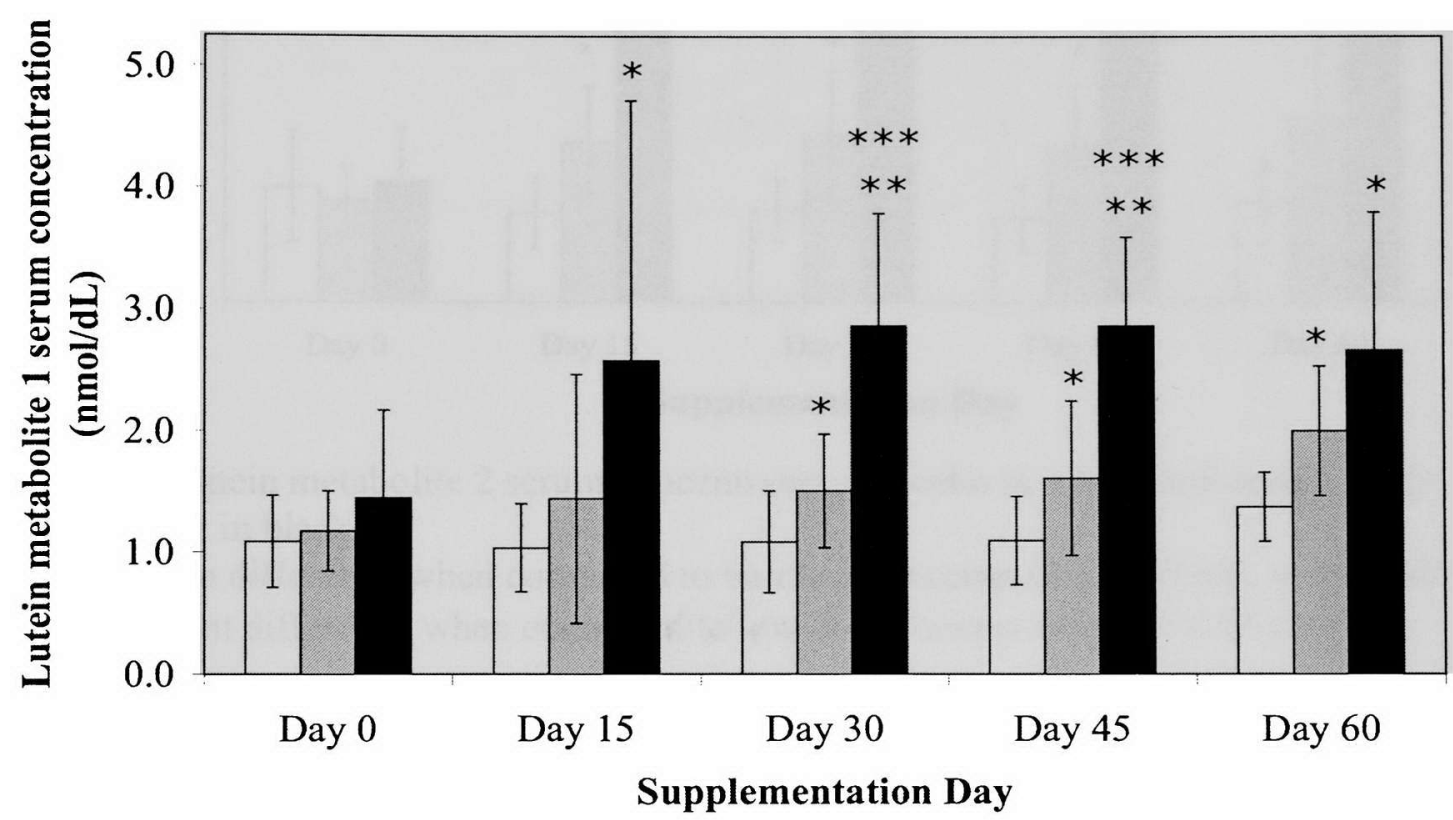

Figure 48. Lutein metabolite 1 serum concentration: placebo in white, low dose in gray and high dose in black

* Significant difference when compared to baseline concentration $(\mathrm{p}<0.05),{ }^{* *} \mathrm{p}<0.001$, $* * *$ Significant difference when compared to low dose concentration $(\mathrm{p}<0.05)$

The serum concentration of lutein metabolite 1 increased from an average baseline of $1.24 \pm 0.48 \mathrm{nmol} / \mathrm{dL}$ to $1.64 \pm 0.67$ and $2.74 \pm 1.24 \mathrm{nmol} / \mathrm{dL}$ for the low and high supplementation groups, respectively. The increase in the concentration of lutein 
metabolite 1 occurred at a lower rate for the low dose supplementation group than for the high dose supplementation group and it was only dose dependant at day 60 .

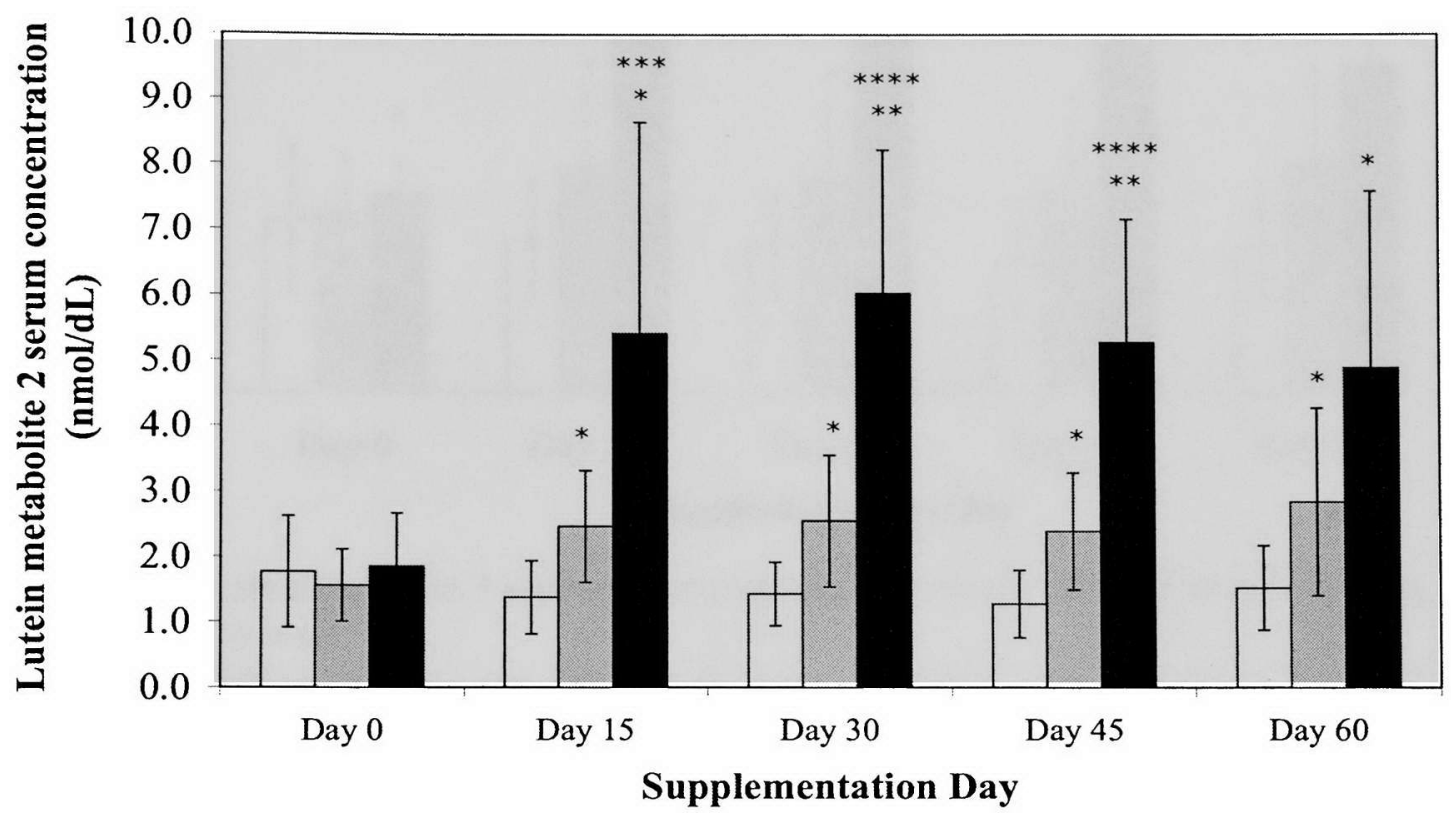

Figure 49. Lutein metabolite 2 serum concentration: placebo in white, low dose in gray and high dose in black

* Significance difference when compared to baseline concentration $(\mathrm{p}<0.05), * * \mathrm{p}<0.001$, $* * *$ Significant difference when compared to low dose concentration $(\mathrm{p}<0.05), * * * * \mathrm{p}$ $<0.001$

The serum concentration of lutein metabolite 2 increased from an average baseline of $1.72 \pm 0.74 \mathrm{nmol} / \mathrm{dL}$ to $2.56 \pm 1.05$ and $5.41 \pm 2.51 \mathrm{nmol} / \mathrm{dL}$ for the low and high supplementation groups, respectively. The serum concentration of lutein metabolite 3 increased from an average baseline of $2.87 \pm 1.04 .74 \mathrm{nmol} / \mathrm{dL}$ to $3.43 \pm 1.27$ and $5.36 \pm$ $2.25 \mathrm{nmol} / \mathrm{dL}$ and of lutein metabolite 4 from an average baseline of $1.39 \pm 0.67 \mathrm{nmol} / \mathrm{dL}$ to $1.84 \pm 1.11$ and $2.10 \pm 1.15 \mathrm{nmol} / \mathrm{dL}$ for the low and high supplementation groups, respectively. 


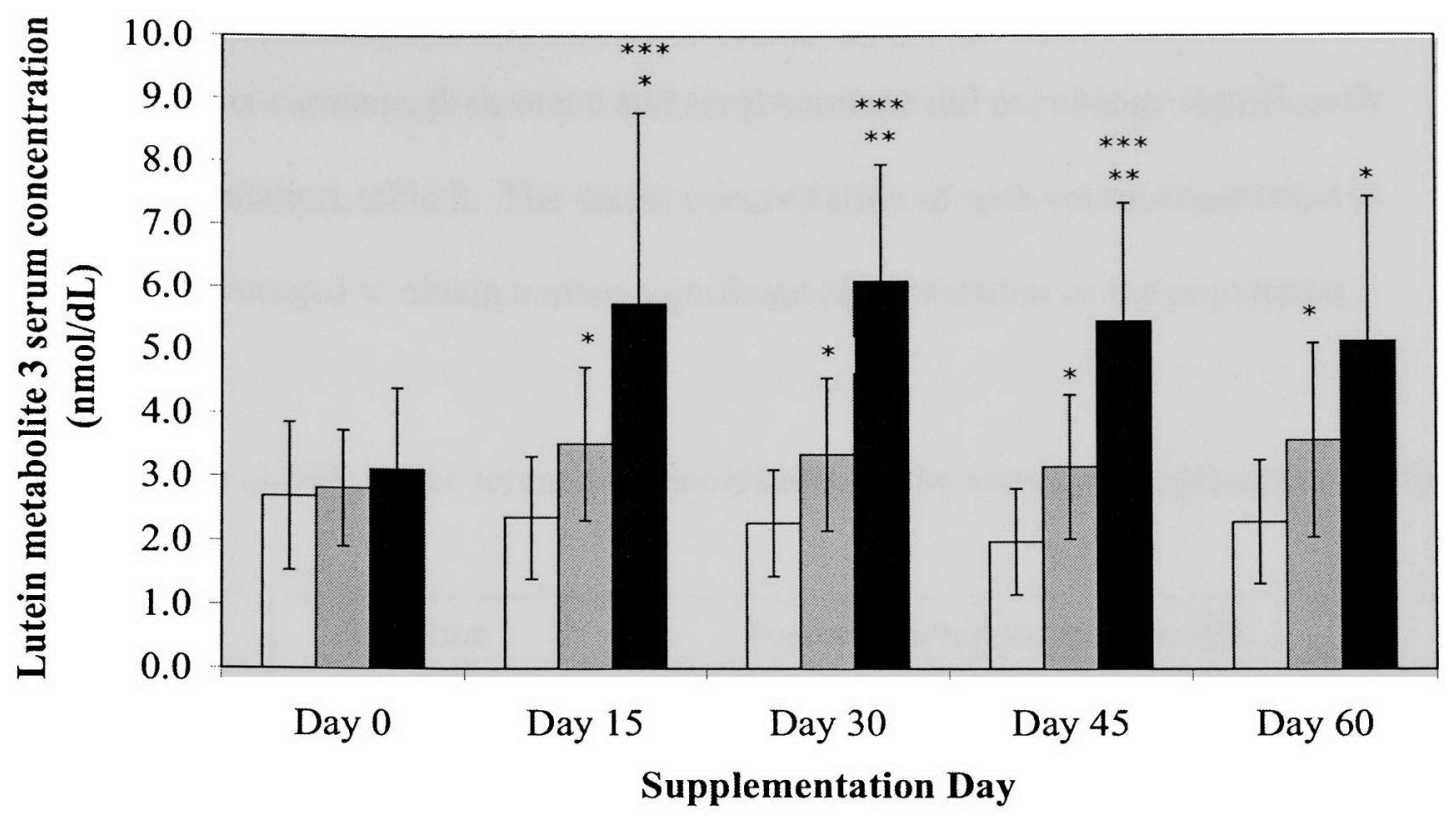

Figure 50. Lutein metabolite 3 serum concentration: placebo in white, low dose in gray and high dose in black

* Significant difference when compared to baseline concentration $(\mathrm{p}<0.05), * * \mathrm{p}<0.001$, $* * *$ Significant difference when compared to low dose concentration $(\mathrm{p}<0.05)$

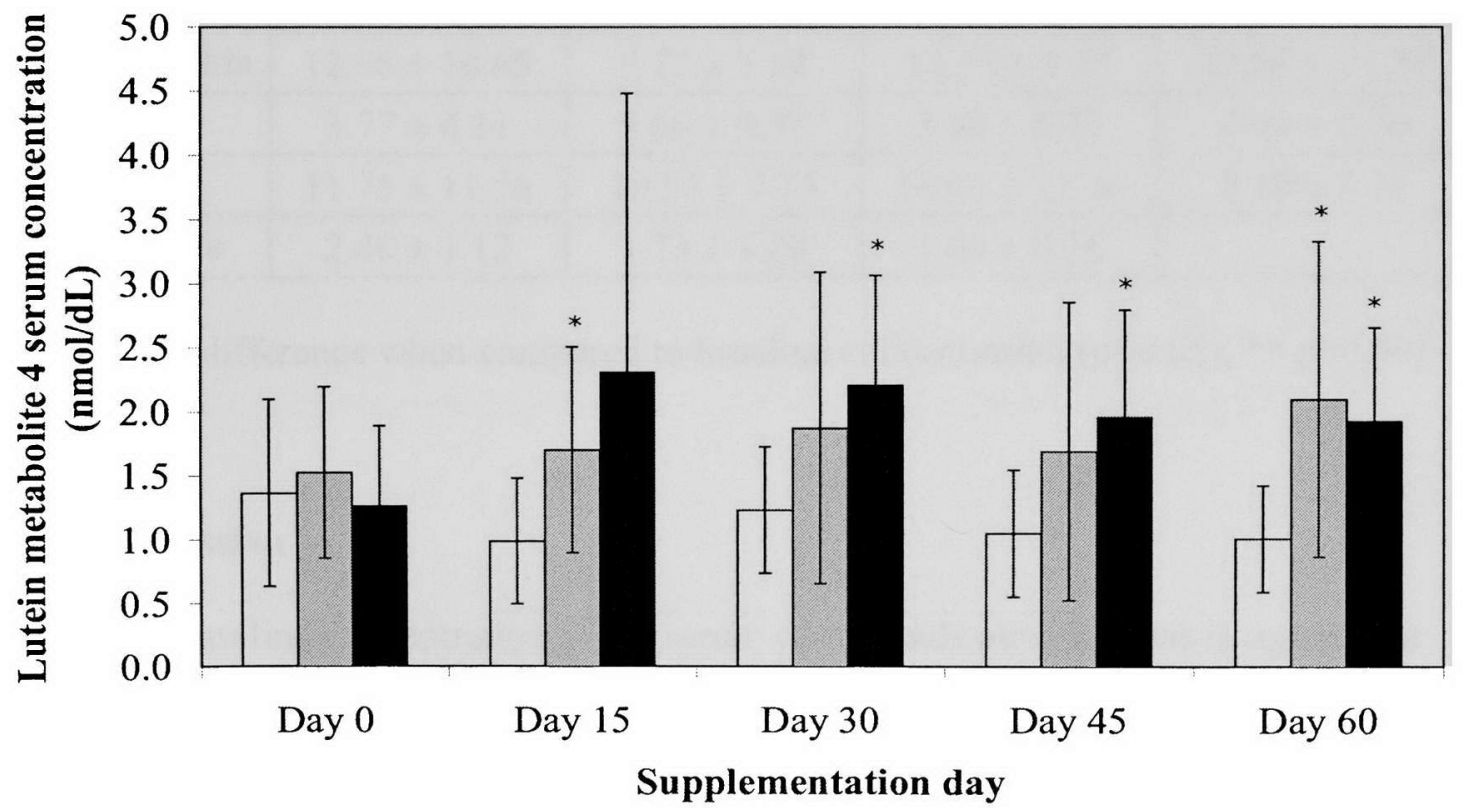

Figure 51. Lutein metabolite 4 serum concentration: placebo in white, low dose in gray and high dose in black

* Significant difference when compared to baseline concentration $(p<0.05)$ 
The serum concentration of other serum carotenoids, $\alpha$-cryptoxanthin, $\beta$ cryptoxanthin, $\alpha$-carotene, $\beta$-carotene and cis- $\beta$-carotene did not change significantly after supplementation, table 5. The serum concentration of each serum component at baseline was averaged to obtain a more significant representation of the population.

Table 5. Mean $( \pm \mathrm{SD})$ major serum carotenoids at baseline and post-supplementation for each group

\begin{tabular}{|l|c|c|c|c|}
\hline & \multirow{2}{*}{$\begin{array}{c}\text { Baseline } \\
(\mathrm{nmol} / \mathrm{dL})\end{array}$} & \multicolumn{3}{|c|}{ Post-supplementation (nmol/dL) } \\
\cline { 3 - 5 } & $1.24 \pm 0.48$ & $1.14 \pm 0.36$ & $1.64 \pm 0.67^{*}$ & $2.74 \pm 1.24^{* *}$ \\
\hline metabolite 1 & Placebo & Low Dose & High Dose \\
\hline metabolite 2 & $1.72 \pm 0.74$ & $1.40 \pm 0.55$ & $2.56 \pm 1.05^{*}$ & $5.41 \pm 2.51^{* *}$ \\
\hline metabolite 3 & $2.87 \pm 1.04$ & $2.34 \pm 0.96$ & $3.43 \pm 1.27^{*}$ & $5.36 \pm 2.25^{*}$ \\
\hline metabolite 4 & $1.39 \pm 0.67$ & $1.13 \pm 0.53$ & $1.84 \pm 1.11^{*}$ & $2.10 \pm 1.15^{*}$ \\
\hline lutein & $15.79 \pm 6.43$ & $15.11 \pm 7.35$ & $34.28 \pm 17.96^{*}$ & $71.41 \pm 35.98^{* *}$ \\
\hline zeaxanthin & $6.03 \pm 2.80$ & $5.03 \pm 1.77$ & $8.03 \pm 2.70^{*}$ & $12.23 \pm 5.85^{*}$ \\
\hline$\alpha$-cryptoxanthin & $3.13 \pm 1.88$ & $2.14 \pm 1.22$ & $3.08 \pm 1.65$ & $2.68 \pm 1.45$ \\
\hline$\beta$-cryptoxanthin & $12.46 \pm 10.65$ & $9.22 \pm 7.14$ & $12.77 \pm 9.23$ & $12.68 \pm 14.35$ \\
\hline$\alpha$-carotene & $3.77 \pm 4.11$ & $5.66 \pm 9.37$ & $3.98 \pm 2.73$ & $4.45 \pm 6.20$ \\
\hline$\beta$-carotene & $11.75 \pm 11.56$ & $10.97 \pm 7.75$ & $16.06 \pm 11.26$ & $8.10 \pm 5.25$ \\
\hline cis- $\beta$-carotene & $2.40 \pm 1.12$ & $1.73 \pm 1.20$ & $1.64 \pm 0.26$ & - \\
\hline
\end{tabular}

* Significant difference when compared to baseline concentration $(\mathrm{p}<0.05),{ }^{* *} \mathrm{p}<0.001$

\subsection{Discussion}

The baseline concentration of the serum carotenoids obtained was in agreement with previously reported values. [60-62, 64-66] In males, the baseline levels of lutein were correlated with the baseline levels of cholesterol, HDL and LDL. These trends did not reach statistical significance in the females or the group as whole and this is probably 
a consequence of the relatively small study size and the sensitivity of a small study to variability in the group. Further investigation of the lutein cholesterol relationship is needed but we would note that the general carriers of carotenoids in serum are the lipoproteins and it has been reported that the proportion of lutein carried by HDL is greater than LDL. The cause of a slightly higher correlation with total cholesterol is likely the result of the subtleties of how these values are derived from the analytical methodology.

Lutein supplementation in our study groups demonstrates a clear relationship between serum response and dosage of the lutein supplement. Males and females were present in all three dosage groups of this study and we have observed significant and comparable responses to supplementation for both males and females. Both the 3 and 6 $\mathrm{mg}$ (equivalent of free lutein) doses produced significant serum responses at $\mathrm{p}<0.005$ by day 15 of supplementation. The $3 \mathrm{mg}$ dose resulted in a $>2$ fold increase upon supplementation and $6 \mathrm{mg}$ dose produced $\mathrm{a}>4$ fold increase in serum lutein level. The serum response remains elevated for subjects at both doses throughout the supplementation trial although there is a small decrease in serum level clearly visible and we attribute this to decreasing compliance of study subjects as the study progressed.

Zeaxanthin is a minor component of the supplement $(\sim 7 \%)$ and an increase in the serum levels of the study participants was observed for both doses. The $3 \mathrm{mg}$ dose (lutein equivalent) would provide approximately $0.21 \mathrm{mg}$ of zeaxanthin and results in a serum response of 1.3 fold over baseline. The $6 \mathrm{mg}$ dose (lutein equivalent) would provide approximately $0.42 \mathrm{mg}$ of zeaxanthin and results in a 1.9 fold increase in serum zeaxanthin over baseline. These increases are statistically significant on day 15 of 
supplementation with $\mathrm{p}$ values $<0.05$. There is some variability in the serum level of zeaxanthin during the supplementation period with the results at day 30 and 45 being below statistical significance for the $3 \mathrm{mg}$ (free lutein equivalent) dose and also on day 45 for the $6 \mathrm{mg}$ (free lutein equivalent) although there is a clear increase in the average serum zeaxanthin concentration on all dates.

The serum response of lutein is $0.72 \mathrm{nmol} / \mathrm{dL} \mathrm{mg}$ equivalent free lutein. The response for zeaxanthin ranged between 4.8 and $6.5 \mathrm{nmol} / \mathrm{dL} \mathrm{mg}$ equivalent of free zeaxanthin when determined on the day 15 data. Lower response rates would be calculated from data obtained on subsequent measurements. It would appear that the zeaxanthin serum response to supplementation is significantly higher than that of lutein but the variability in these data resulting from the relatively low dose of this carotenoid makes this measurement questionable.

In addition we observed that in males but not females the serum increase in lutein is correlated with the baseline level of lipids. For triglycerides a negative correlation is observed. We do not have an adequate explanation for this observation and there is no obvious reason why such a relationship should exist for males but not females. The serum response of lutein in men shows a positive correlation to baseline HDL and is a trend one would expect if HDL is the dominant carrier of lutein in the serum. A significant negative correlation is also observed between the serum response of lutein and serum VLDL for males but not females. A final observation that was found in males but not females in this study was a negative correlation between baseline serum C-reactive protein and the serum lutein supplementation response. A speculative hypothesis for this observation would be that $\mathrm{C}$-reactive protein is a marker for oxidative stress and 
inflammation and that higher stress levels in subjects would predict lower lutein responses because absorbed lutein is degraded to a greater extent.

In addition to the lutein and zeaxanthin concentration increases there are measurable levels of the xanthophyll metabolites that increase significantly during the supplementation period. Other carotenoids, including lycopene, $\alpha$ - and $\beta$-cryptoxanthin, $\alpha$ - and $\beta$-carotene do not change significantly during the supplementation period. We conclude that any competition for the absorption is insignificant at the level of supplementation we are conducting in this study and therefore these supplements will not have a negative influence on the level of other nutritionally significant carotenoids.

This study demonstrates that lutein esters are highly bioavailable in humans when provided in capsules containing 3 or $6 \mathrm{mg} /$ day equivalent of free lutein. The natural zeaxanthin component of this ester formulation is also highly bioavailable and produces statistically significant serum increases although with much greater variability in the measured values. 


\section{CHAPTER IV:}

\section{CONCLUSIONS}

The purpose of this study was to assess the bioavailability of a low dose xanthophyll ester supplement in serum and to help understand the importance of the conformational barrier for rotation in biological important carotenoids. Nearly all carotenoids present in serum, with the exemption of lycopene, contain either a $\beta$ - or an $\varepsilon$ ionone ring, thus understanding the significance of these rings on the structure and properties will shed light onto why certain carotenoids are absorbed from the diet while others are not. The major serum carotenoids with $\beta$-ionone rings include $\beta$-carotene, zeaxanthin and $\beta$-cryptoxanthin and with both $\beta$ - and $\varepsilon$-ionone rings include lutein, $\alpha$ cryptoxanthin and $\alpha$-carotene.

The study demonstrates that the conformational energy curve is greatly affected by the type of ring present in the carotenoid. A large barrier is observed for the interconversion of conformers in the epsilon rings in which the conformational barrier ranges in value from $8.55 \mathrm{kcal} / \mathrm{mol}$ for $(3 \mathrm{~S}, 6 \mathrm{~S})$-3-hydroxy-15-apo-e-carotenal and

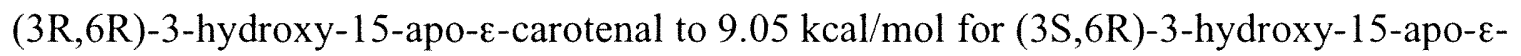
carotenal and $(3 \mathrm{R}, 6 \mathrm{~S})-3$-hydroxy-15-apo- $\varepsilon$-carotenal when compared to beta rings for which the conformational barrier ranges in value from $3.06 \mathrm{kcal} / \mathrm{mol}$ for 15 -apo- $\beta$ carotenal to $3.40 \mathrm{kcal} / \mathrm{mol}$ for 3-oxo- 15 -apo- $\beta$-carotenal, table 6 . These results indicate that the $\varepsilon$-ionone ring must overcome a larger potential energy barrier to rotation in order to adopt certain conformations than is required for a $\beta$-ionone ring. The energy 
difference between the most stable and second most stable conformation was larger for the $\varepsilon$-rings in which it ranged from 0.92 to $3.06 \mathrm{kcal} / \mathrm{mol}$ than for $\beta$-rings in which the energy difference ranged from 0.24 to $0.35 \mathrm{kcal} / \mathrm{mol}$.

Table 6. Summary of selected conformational barrier parameters

\begin{tabular}{|c|c|c|c|c|}
\hline Structure & $\begin{array}{l}\text { Most Stable } \\
\text { Geometry }\end{array}$ & \begin{tabular}{|c} 
Second Most \\
Stable \\
Geometry \\
\end{tabular} & $\begin{array}{c}\text { Energy } \\
\text { Difference } \\
\text { (kcal/mol) }\end{array}$ & $\begin{array}{c}\text { Conformational } \\
\text { Barrier }(\mathrm{kcal} / \mathrm{mol})\end{array}$ \\
\hline 15-apo- $\beta$-carotenal & $49.6^{\circ}$ & $-45.9^{\circ}$ & 0.27 & 3.06 \\
\hline $\begin{array}{l}\text { (3R)-hydroxy-15-apo- } \beta \text { - } \\
\text { carotenal }\end{array}$ & $46.7^{\circ}$ & $-47.4^{\circ}$ & 0.24 & 3.18 \\
\hline $\begin{array}{l}\text { (3S)-hydroxy-15-apo- } \beta \text { - } \\
\text { carotenal }\end{array}$ & -46.3 & 46.8 & 0.55 & 3.35 \\
\hline 3-oxo-15-apo- $\beta$-carotenal & $47.3^{\circ}$ & $-49.8^{\circ}$ & 0.03 & 3.40 \\
\hline (6R)-13-apo- $\varepsilon$-carotene & $122.5^{\circ}$ & $-39.6^{\circ}$ & 3.05 & 8.88 \\
\hline $\begin{array}{l}\text { (3R,6R)-3-hydroxy-15- } \\
\text { apo- } \varepsilon \text {-carotenal }\end{array}$ & $113.3^{\circ}$ & $-23.3^{\circ}$ & 0.92 & 8.55 \\
\hline $\begin{array}{l}\text { (3S,6R)-3-hydroxy-15- } \\
\text { apo- } \varepsilon \text {-carotenal }\end{array}$ & $113.3^{\circ}$ & $-27.5^{\circ}$ & 0.92 & 9.05 \\
\hline $\begin{array}{l}\text { (3R,6S)-3-hydroxy-15- } \\
\text { apo- } \varepsilon \text {-carotenal }\end{array}$ & $-113.3^{\circ}$ & $27.5^{\circ}$ & 0.92 & 9.05 \\
\hline $\begin{array}{l}(3 \mathrm{~S}, 6 \mathrm{~S})-3 \text {-hydroxy-15- } \\
\text { apo- } \varepsilon \text {-carotenal }\end{array}$ & $-113.3^{\circ}$ & $23.3^{\circ}$ & 0.92 & 8.55 \\
\hline $\begin{array}{l}\text { (6R)-3-oxo-15-apo- } \varepsilon- \\
\text { carotenal }\end{array}$ & $120.3^{\circ}$ & $-45.6^{\circ}$ & 3.06 & 8.68 \\
\hline
\end{tabular}

Other factors such as the length of the apocarotenal, the chain termination and the presence of various functional groups at carbon 3 do not significantly affect the conformational barrier. The presence of a stereocenter at carbon 6 in the $\varepsilon$-ionone rings dictates the rotational direction of the conformational barrier while the presence of a stereocenter at carbon 3 weakly influences the overall conformational barrier. The conformation barriers of the enantiomers, (3R,6R)-3-hydroxy-15-apo- $\varepsilon$-carotenal and 
(3S,6S)-3-hydroxy-15-apo- $\varepsilon$-carotenal, are identical but reversed. The conformational barriers of the diastereomers, (3R,6R)-3-hydroxy-15-apo- $\varepsilon$-carotenal and $(3 R, 6 S)-3$ -

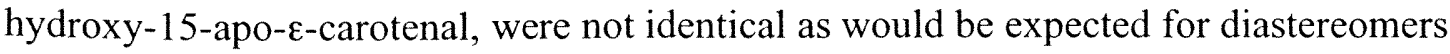
but differ in the overall conformational barrier. The importance of these structural differences between carotenoids and the mechanism by which carotenoids exert their effect on human health remains incompletely understood.

The results from the supplementation study suggest that xanthophyll esters are highly bioavailable in humans. The post-supplementation concentrations of lutein increased two- and four-fold in the 3 and $6 \mathrm{mg}$ of lutein equivalent per day, respectively. The study suggests that the serum increase in lutein is correlated with the baseline level of lipids for the males but not for the females. A study by Brady et al. found that all serum carotenoids were significantly related to total cholesterol and non-HDL cholesterol and that lutein + zeaxanthin was related to HDL cholesterol. [65] In the present study we observe a direct significant relation between the baseline serum levels of lutein with that of cholesterol $(\mathrm{r}=0.875)$, HDL $(\mathrm{r}=0.748)$ and LDL $(\mathrm{r}=0.188)$.

Zeaxanthin is a minor component of the supplement $(\sim 7 \%)$ and an increase in the serum levels of the study participants was observed for both doses. The $3 \mathrm{mg}$ dose (lutein equivalent) would provide approximately $0.21 \mathrm{mg}$ of zeaxanthin and results in a serum response of 1.3 fold over baseline. The $6 \mathrm{mg}$ dose (lutein equivalent) would provide approximately $0.42 \mathrm{mg}$ of zeaxanthin and results in a 1.9 fold increase in serum zeaxanthin over baseline.

In addition to the lutein and zeaxanthin concentration increases, there are measurable levels of the xanthophyll metabolites that increase significantly during the 
supplementation period, table 7. Other carotenoids, including lycopene, $\alpha$ - and $\beta$ cryptoxanthin, $\alpha$ - and $\beta$-carotene do not change significantly during the supplementation period.

Table 7. Summary of serum carotenoids that experienced an increase in concentration with supplementation

\begin{tabular}{|l|c|c|c|c|}
\hline & \multirow{2}{*}{$\begin{array}{c}\text { Baseline } \\
(\mathrm{nmol} / \mathrm{dL})\end{array}$} & \multicolumn{3}{|c|}{ Post-supplementation $(\mathrm{nmol} / \mathrm{dL})$} \\
\cline { 3 - 5 } & & Placebo & Low Dose & High Dose \\
\hline metabolite 1 & $1.24 \pm 0.48$ & $1.14 \pm 0.36$ & $1.64 \pm 0.67^{*}$ & $2.74 \pm 1.24^{* *}$ \\
\hline metabolite 2 & $1.72 \pm 0.74$ & $1.40 \pm 0.55$ & $2.56 \pm 1.05^{*}$ & $5.41 \pm 2.51^{* *}$ \\
\hline metabolite 3 & $2.87 \pm 1.04$ & $2.34 \pm 0.96$ & $3.43 \pm 1.27^{*}$ & $5.36 \pm 2.25^{*}$ \\
\hline metabolite 4 & $1.39 \pm 0.67$ & $1.13 \pm 0.53$ & $1.84 \pm 1.11^{*}$ & $2.10 \pm 1.15^{*}$ \\
\hline lutein & $15.79 \pm 6.43$ & $15.11 \pm 7.35$ & $34.28 \pm 17.96^{*}$ & $71.41 \pm 35.98^{* *}$ \\
\hline zeaxanthin & $6.03 \pm 2.80$ & $5.03 \pm 1.77$ & $8.03 \pm 2.70^{*}$ & $12.23 \pm 5.85^{*}$ \\
\hline
\end{tabular}

* Significant difference when compared to baseline concentration $(p<0.05),{ }^{* *} p<0.001$ 


\section{LIST OF REFERENCES}

1. Britton, G., S. Liaaen-Jensen, and H. Pfander, eds. Handbook of Carotenoids. 2004, Birkhauser-Verlag: Basel. 670.

2. Britton, G., Structure and properties of carotenoids in relation to function. FASEB J., 1995. 9: p. 1551-1558.

3. Krinsky, N.I., et al., Structural and geometrical isomers of carotenoids in human plasma. J Nutr, 1990. 120(12): p. 1654-62.

4. Nomenclature of carotenoids. Pure Appl. Chem., 1975. 41(3): p. 405-431.

5. Sommerburg, O., et al., Fruits and vegetables that are sources for lutein and zeaxanthin: the macular pigment in human eyes. $\mathrm{Br} \mathrm{J}$ Ophthalmol, 1998. 82(8): $\mathrm{p}$. 907-10.

6. Bone, R.A., et al., Stereochemistry of the Human Macular Carotenoids. Invest. Ophthalmol. Vis. Sci., 1993. 34: p. 2033-2040.

7. Landrum, J.T. and R.A. Bone, Lutein, Zeaxanthin, and the Macular Pigment. Arch. Biochem. Biophys., 2001. 385: p. 28-40.

8. Maoka, T., et al., The first isolation of enantiomeric and meso-zeaxanthin in nature. Comp. Biochem. Physiol., 1986. 83B: p. 121-124.

9. Schiedt, K., et al., Absorption, retention and metabolic transformation of carotenoids in rainbow trout, salmon and chicken. Pure Appl. Chem., 1985. 57: p. 685-692.

10. Schaeffer, J., et al., Carotenoid composition of serum and egg yolks of hens fed diets varying in carotenoid composition. Poult. Sci., 1988. 67(4): p. 608-614.

11. McGraw, K., et al., Lutein-based plumage coloration in songbirds is a consequence of selective pigment incorporation into feathers. Comparative Biochem. and Physiol. B, 2003. 135: p. 689-696.

12. Bone, R.A., et al., Analysis of the Macular Pigment by HPLC: Retinal Distribution and Age Study. Invest. Ophthalmol. Vis. Sci., 1988. 29: p. 843-849.

13. Broekmans, W.M., et al., Macular pigment density in relation to serum and adipose tissue concentrations of lutein and serum concentrations of zeaxanthin. Am J Clin Nutr, 2002. 76(3): p. 595-603.

14. Buchecker, R. and C. Eugster, Search for the presence in egg yolk, in flowers of Caltha palustris and in autumn leaves of 3'-epilutein [( $3 R, 3$ 'S, 6'S)-b,e-carotene- 
3,3'-diol] and 3'O-didehydrolutein [(3R,6'R)-3-hydroxy-b,e-carotene-3'-one]. Helv. Chim. Acta, 1979. 62: p. 2817-2824.

15. Dabbagh, A. and K. Egger, Calthaxanthin-Ein Stereoisomers des Lutein aus Caltha palustris. Z. Pflanzenphysiol, 1974. 72: p. 177-180.

16. Marki-Fischer, E. and C. Euster, Eine weitere, dismal erfolgreiche Suche nach 3'Epilutein in Pflanzen. Helv. Chim. Acta, 1990. 73: p. 1205-1209.

17. Matsuno, T., H. Matsutaka, and S. Nagata, Metabolism of lutein and zeaxanthin to ketocarotenoids in goldfish, Carassius auratus. Bull. Jp. Soc. Sci. Fish, 1981. 47(605-611): p. 605.

18. Matsuno, T. and H. Matsutaka, Carotenoids of Four Species of Crucian Carp and Two Varieties of Goldfish. Bull. Jp. Soc. Sci. Fish, 1981. 47(85-88): p. 85.

19. Matsuno, T., et al., Occurence of 3'-Epimer of lutein (Calthaxanthin, 3'-Epilutein) from fishes. Bull. Jp. Soc. Sci. Fish, 1980. 46(337-340): p. 337.

20. Matsuno, T., et al., Comparative biochemical studies of carotenoids in fishes $X X I X$. Isolation of new luteins, lutein $F$ and lutein $G$ from marine fishes. Comp. Biochem. Physiol.B, 1986. 85(77-80): p. 77.

21. Matsuno, T., et al., Reductive metabolic pathwaysof carotenoids in fish (3S,3'S)astaxanthin to tunaxanthin $A, B$ and C. Comp. Biochem. Physiol.B, 1985. 80: p. 779-789.

22. Carotenoids Volume 1B: Spectroscopy. Carotenoids, ed. G. Britton, S. LiaaenJensen, and H. Pfander. Vol. 1B. 1995, Basel, Boston, Berlin: Birkhäuser Verlag. 360 .

23. Siefermann-Harms, D., et al., Carotenoids in higher plants. Part 13. Lactucaxanthin, an e,e-caroten-3,3'-diol from Lactuca sativa. Phytochemistry (Elsevier), 1981. 20(1): p. 85-88.

24. Iwata-Reuyl, D., et al., Bacterial phytoene synthase: molecular cloning, expression, and characterization of Erwinia herbicola phytoene synthase. Biochemistry, 2003. 42: p. 3359-3365.

25. Britton, G., Overview of Carotenoid Biosynthesis, in Carotenoids, G. Britton, S. Liaaen-Jensen, and H. Pfander, Editors. 1998, Birkhauser-Verlag: Basel. p. 13147.

26. Umeno, D., A. Tobias, and F. Arnold, Diversifying Carotenoid Biosynthetic pathways by Direct Evolution. Microbiology and Molecular Biology Reviews, 2005. 69(1): p. 51-78. 
27. Hornero-Mendez, D. and G. Britton, Involvement of NADPH in the cyclization reaction of carotenoid biosynthesis. FEBS Lett., 2002. 515: p. 133-136.

28. Breithaupt, D., U. Wirt, and A. Barnedi, Differentiation between Lutein Monoester Regioismoers and Detection of Lutein Diesters from Marigold Flowers (Targetes Erecta L.) and Several fruits by Liquid Chromatography-Mass Spectrometry. J. Agric. Food Chem, 2002. 50: p. 66-70.

29. Perez-Galvez, A. and M. Minguez-Mosquera, Esterification of xanthophylls and its effect on chemical behavior and bioavailability of carotenoids in the human. Nutrition Research, 2005. 25: p. 631-640.

30. Goodwin, T., The comparative biochemistry of the carotenoids, ed. T. Goodwin. 1952, London: Chapman and Hall.

31. Perez-Galvez, A. and M. Minguez-Mosquera, Degradation of non-esterified and esterified xanthophylls by free radicals. Biochem. Biophys. Acta, 2002. 1569: p. 31-34.

32. Cogdell, R., Carotenoids in photosynthesis. Pure and Appl. Chem., 1985. 57(5): p. $723-728$.

33. Niyogi, K., Photoprotection Revisited: Genetic and molecular approaches. Annu. Rev. Plant Physiol. and Plant Mol. Biol., 1999. 50: p. 333-359.

34. Sarry, J., et al., The protective function of the xanthophyll cycle in photosynthesis. FEBS Lett., 1994. 353(2): p. 147-150.

35. Demmig-Adams, B., A. Gilmore, and W. Adams III, In vivo functions of carotenoids in higher plants. FASEB J., 1996. 10: p. 403-412.

36. Breithaupt, D., A. Bamedi, and U. Wirt, Carotenol fatty acid esters: easy sybstrates for digestive enzymes? Comparative Biochem. and Physiol. B, 2002. 132: p. 721-728.

37. Granado, F., et al., Lutein ester in serum after lutein supplementation in human subjects. Brit. J. Nutr., 1998. 80: p. 445-449.

38. Yonekura, L. and A. Nagao, Intestinal Absorption of dietary carotenoids. Mol. Nutr. Food Res., 2007. 51: p. 107-115.

39. Furr, H. and R. Clark, Transport, uptake, and target tissue storage of carotenoids, in Carotenoids in Health and Disease, N. Krinsky, H. Sies, and S. Mayne, Editors. 2004, Marcel Dekker Inc: New York. p. 229-278. 
40. Landrum, J.T., R.A. Bone, and M.D. Kilburn, The Macular Pigment: a possible role in protection from age-related macular degeneration, in $A d v$. in Pharmacology, H. Sies, Editor. 1997, Academic Press: San Diego. p. 537-556.

41. Knekt, P., et al., Serum antioxidant vitamins and risk of cataract. Br. Med. J., 1992. 305: p. 1392-1394.

42. Gerster, H., Potential role of b-carotene in the prevention of cardiovascular disease. Int. J. Vitam. Nutr. Res., 1991. 38: p. 537-556.

43. Krinsky, N.I., M. Peacocke, and R.M. Russell, Antioxidant vitamins, cancer, and cardiovascular disease. N Engl J Med, 1996. 335(14): p. 1066-7; author reply 1069.

44. Nishino, H., et al., Cancer prevention by natural carotenoids. Biofactors, 2000. 13(1-4): p. 89-94.

45. Ribaya-Mercado, J.D. and J.B. Blumberg, Lutein and zeaxanthin and their potential roles in disease prevention. J Am Coll Nutr, 2004. 23(6 Suppl): p. 567S$587 \mathrm{~S}$.

46. Olson, J.A., Provitamin A Function of Carotenoids: The Conversion of bCarotene into Vitamin A. Am. Institute of Nutr., 1989. NA: p. 105-108.

47. Hughes, D., Dietary carotenoids and human immune function. Nutrition, 2001. 17(10): p. 823-827.

48. Foote, C.S., Y.C. Chang, and R.W. Denny, Chemistry of Singlet Oxygen. X. Carotenoid Quenching Parallels Biological Protection. J. Am. Chem. Soc., 1970. 92: p. 5216-5218.

49. Khachik, F., et al., Identification, quantification, and relative concentrations of carotenoids and their metabolites in human milk and serum. Anal Chem, 1997. 69(10): p. 1873-81.

50. Bieri, J., E. Brown, and S. JC, Determination of individual carotenoidsin human plasma by high performance liquid chromatograohy. J. Liq. Chromatogr., 1985. 8: p. $473-484$.

51. Schmitz, H.H., et al., Concentrations of selected carotenoids and vitamin $A$ in human liver, kidney and lung tissue. J. Nutr., 1991. 121: p. 1613-1621.

52. Alaluf, S., et al., Dietary carotenoids contribute to normal skin color and UV photosensitivity. J. Nutr., 2002. 132: p. 399-403.

53. Amunts, A., O. Drory, and N. Nelson, The structure of a plant photosystem I supercomplex at 3.4 angstrom resolution. Nature, 2007. 447: p. 58-63. 
54. Subczynski, W.K., et al., Effects of polar carotenoids on dimyristoylphosphatidylcholine membranes: a spin-label study. Biochim Biophys Acta, 1992. 1105(1): p. 97-108.

55. Wisniewska, A., J. Widomska, and W. Subczynski, Carotenoid-membrane interactions in liposomes: effect of dipolar, monopolar, and nonpolar carotenoids. Acta Biochimica Polonica, 2006. 53(3): p. 475-484.

56. Young, A., D. Phillip, and H. Hashimoto, Ring-to-chain conformation may be a determining factor in the ability of xanthophyllsto bind to the bulk lightharvesting complex of plants. J. of Molec. Structure, 2002. 642: p. 137-145.

57. Foresman, J. and A. Frisch, Exploring Chemistry with Electronic Structure Methods. Second ed. 1999, Pittsburgh: Gaussian Inc.

58. Phillip, D., et al., The Binding of Xanthophylls to the Bulk Light-harvesting Complex of Photosystem II of Higher Plants. J. Biol. Chem., 2002. 277(8): p. 25160-25169.

59. Pintea, A., et al., Incorporation of carotenoid esters into liposomes. Biophysical Chemistry, 2005. 118(1): p. 7-14.

60. Trieschmann, M., et al., Changes in macular pigment optical density and serum concentrations of its constituent carotenoids following supplemental lutein and zeaxanthin: The LUNA study. Exp. Eye Research, 2006. xx: p. 1-11.

61. Schalch, W., et al., Xanthophyll accumulation in the human retina during supplementation with lutein or zeaxanthin - the LUXEA (LUtein Xanthophyll Eye Accumulation) study. Arch. Biochem. Biophys., 2007. 458: p. 128-135.

62. Bone, R.A., et al., Lutein and Zeaxanthin in Eyes, Serum and Diet of Human Subjects. Exp. Eye Res., 2000. 71: p. 239-245.

63. Van Breemen, R., et al., Liquid Chromatography-Mass spectrometry of cis-and all-trans-lycopene in human serum and prostate tissue after dietary supplementation with tomato sauce. J. Agric. Food Chem., 2002. 50(8): p. 22142219.

64. Rajendran, V., Y. Pu, and B. Chem, An improved HPLC method for determination of carotenoids in human serum. J. of Chromatography B, 2005. 824: p. 99-106.

65. Brady, W., et al., Human serum carotenoid concentrations are related to physiologic and lifestyle factors. J. Nutr., 1996. 126: p. 129-137. 
66. Khachik, F., et al., Separation, identification, and quantification of carotenoids in fruits, vegetables and human plasma by high performance liquid chromatography. Pure \& Appl. Chem, 1991. 63: p. 71-80. 
APPENDICES 


\title{
RECEIVED
}

\section{FEB 142007}

\section{MEMORANDUM}

\author{
FIU University \\ Graduate School
}

To:

Dr. John Landrum

CC:

File

From:

Date:

Chris Grayson, CIM, Institutional Review Board Coordinator

May 31, 2006

Proposal Title: Lutein Bioavailability in a Commercial Supplement.

Approval \# ,052606-01

The Institutional Review Board of Florida International University has approved your study for the use of human subjects. Your IRB approval date is May 26, 2006 and this approval will expire on May 26, 2007. As a requirement of IRB approval you are required to:

1) Provide immediate written notification to the IRB of:

- Any additions to, or changes in the procedures involving human subjects,

- Every serious or unusual or unanticipated adverse event as well as problems with the rights or welfare of the human subjects. Confirmation of receipt of serious AE reports must be made with the IRB office.

2) Utilize copies of the date stamped consent document(s) for the recruitment of subjects and receive annual renewal of consent documents.

3) Receive annual review and re-approval prior to your expiration date.

Special Conditions: N/A

Please note your approval number is indicated above. For further information, you may contact the IRB Coordinator by email at irbiacuc@fiu.edu or visit the OSRA - Human Subjects website at www.osra.fiu.edu. 


\section{MEMORANDUM}

To:

CC:

From:

Date:

Proposal Title:
Dr. John Landrum

Francesca Alvarez-Calderon

File

Chris Grayson, CIM, Institutional Review Board Coordinator

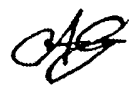

May 2, 2007

Lutein Bioavailability in a Commercial Supplement.

Approval \# 052606-01

The Institutional Review Board of Florida International University has re-approved your study for the use of human subjects. Your IRB approval date is May 2, 2007 and this approval will expire on May 26, 2008. As a requirement of IRB approval you are required to:

1) Provide immediate written notification to the IRB of:

- Any additions to, or changes in the procedures involving human subjects,

- Every serious or unusual or unanticipated adverse event as well as problems with the rights or welfare of the human subjects. Confirmation of receipt of serious AE reports must be made with the IRB office.

2) Utilize copies of the date stamped consent document(s) for the recruitment of subjects and receive annual renewal of consent documents.

3) Receive annual review and re-approval prior to your expiration date.

\section{Special Conditions: N/A}

Please note your approval number is indicated above. For further information, you may contact the IRB Coordinator by email at irbiacuc(afiu.edu or visit the OSRA - Human Subjects website at wwivosra fiu edu. 


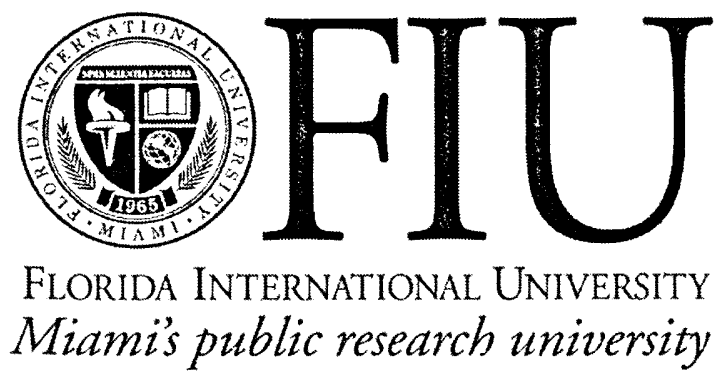

\section{Informed Consent \\ Biolut Bioavailability Study}

\section{Laboratory Participation of Prospective Research Subjects}

You are being asked to consent to participate in a two month study to measure how well lutein is absorbed from a nutritional supplement. The research project will be conducted at Florida International University during the Summer/Fall semesters, 2006. Dr. John T. Landrum is the Principal Investigator. The project objective is to determine how well a nutrient, called lutein, is absorbed when it is taken as pill. Your involvement will include an orientation to the study, daily consumption of a dietary supplement pill containing lutein, and visits to the health center for the purpose of obtaining blood samples once every other week for the eight week period of the study.

As part of this study you will be asked to take a supplement of lutein esters once each day for a period of eight weeks. Lutein is a naturally occurring substance found in green and yellow vegetables. The supplement you will consume is a commercially produced product. Lutein is accumulated in the retina and it functions there to protect the retina from damage by blue light. Supplements containing lutein esters $(0,6$, or $12 \mathrm{mg})$ will be taken at a regular time with a main meal. These amounts are in the normal range of supplements of lutein that are commercially available and there are no known risks associated with the consumption of lutein.

Blood samples will be drawn at the University Health Center on alternate weeks throughout the study. This will involve a roughly 15 minute visit at the University Health Center and can be scheduled in advance. You will be compensated for your participation with a $\$ 20$ gift card after each blood sample is drawn. If at any time you feel uncomfortable with any procedure it will be discontinued immediately upon request. We hope you will find your participation in the study gratifying in that it will contribute to the knowledge we have about this important nutrient. Participation will enable you to become more aware of the nature of nutritional research and the importance of a solid scientific understanding of how nutrients are absorbed by the human body. We hope to provide you an analysis of your serum lipid profile as part of the study, this includes your cholesterol levels. There will be no cost for this analysis. We will collecting your age and sex as part of the study but will not be collecting other identifiable personal information.

The phlebotomist will draw a small quantity of blood (equivalent to about two teaspoons) every two weeks during the study. There may be a minor discomfort associated with the venipuncture 


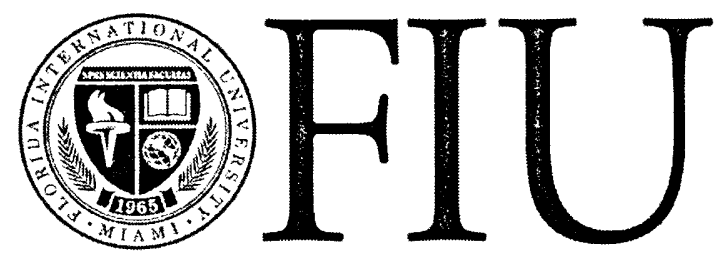

\section{FLORIDA INTERNATIONAL UNIVERSITY \\ Miamis public research university}

and may produce some soreness or bruising. The only known risks associated with this study is the very slight risk of infection as a result of venipuncture and this is minimized by the use of sterile procedure by a professional phlebotomist. The risk level is identical to that of providing blood samples for a physician's diagnosis.

If you believe you have suffered an injury during this study, or if you have any questions about the rights of human subjects, you may contact Prof. Jonathan Tubman, Chairperson of the Institutional Review Board, at 305-348-3024 or 305-348-2494.

If you desire further information about this research you should contact Dr. John T. Landrum, (305)-348-3091.

This evaluation procedure has been explained to me. I understand I can withdraw from the study at any time and for any reason without penalty of any kind. All of my questions have been answered to my liking. I am aware of my rights and agree to be in this study. I have been offered a copy of this informed consent form.

Participant's signature

Date

$\overline{\text { Participant's name typed or printed }}$

Telephone

e-mail

I have explained the research procedure, subject rights and answered question asked by the participant. I have offered him/her a copy of this informed consent form.

John T. Landrum

Date

Annual review May 2006

Chemistry and Biochemistry Department

$11200 \mathrm{SW} 8^{\text {th }}$ Street Miami, FL 33199 